Felipe Massicano

\title{
QUANTIFICAÇÃO DE IMAGENS TOMOGRÁFICAS PARA CÁlCULO DE DOSE EM DIAGNOSE E TERAPIA EM
} MEDICINA NUCLEAR

Dissertação apresentada como parte dos requisitos para obtenção do grau de mestre em Ciências na Área de Tecnologia de Aplicações Nucleares.

Área de Concentração: Tecnologia Nuclear - Reatores Orientador: Dr. Hélio Yoriyaz

São Paulo 
Ao meu pai, Edson Antônio Massicano, e à minha mãe, Hilda Lídia Farina Massicano, por fazerem de meus sonhos os seus e tornarem mais esse possível. Às minhas irmãs Renata Massicano Borlenghi e Daniela Massicano Fichera que são parte do que sou hoje e à minha esposa, Adriana Vidal Fernandes Massicano, por jamais me permitir desistir. 


\section{AGRADECIMENTOS}

À Deus pois sem Ele absolutamente nada foi, é ou será possível.

Aos meus pais, pelo carinho, exemplo, amor, fé, guia... "Nada se pode ensinar a um homem; você pode apenas ajudá-lo a encontrar a resposta dentro dele mesmo" (Galileu Galilei).

Às minhas irmãs Renata e Daniela, pelos risos, pelas lembranças, pelos sobrinhos, pela infância... pela vida. "O valor das coisas não está no tempo que elas duram, mas na intensidade com que acontecem. Por isso existem momentos inesquecíveis, coisas inexplicáveis e pessoas incomparáveis" (Fernando Sabino).

À minha esposa Adriana. "Depois de um tempo você aprende que o que importa não é o que você tem na vida, mas quem você tem na vida" (William Shakespeare).

Ao meu orientador Dr. Hélio Yoriyaz, pela oportunidade, pelo conhecimento transmitido, pelo auxílio sempre presente e pela amizade. "Mestre não é aquele que aprendeu a ensinar, mas aquele que ensina a aprender" (Marcelo Soriano).

Aos amigos: Douglas, Paula, Gregório, Leonardo, Milena, Miréia, Pedro, Lubianca, Rafael Possani, Rodrigo, Rafael Muniz, Felipe Cintra, Luís Felipe, César, Talita, Gabriel Paiva, Gabriel, Thiago e Sudenir por todos os momentos descontraídos, pelo profissionalismo, pela ajuda... "Um Amigo se faz rapidamente; já a amizade é um fruto que amadurece lentamente." (Aristóteles).

Ao Dr. Sérgio Furuie e ao Dr. Marcel Jackowski pelas orientações preciosas. "Feliz aquele que transfere o que sabe e aprende o que ensina" (Cora Coralina).

Ao Instituto de Pesquisas Energéticas e Nucleares, em especial o Centro de Engenharia Nuclear pelo provimento dos recursos necessário para o desenvolvimento e divulgação deste trabalho. 
Aos funcionários do CEN.

Ao Hospital Hcor pelo fornecimento das imagens tomográficas.

Aos funcionários da divisão de pós-graduação do IPEN.

Aos demais amigos e familiares de todas as partes.

Ao CNPq pela bolsa concedida. 
"Não se aparte da tua boca o livro desta lei; antes medita nele dia e noite, para que tenhas cuidado de fazer conforme a tudo quanto nele está escrito; porque então farás prosperar o teu caminho, e então prudentemente te conduzirás" 


\section{QUANTIFICAÇÃO DE IMAGENS TOMOGRÁFICAS PARA CÁLCULO}

\section{DE DOSE EM DIAGNOSE E TERAPIA EM MEDICINA NUCLEAR}

\section{Felipe Massicano}

\section{RESUMO}

A área da medicina nuclear possui uma crescente vertente em terapia de doenças, particularmente no tratamento de tumores radiosenssíveis. Devido à alta dose utilizada na terapia desses tumores é de extrema importância a quantificação da distribuição da dose, para assim evitar os efeitos deletérios nos tecidos sadios. No Brasil o sistema de dosimetria interna utilizado é o MIRD (Medical Internal Radiation Dose) baseado em um modelo de referência que não possui dados suficientes do paciente para obter uma avaliação detalhada da dose em terapia. Novos sistemas de dosimetria interna utilizam imagens de tomografia computadorizada para obter tanto informações do corpo do paciente, como informações da distribuição da atividade interna do paciente, para assim, com base nessas informações, realizar o cálculo de dose mediante um código de Monte Carlo. Esse tipo de dosimetria é denominado dosimetria personalisada do paciente. No Centro de Engenharia Nuclear do Ipen, está em desenvolvimento uma metodologia em que as informações das imagens tomográficas são inseridas no código de Monte Carlo MCNP5 mediante um software denominado SCMS (Sistema Construtor de Manequins Segmentadores). Assim, a dosimetria pode ser realizada de forma personalizada para cada paciente, obtendo-se a deposição de energia nos órgãos de interesse. O presente trabalho teve por objetivo contribuir para a área de medicina nuclear com o desenvolvimento de parte do sistema mencionado de dosimetria personalizada do paciente para terapia radionuclídica. Para isso foram propostos três objetivos específicos: (1)Desenvolver um software para converter imagens de 
tomografia computadorizada (CT) em parâmetros do tecido $\left(\rho, \omega_{i}\right) ;(2)$ Desenvolver um software para realizar a correção de atenuação em imagens tomográficas de medicina nuclear (SPECT ou PET) para fornecer o mapa de atividade relativa e (3) Preparar os dois softwares anteriores para fornecerem dados de entrada ao SCMS. O software desenvolvido para o primeiro objeto específico foi o Image Converter Computed Tomography (ICCT) que obteve uma boa precisão para determinar a densidade, e em relação à composição dos tecidos, os únicos elementos que obtiveram alta variação foram o carbono e oxigênio. Felizmente, essa variação para a faixa de energia utilizada em terapia radionuclídica não é prejudicial para a distribuição da dose. Uma das vantagens é a alta precisão em relação a cálcio e fósforo que possuem grande influência na distribuição da dose. Para o segundo objetivo foi desenvolvido o Attenuation Corretion PET SPECT (ACPS) que efetua a correção de atenuação em imagens de PET e SPECT mediante o método de Chang de $1^{a}$ ordem e gera a distribuição da atividade relativa no interior do paciente. Por fim, os dados gerados pelos dois softwares foram formatados para o SCMS. 


\title{
QUANTIFICATION OF TOMOGRAPHY IMAGES FOR DOSE
}

\section{CALCULATION FOR DIAGNOSIS AND THERAPY IN NUCLEAR}

\author{
MEDICINE
}

\section{Felipe Massicano}

\begin{abstract}
The nuclear medicine area has an increasing slope in the therapy of diseases, particularly in the treatment of radiosensitive tumors. Due to the high dose levels in radionuclide therapy, it is very important the accurate quantify of the dose distribution to avoid deleterious effects on healthy tissues. In Brazil, the internal dosimetry system used is the MIRD (Medical Internal Radiation Dose) based on a reference model that does not have adequate patient data to obtain a dose accurate assessment in therapy. However, in recent years, internal radionuclide dosimetry evaluates the spatial dose distribuition basead on information obtained from CT and SPECT or PET images together with the using of Monte Carlo codes. Those systems are called patient-specific dosimetry systems. In the Nuclear Engineering Center at IPEN, this methodology is in development. When the CT images are inserted into the Monte Carlo code MCNP5 through of use of a interface software called SCMS the dosimetry can be accomplished using patient-specific data, resulting in a more accurate energy deposition in organs of interest. This work aim to contribute with the development of part of that patient-specific dosimetry for therapy. To achieve this goal we have proposed three specific objectives: (1) Development of a software to convert images from Computed Tomography (CT) in the tissue parameters $(\rho, \omega(i)) ;(2)$ Development of a software to perform attenuation correction in nuclear medicine tomographic images
\end{abstract}


(SPECT or PET) and to provide the map of relative activity and (3) Provide data to the SCMS code by these two softwares. The software developed for the first specific objective was the Image Converter Computed Tomography (ICCT), which obtained a good accuracy to determine the density and the tissue composition; the elements that had high variation were carbon and oxygen. Fortunately, this variation for the energy range used in radionuclide therapy is not detrimental to the dose distribution. A major advantage is the high accuracy obtained to calcium and phosphorus which have great influence on the dose distribution calculation. For the second objective it was developed the Attenuation Corretion SPECT PET (ACPS) software which performs the attenuation correction in PET and SPECT images through of $1^{a}$ order Chang method and create the relative activity distribution within of patient. Finally, the data generated by the two softwares, was formatted to SCMS which in provides the complete information do the MCNP5 Monte Carlo code for radiation transport simulation for dose distribution estimation. 


\section{Lista de Figuras}

1.1 Esquema da metodologia de dosimetria personalizada para o paciente. . . . 20

3.1 Esquema do efeito fotoelétrico. . . . . . . . . . . . . . 24

3.2 Esquema do efeito Compton. . . . . . . . . . . . . . . . . . 25

3.3 Esquema da produção de pares. . . . . . . . . . . . . . . . . . 28

3.4 Representação do parâmetro de impacto $b$ e do raio atômico $a$. . . . . . . . 32

3.5 Comparação de um modelo de um objeto simulador antropomórfico antigo (A) com um modelo usado atualmente (B) (RADAR, 2010). . . . . . . . . 48

3.6 Esquema dos componentes da câmara de cintilação. . . . . . . . . . . . . . 53

3.7 Fatores que produzem variação no tamanho do pulso do detector. . . . . . 58

3.8 Espectro produzido por uma fonte radioativa monoenergética por um típico detector. . . . . . . . . . . . . . . . . . . 59

3.9 Demonstração da linha de resposta LOR (Adaptada de Sprawls Junior et al., 1995). . . . . . . . . . . . . . . . . 64

3.10 Esquema da fase de varredura . . . . . . . . . . . . . . . . 65

4.1 Correlação da unidade de Hounsfield com os parâmetros do tecido $\left(\rho, \omega_{i}\right)$. . $\quad 77$

4.2 Correlação da unidade de Hounsfield com os parâmetros do tecido $\left(\omega_{i}, \rho\right)$. . 81

4.3 Proporção de água e de gordura em tecidos moles versus o valor de Hounsfield calculado. . . . . . . . . . . . . . . . . . . 87

4.4 Esquema da configuração para o cálculo da energia depositada no MCNP5. 89

4.5 Uma das imagens de CT utilizada nas metodologias, com detalhe da região de interesse para o cálculo da distribuição de dose (A) e detalhe ampliado da região de interesse $(\mathrm{B}) . \ldots \ldots \ldots \ldots$ 
4.6 Representação do processo de cálculo de $C(x, y)$ com a utilização de quatro projeções. . . . . . . . . . . . . . . . . . . . 93

5.1 Apresentação geral dos módulos do ICCT e suas respectivas funções. . . . . 95

5.2 Apresentação de um grupo de imagens abertas com uma região de interesse selecionada. . . . . . . . . . . . . . . . . . 96

5.3 Tela do software ICCT. . . . . . . . . . . . . . . . . . . . . . . . 97

5.4 Fluxograma do Módulo 1 . . . . . . . . . . . . . . . . . . . . . . 97

5.5 Fluxograma do Módulo 2. . . . . . . . . . . . . . . . . . . . . . . . 99

5.6 Aviso de erro emitido pelo ICCT. . . . . . . . . . . . . . . . . . . . 101

5.7 Fluxograma do Módulo $3 . \quad$. . . . . . . . . . . . . . . . . . . . . . 102

5.8 Fluxograma do Módulo 4. . . . . . . . . . . . . . . . . . . . . . . . 103

5.9 Correlação da unidade de Hounsfield com a densidade. . . . . . . . . . . . 107

5.10 Correlação da unidade de Hounsfield com a densidade. Ampliação da região de $H$ de 0 á 120 da FIG.5.9. . . . . . . . . . . . . . . . . 108

5.11 Fluxograma do Módulo 5. . . . . . . . . . . . . . . . . . . . . . . . . 109

5.12 Esquema da utilização do ICCT para fornecer dados para o SCMS e para o MCNP5. ................................. 110

5.13 Comparação do cálculo do número de Hounsfield entre ICCT e Schneider et al. (2000). . . . . . . . . . . . . . . . . . 111

5.14 Imagens de CT utilizadas para adquirir os resultados do ICCT. . . . . . . 117

5.15 Apresentação do arquivo Table_MDId. . . . . . . . . . . . . . . . 117

5.16 Mapa de tecido (à esquerda) e mapa de densidade (direita). . . . . . . . . 118

5.17 Apresentação do arquivo Components. . . . . . . . . . . . . . . . . . . . . 119

5.18 Especificação geral de cada módulo e suas respectivas funções. . . . . . . . 120

5.19 Fluxograma do Módulo 1. . . . . . . . . . . . . . . . . . . . . . . . . 122

5.20 Tela inicial do Módulo 2, denominada "Parameters for Attenuation Correc-

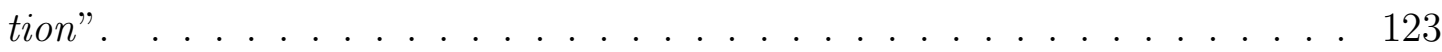

5.21 Fluxograma do Módulo 2. . . . . . . . . . . . . . . . . . . . . . . . . 126

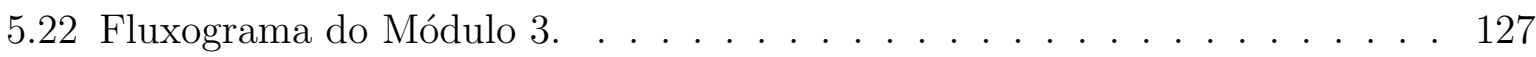

5.23 Esquema da imagem utilizada para verificar o funcionamento do ACPS. . . 128

5.24 Arquivo de saída gerado pelo ACPS. . . . . . . . . . . . . . . . . . . . 128 
5.25 Representação de uma imagem de CT. . . . . . . . . . . . . . . . . . 130

5.26 Matriz da imagem de CT. . . . . . . . . . . . . . . . . . 130

5.27 Resultado gerado pelo ACPS. . . . . . . . . . . . . . . . 130

5.28 Matriz dos coeficientes de atenuação. . . . . . . . . . . . . . . . . 131

5.29 Imagem do mapa de tecidos com 19 tecidos (A), imagem do mapa de tecido com 4 tecidos $(\mathrm{B}) . \ldots \ldots \ldots \ldots \ldots$ 


\section{Lista de Tabelas}

3.1 Panfletos MIRD (Stabin, 2006) . . . . . . . . . . . . . . . 41

4.1 Composição dos tecidos moles: densidade $(\rho)$ e as frações em pesos $\left(\omega_{i}(f p)\right)$ de cada elemento dos tecidos (Woodard et al., 1986 ; White et al., 1987). . 78

4.2 Composição dos tecidos esqueléticos: densidade $(\rho)$ e as frações em peso $\left(\omega_{i}(f p)\right)$ de cada elemento dos tecidos (Woodard et al., 1986 ; White et al., 1987).

5.1 Composição dos Objetos Simuladores: densidade $(\rho)$ e as frações me peso $\left(\omega_{i}(f p)\right)$ de cada elemento. . . . . . . . . . . . . . . . . . 98

5.2 Grupo do ar e do pulmão com a fração em peso de cada elemento químico. 105

5.3 Grupos do tecido mole os intervalos de Hounsfield correspondentes. . . . . 105

5.4 Grupos de tecido mole, $I D=7$ e $I D=8$, com a fração em peso de cada elemento químico. . . . . . . . . . . . . . . . . . 106

5.5 Unidade de Hounsfield dos tecidos esqueléticos calculada pelo software ICCT.111

5.6 Unidade de Hounsfield dos tecidos esqueléticos calculada pelo software ICCT.112

5.7 Parâmetros do tecido $\left(\rho, \omega_{i}\right)$, construídos pelo ICCT, dos 24 grupos. . . . . 113

5.8 Desvios máximos, em frações em peso $(f p)$, obtidos para os grupos de $I D=$ 2 aо $I D=6 . \ldots \ldots \ldots \ldots \ldots$

5.9 Desvios máximos, em frações em peso $(f p)$, para o grupo de $I D=7$. . . 115

5.10 Desvios máximos em relação a $\omega_{i}$, em frações em peso $(f p)$, obtidos para os grupos do tecido mole . . . . . . . . . . . . . . . . . 115

5.11 Desvios máximos em relação a $\omega_{i}$, em frações em peso $(f p)$, obtidos para os grupos do tecido esquelético . . . . . . . . . . . . . . . 116 
5.12 Desvios máximos em relação a $\omega_{i}$, em frações em peso $(f p)$, obtidos para os grupos do tecido esquelético . . . . . . . . . . . . . . . . 116

5.13 Variações, em frações em pesos $(f p)$, da composição química, obtidas entre a urina e o grupo de $I D=7 \ldots \ldots \ldots \ldots \ldots$. . . . . . . . . . . . . . . . . . .

5.14 Diferença percentual na dose absorvida obtidas entre a urina e o grupo de

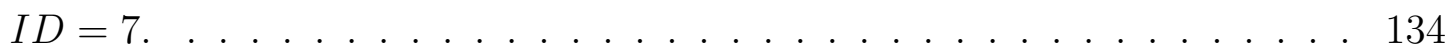

5.15 Variações, em frações em pesos $(f p)$, da composição química, obtidas entre o tecido D6, L3 incluindo Cartilagem (homem) e o grupo de $I D=12$. . . 134

5.16 Diferença percentual na dose absorvida obtidas entre o tecido D6, L3 incluindo Cartilagem (homem) e o grupo de $I D=12 \ldots \ldots$. . . . . . . . . 134 


\section{Sumário}

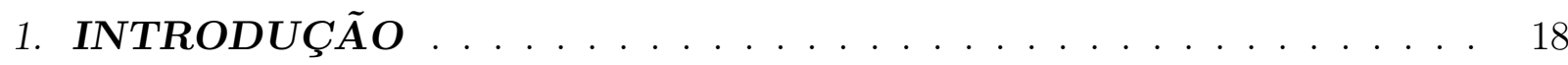

1.1 Justificativa . . . . . . . . . . . . . . . . . . 20

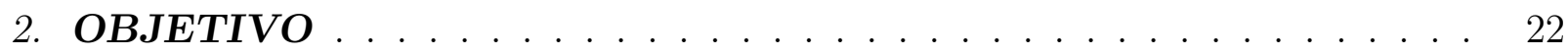

2.1 Objetivos específicos . . . . . . . . . . . . . . . 22

3. REVISÃO BIBLIOGRÁFICA . . . . . . . . . . . . . . . . . 23

3.1 Introdução à radiação gama . . . . . . . . . . . . . . . . . . . 23

3.1.1 Interação da radiação gama com a matéria . . . . . . . . . 23

3.1 .2 Atenuação da radiação gama com a matéria . . . . . . . . . . 29

3.1.3 Coeficiente de atenuação de massa . . . . . . . . . . . . . . 29

3.1.4 Coeficiente de atenuação linear em termos da densidade, composição de um composto químico e da seção de choque total para interações de fótons por átomo . . . . . . . . . . 30

3.2 Introdução a elétrons e pósitrons . . . . . . . . . . . . . . . 31

3.2.1 Tipos de interações por forças Coulombianas pelas partículas carregadas . . . . . . . . . . . . . . . . . . . 32

3.2.2 Poder de freamento . . . . . . . . . . . . . . 35

3.3 Método Monte Carlo . . . . . . . . . . . . . . . . . . . . 36

3.3.1 Transporte de partículas pelo método de Monte Carlo . . . 37

3.4 Medicina Nuclear . . . . . . . . . . . . . . . . . . 37

3.4.1 Breve histórico da dosimetria na Medicina Nuclear . . . . . 38

3.4.2 Dose Absorvida . . . . . . . . . . . . . . . 39 
3.4.3 Método de Marinelli e Quimby . . . . . . . . . . . . . . . 40

3.4.4 O sistema MIRD (Medical Internal Radiation Dose) . . . . 41

3.4.5 Objeto simulador antropomórfico . . . . . . . . . . . 47

3.4.6 Softwares de dosimetria interna baseado em objetos simuladores . . . . . . . . . . . . . . . . . . . . . . 49

3.4.7 Dosimetria Interna mediante imagens médicas nucleares 3D 49

3.4.8 Cálculo de dose através de informações nucleares e dose kernels ........................... 51

3.4.9 Cálculo de dose com base em códigos de Monte Carlo . . . 52

3.4.10 Problemas que podem afetar o cálculo da dose mediante imagens médicas . . . . . . . . . . . . . . 53

4. MATERIAIS E MÉTODOS . . . . . . . . . . . . . . . . 70

4.1 MATERIAIS . . . . . . . . . . . . . . . . . . 70

4.1 Linguagem de programação Java . . . . . . . . . . . . . . . 70

4.1 .2 Software ImageJ . . . . . . . . . . . . . . . . . 73

4.1.3 Software MCNP5 . . . . . . . . . . . . . . 73

4.1.4 Sistema de Construção de Manequins Segmentados - SCMS 74

4.1.5 Padrão DICOM - Digital Imaging and Communications in Medicine . . . . . . . . . . . . . . . . . . 74

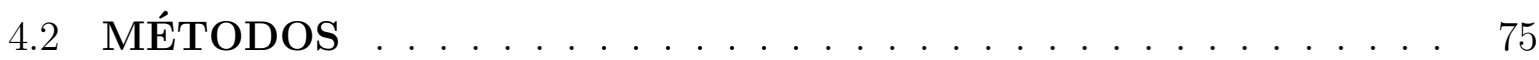

4.2.1 Desenvolvimento do software ICCT ( Image Converter for Computer Tomography ) e do ACPS (Attenuation Correc-

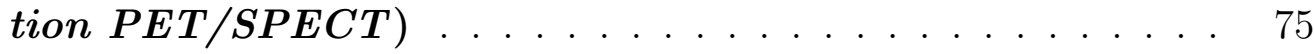

4.2.2 Metodologia de conversão da unidade de Hounsfield em parâmetros do tecido . . . . . . . . . . . . . . . . . 76

4.2.3 Influência da composição dos tecidos no cálculo da dose absorvida . . . . . . . . . . . . . . . . . . . . 88

4.2.4 Análise da influência da quantidade de tecidos no cálculo da dose absorvida . . . . . . . . . . . . . . . . . . 89

4.2.5 Método de Chang de $\mathbf{1}^{a}$ ordem f . . . . . . . . . . . . 90 
5. RESULTADOS E DISCUSSÃO

5.1 Software Conversor de Imagens de Tomografia Computadorizada - ICCT . . . . . . . . . . . . . . . . . . 95

5.1 Testes efetuados no Software ICCT . . . . . . . . . . . 110

5.2 Software para Correção de Atenuação para imagens PET e SPECT -ACPS . . . . . . . . . . . . . . . 120

5.2.1 Testes efetuados no Software ACPS . . . . . . . . . . 128

5.3 Influência da composição química dos tecidos no cálculo da dose absorvida . . . . . . . . . . . . . . . . . . . 133

5.4 Análise da influência da quantidade de tecidos no cálculo da dose absorvida . . . . . . . . . . . . . . . . . . 135

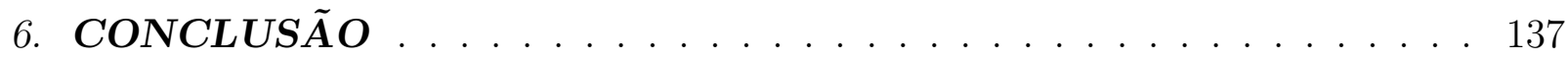

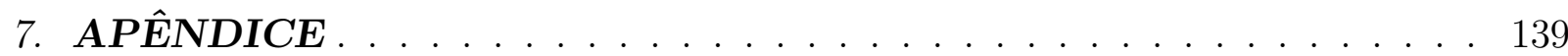

8. REFERÊNCIAS BIBLIOGRÁFICAS . . . . . . . . . . . . . 141 
Capítulo 1

\section{INTRODUÇÃO}

De acordo com o Instituto Nacional do Câncer (INCA) o impacto global do câncer mais que dobrou em 30 anos. No Brasil, as estimativas, para o ano de 2010, que também serão válidas para o ano de 2011, apontam para a ocorrência de 489.270 novos casos de câncer (INCA, 2010).

Assim, fica evidente a necessidade de investimentos no desenvolvimento de ações para o controle do câncer em diferentes níveis de atuação e uma das áreas importantes no tratamento e diagnóstico de câncer é a medicina nuclear.

A medicina nuclear permite por meio de equipamentos especializados a visualização de processos funcionais através da administração de radiofármacos no organismo. Os radiofármacos são fármacos marcados com material radioativo (radioisótopos ou radionuclídeos), utilizados em pequenas quantidades com a finalidade de diagnosticar patologias e disfunções do organismo. Em menor extensão, são aplicados em terapia de doenças, particularmente no tratamento de tumores radiosenssíveis. Estes radioisótopos podem ser emissores de partículas radioativas $\left(\alpha, \beta^{+}\right.$e $\left.\beta^{-}\right)$e de energia gama ou raios-x (Cherry et al., 2003a e 2003b; Saha, 1998).

Devido à alta dose utilizada em exames terapêuticos, a quantificação da dose é de extrema importância, pois fornece uma previsão da dose no tumor e em tecidos saudáveis, o que permite um melhor entendimento sobre a resposta no tumor e toxicidade nos tecidos saudáveis, causada pela atividade administrada (Sgouros, 2005).

No Brasil os centros de medicina nuclear utilizam o sistema MIRD (Medical Internal Radiation Dose) para realizar a quantificação da dose interna. Esse sistema é baseado num modelo de referência denominado "MIRD phantom" (simulador MIRD) que representa um indivíduo padrão. Este modelo de referência não apresenta detalhes necessários para se 
obter uma avaliação precisa da dose em uma terapia, apenas fornece uma dose média para os órgãos do corpo (Zanzonico et al., 2003).

Devido o método de Monte Carlo ser utilizado de forma exemplar na solução de problemas estatísticos e pelo fato da emissão, transporte e detecção da radiação serem de natureza estocástica, o uso deste método para simular o transporte de radiação, tem sido um dos meios mais precisos de prever a distribuição de dose absorvida, e outras grandezas de interesse, no tratamento de câncer por radiação, usando tanto fonte interna quanto fonte externa ao paciente (Stabin et al., 2003).

Um dos códigos de Monte Carlo mais utilizados no mundo é o MCNP5, (Monte Carlo $N$-Particle transport code, version 5 ) que foi desenvolvido no Laboratório Nacional de Los Alamos (Los Alamos, Novo México), originalmente para transporte de nêutrons e fótons com a finalidade em análise de reatores. Umas das vantagens desse código é que ele permite calcular a distribuição de energia depositada pela radiação em meios que possuem geometrias complexas (Booth et al., 2003).

Trabalhos recentes em dosimetria interna utilizam imagens de tomografia computadorizada (Computer Tomography - CT) e/ou ressonância magnética (Magnetic Resonance Imaging - MRI) do próprio paciente, para obter informações mais realistas do corpo do mesmo. Também utilizam a imagem funcional, tomografia por emissão de fóton único (Single Photon Emission Computer Tomography - SPECT) e tomografia por emissão de pósitrons (positron emission tomography -PET), para proporcionar a representação tridimensional da distribuição de atividades dentro do paciente. E através dessas informações realizam o cálculo de dose pelo método de Monte Carlo (Chiavassa, et al., 2005; Guy, et al., 2003; Gardin, et al., 2003; Yoriyaz, et al., 2001; Grudzinski et al., 2010).

O código MCNP5 necessita de cinco informações básicas para realizar o transporte da radiação: geometria, densidade, composição química, localização dos materiais e a distribuição de atividade(Booth et al., 2003). As quatro primeiras informações podem ser obtidas através do CT e a última por meio do SPECT ou PET.

No Centro de Engenharia Nuclear do Ipen, está em desenvolvimento uma metodologia em que as informações de CT, SPECT/PET são inseridas no MCNP5 mediante um software denominado SCMS (Sistema Construtor de Manequins Segmentados) para assim obter a distribuição de dose interna personalizada para cada paciente. Na FIG.1.1 há uma 
representação desse sistema de dosimetria personalizado para paciente.

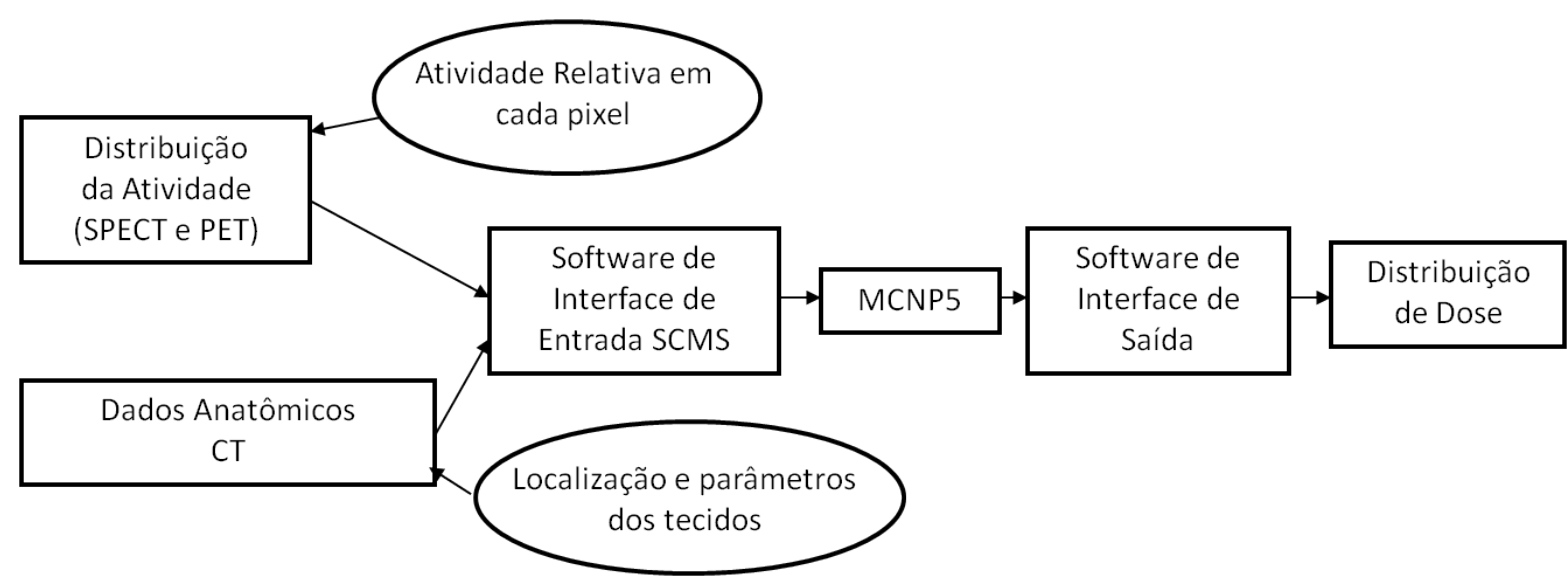

Figura 1.1: Esquema da metodologia de dosimetria personalizada para o paciente.

Cada paciente apresenta captação e retenção de agente radioativo de forma diferente e também diferenças físicas e radiosenssíveis, portanto, fica clara a importância desse tipo de dosimetria em procedimentos terapêuticos (Stabin, et al., 2008a e 2008b; Divoli, et al., 2009).

\subsection{Justificativa}

Geralmente os centros de terapia radionuclídica administram níveis similares de atividade ou atividade por massa corpórea, isto é, a mesma dosagem farmacêutica em todos os pacientes que apresentam o mesmo diagnóstico de câncer ou de alguma outra doença (Stabin et al., 2007).

Esse tipo de abordagem funciona muito bem para determinados tipos de cânceres como, por exemplo, o de tireóide em que a janela terapêutica é elevada, isto é, a quantidade de radiofármaco que é captada pelo tumor é muito maior que a captada pelos tecidos normais.

Todavia, alguns centros começam a usar a dosimetria específica em pacientes mesmo nesses casos discutidos anteriormente para assim diminuir os efeitos colaterais tais como sialoadenite e síndrome de sicca (Stabin et al., 2007).

Pesquisas que utilizam anticorpos monoclonais e peptídeos radiomarcados com radionuclídeos emissores $\beta^{-}$ou $\alpha$ tornam-se promissoras pela alta especificidade desses radiofármacos (DeNardo et al., 2006; Rasaneh et al., 2009; Goldsmith, 2010). 
Esses quando administrados ao paciente, podem ter uma baixa razão da dose absorvida no tecido tumoral em relação ao normal o que indica que é pequena a diferença entre o que é captado pelo tecido tumoral e pelas células normais.

Consequentemente, sem o uso da dosimetria personalizada os pacientes recebem uma baixa quantidade desses agentes radioterápicos para evitar efeitos deletérios nos tecidos normais, sobretudo na medula óssea.

Outro fator é que há diferenças intrínsecas entre cada paciente, assim como os níveis de tumor, concentração na captação pelos tecidos normais e a taxa de eliminação (taxa de eliminação dos agentes radioterápicos pelos tecidos normais).

Uma das implicações dessas diferenças é que pacientes que possuem alta taxa de eliminação certamente receberão doses mais baixas do que aqueles que apresentam uma taxa lenta.

Levando-se em conta as diferenças entre os pacientes e a alta especificidade dos novos agentes radioterápicos é notável que sem o uso de dosimetria personalizada poucos pacientes receberão um tratamento adequado.

Isso não quer dizer que durante o tratamento o paciente terá efeito deletério no tecido sadio, mas sim terá uma dose absorvida subestimada no tecido tumoral o que certamente provocará uma baixa taxa de resposta e uma elevada taxa de recidiva.

Por fim, além do sistema de dosimetria personalizada melhorar a qualidade da terapia radionuclídica ele também permitirá estabelecer um banco de dados para a literatura proporcionando novos trabalhos na compreensão da variabilidade entre os indivíduos e o intervalo dos valores de captação e eliminação esperados por diferentes agentes terapêuticos. 
Capítulo 2

\section{OBJETIVO}

O presente trabalho pretende contribuir com a área de medicina nuclear através do desenvolvimento de parte da metodologia de dosimetria personalizada do paciente para terapia radionuclídica. As demais frentes de pesquisa deste trabalho estão em desenvolvimento pelo grupo de Física Médica do Centro de Engenharia Nuclear do Ipen.

\subsection{Objetivos específicos}

- Desenvolver um software para converter a unidade de Hounsfield adquirida por imagens de tomografia computadorizada (CT) em mapa de densidade, mapa de tecidos e fração em peso de cada elemento químico que constitui os tecidos;

- Desenvolver um software para realizar a correção de atenuação em imagens tomográficas de medicina nuclear (SPECT ou PET) para fornecer o mapa de atividade relativa;

- Preparação dos dois softwares acima para fornecerem dados de entrada ao SCMS. 
Capítulo 3

\section{REVISÃO BIBLIOGRÁFICA}

\subsection{Introdução à radiação gama}

A interação dos raios- $\gamma$ com a matéria difere da interação de partículas carregadas, tais como $\alpha$ e $\beta$, com a matéria. Umas das diferenças é o seu alto poder de penetração, outra, é a forma como eles sofrem atenuação na matéria, que é representada exponencialmente.

O alto poder de penetração dos raios- $\gamma$, está no fato da ausência de carga. Isso o torna desprovido do campo de força Coulombiano e por consequência drasticamente menos sensível, do que as particulas carregadas, ao meio que atravessa.

\subsubsection{Interação da radiação gama com a matéria}

Há quatro principais processos responsáveis pela absorção de raios- $\gamma$ : efeito fotoelétrico, espalhamento Compton, espalhamento Rayleigh e a produção de pares.

\section{EFEITO FOTOELÉTRICO}

No efeito fotoelétrico, toda a energia $E_{i}(h \nu)$ do fóton incidente é transferida ao elétron, sendo esse ejetado do átomo com uma energia cinética $E_{s}=E_{i}-E_{l}$, onde $E_{l}$ é o potencial de ionização do elétron, isto é, a energia mínima necessária para remover o elétron do átomo (Kaplan, 1977).

O potencial de ionização aumenta à medida que o elétron atômico se encontra numa camada mais próxima do núcleo, o que diminui a energia cinética do elétron ejetado.

Se o elétron ejetado for emitido de uma camada interna ocorrerá um reajuste dos elétrons da camada mais externa para preencher a vacância e isso por consequência acarretará na emissão de um fóton com energia igual a diferença das energias das camadas, 
denominado fóton de fluorescência (Kaplan, 1977).

O elétron ejetado através desse processo recebe o nome de fotoelétron. O esquema do efeito fotoelétrico é apresentado na Fig.(3.1).

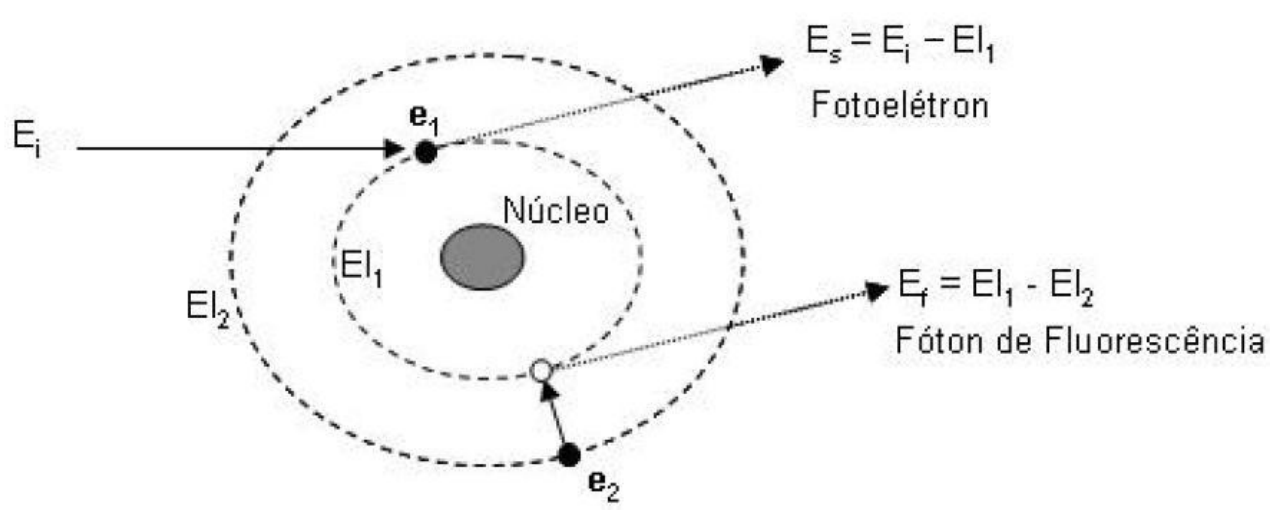

Figura 3.1: Esquema do efeito fotoelétrico.

Diferentes fórmulas devem ser usadas se a seção de choque da interação fotoelétrica, expressada como um coeficiente de absorção, for calculada sobre um intervalo de energia de 0,1 a $5 \mathrm{MeV}$ ou $10 \mathrm{MeV}$.

Se a energia do fóton for suficientemente pequena de modo que o efeito relativístico não seja importante, mas grande o bastante para que a energia de ligação dos elétrons da camada K possa ser negligenciada, a seção de choque por átomo ${ }_{a} \tau$ para a absorção fotoelétrica é:

$$
{ }_{a} \tau=\phi_{0} Z^{5}\left(\frac{1}{137}\right)^{4} 4 \sqrt{2}\left(\frac{m_{0} c^{2}}{h \nu}\right)^{\frac{7}{2}}
$$

Sendo:

$$
\phi_{0}=\frac{8 \pi}{3}\left(\frac{e^{2}}{m_{0} c^{2}}\right)^{2}=6,651 X 10^{-25} \mathrm{~cm}^{2}
$$

onde,

- $h \nu$ é a energia do fóton incidente;

- $m_{0} c^{2}$ é a energia de repouso do elétron;

- $Z$ é o número atômico;

- $\phi_{0}$ representa a seção transversal para espalhamento de fóton de baixa energia por elétron livre em repouso. 
A Eq.(3.1) aplica-se somente para a ejeção de elétrons da camada K do átomo, que representa $80 \%$ do efeito fotoelétrico. Observa-se nessa equação que ${ }_{a} \tau$ é proporcional a $Z^{5}$ e inversamente proporcional a $(h \nu)^{7 / 2}$. Isso significa que para uma dada energia do fóton, o efeito fotoelétrico ocorrerá em maior quantidade nos metais que possuírem elevado número atômico e que para um dado material o efeito prevalecerá conforme menor for a energia do fóton incidente.

Dessa forma o efeito fotoelétrico será de grande importância para fótons de baixa energia ao colidir em metais de número atômico relativamente elevado.

\section{EFEITO COMPTON}

No efeito Compton ocorre um choque elástico, em que há conservação da energia e do momento, entre um fóton e um elétron atômico. Por simplificação assume-se que o elétron esteja livre (Kaplan, 1977).

A fim de que o momento seja conservado, o elétron é espalhado com um momento igual ao do vetor diferença entre o fóton incidente e o espalhado. O esquema do Efeito Compton é apresentado na FIG.(3.2).

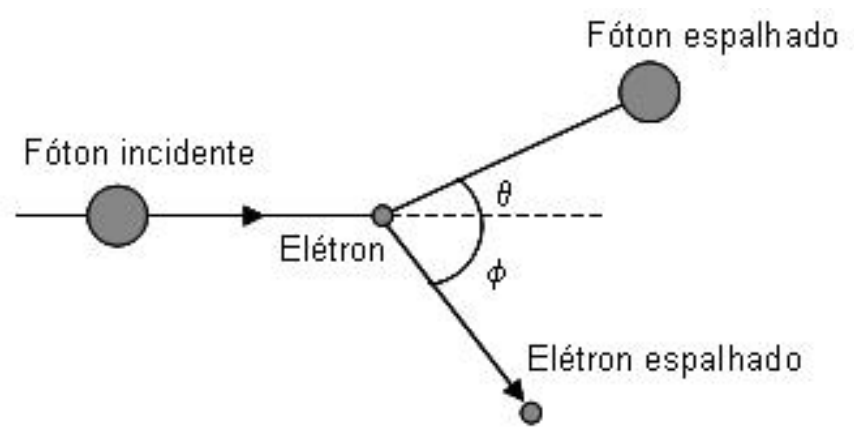

Figura 3.2: Esquema do efeito Compton.

A energia do elétron ejetado é dada pela energia do fóton incidente subtraída pela energia do fóton espalhado. A equação a seguir apresenta a conservação da energia:

$$
h \nu_{0}=h \nu+m_{0} c^{2}\left(\frac{1}{\sqrt{1-\left(\frac{v^{2}}{c^{2}}\right)}}-1\right)
$$

onde,

- $\nu_{0}$ é a frequência do fóton incidente; 
- $\nu$ é a frequência do fóton espalhado pelo elétron;

- $v$ é a velocidade do elétron adquirida pelo choque.

A conservação do momento é representada pelas seguintes equações, em que a primeira refere-se a componente " $X$ " do momento e a segunda a componente " $Y$ ":

$$
\begin{gathered}
\frac{h \nu_{0}}{c}=\frac{h \nu}{c} \cos \theta+\frac{m_{0} v}{\sqrt{1-\left(\frac{v^{2}}{c^{2}}\right)}} \cos \phi \\
0=\frac{h \nu}{c} \sin \theta-\frac{m_{0} v}{\sqrt{1-\left(\frac{v^{2}}{c^{2}}\right)}} \sin \phi
\end{gathered}
$$

Através das Eq.(3.3), Eq.(3.4) e Eq.(3.5) é possivel encontrar a seguinte equação:

$$
\Delta \lambda=\lambda-\lambda_{0}=\frac{h}{m_{0} c}(1-\cos \theta)
$$

onde,

- $\lambda_{0}$ é o comprimento de onda do fóton antes da colisão;

- $\lambda$ é o comprimento de onda do fóton depois da colisão;

- $\theta$ é o ângulo de espalhamento do fóton.

A Eq. (3.6) representa a perda de energia de um fóton, pelo efeito Compton, através da variação do seu comprimento de onda.

A energia cinética do elétron espalhado é representada pela seguinte equação:

$$
T=\frac{(1-\cos \theta) \frac{h \nu_{0}}{m_{0} c^{2}}}{1+\frac{h \nu_{0}}{m_{0} c^{2}}(1-\cos \theta)}
$$

Esta energia depende somente do ângulo $\phi$, sendo máxima quando o valor do $\cos (\phi)=$ -1 ou $\phi=180^{\circ}$, isto é, no caso do fóton espalhado voltar na direção do fóton incidente.

Para tratar a contribuição do efeito Compton na atenuação de feixes de raios- $\gamma$ na matéria, é necessário calcular a probabilidade desse processo ocorrer.

A fórmula obtida para a seção de choque por elétron, $e^{\sigma}$, é dado por:

$$
{ }_{e} \sigma=\frac{3}{4} \phi_{0}\left\{\frac{1+\alpha}{\alpha^{2}}\left[\frac{2(1+\alpha)}{1+2 \alpha}-\frac{1}{\alpha} \ln (1+2 \alpha)\right]+\frac{1}{2 \alpha} \ln (1+2 \alpha)-\frac{1+3 \alpha}{(1+2 \alpha)^{2}}\right\}
$$

Sendo:

$$
\alpha=\frac{h \nu_{0}}{m_{0} c^{2}} \quad e \quad \phi_{0}=\frac{8 \pi}{3}\left(\frac{e^{2}}{m_{0}^{2}}\right)^{2}=6,651 X 10^{-25} \mathrm{~cm}^{2}
$$


Quando $e_{e} \sigma$ é multiplicado por $\rho N_{A}(Z / A)$, o resultado é o coeficiente de absorção Compton $\mu\left(\mathrm{cm}^{-1}\right)$, que representa a probabilidade de um fóton ser espalhado para fora do feixe original, por centímetro do material absorvedor.

$$
\mu\left(\mathrm{cm}^{-1}\right)=\rho N_{A} \frac{Z}{A}{ } \sigma
$$

Levando-se em consideração a Eq.(3.10) temos que a probabilidade de ocorrer espalhamento Compton é proporcional a $Z$ e, além disso, decresce lentamente com o aumento da energia do fóton incidente (Kaplan, 1977).

\section{ESPALHAMENTO RAYLEIGH}

Também chamado de espalhamento "coerente", nesse tipo de interação o fóton não perde energia significativa e o átomo move-se o suficiente para conservação do momento (Attix, 2004a).

O ângulo que o fóton é espalhado depende tanto do número atômico $(Z)$ como da energia desse fóton $(h \nu)$. A seção de choque para esse tipo de interação em unidade de $\mathrm{cm}^{2} /$ atom é dado por:

$$
{ }_{a} \sigma_{R} \propto \frac{Z^{2}}{(h \nu)^{2}}
$$

Esse tipo de interação tem uma importância mais prática em baixas energias. No entanto, sua contribuição para o coeficiente de atenuação de um estreito feixe de fótons é ínfima em comparação ao efeito fotoelétrico e Compton (Attix, 2004a).

\section{PRODUÇÃO DE PARES}

Esse processo que não tem análogo na física clássica, é considerado estritamente um fenômeno experimental.

Um raio- $\gamma$ de energia igual ou superior a $2 m_{0} c^{2}(=1,022 \mathrm{MeV})$ ao interagir com o Campo Coulombiano de um núcleo atômico produrizirá o par elétron-pósitron (Kaplan, 1977). Na Fig.(3.3) há o esquema desse processo.

Pela conservação da energia, negligenciando a energia cinética dada ao núcleo, tem-se:

$$
h \nu=2 m_{0} c^{2}+T^{-}+T^{+}
$$

onde, 
- $T^{-}$representa a energia cinética do elétron;

- $T^{+}$representa a energia cinética do pósitron.

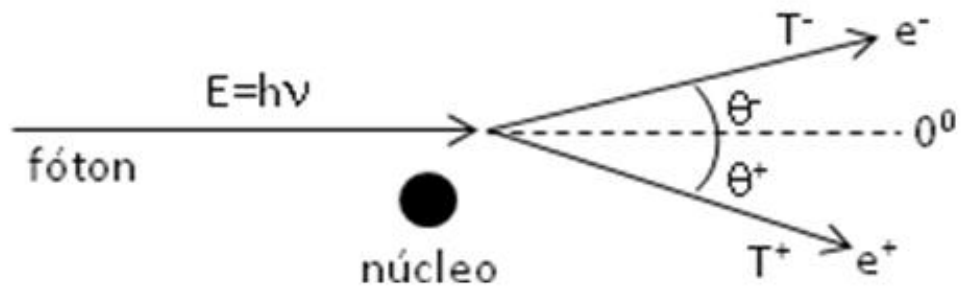

Figura 3.3: Esquema da produção de pares.

Essas energias não são necessariamente iguais, porém, a média delas é dada por:

$$
\bar{T}=\frac{h \nu-2 m_{0} c^{2}}{2}
$$

Uma explicação simplificada é que um fóton de energia maior do que 1,022 $\mathrm{MeV}$ pode fazer com que um elétron altere seu estado de energia negativa para um estado de energia positiva, isto produz um "buraco", significando o aparecimento de um pósitron (Kaplan, 1977).

O aparecimento de um elétron no estado de energia positiva significa o aparecimento de um elétron ordinário. Então, o par elétron-pósitron é criado.

A seção de choque para esse processo é dada por:

$$
\bar{\phi}=Z^{2} \frac{r_{0}^{2}}{137}=Z^{2} \cdot 5,796 \times 10^{-28} \mathrm{~cm}^{2}
$$

onde,

- $r_{0}$ é o raio clássico do elétron.

Essa seção de choque é nula para fótons com energia menores do que 1,022 $\mathrm{MeV}$, sendo que apartir desse ponto ela aumenta drasticamente com o aumento da energia. Além disso, ela é proporcional a $Z^{2}$.

Para altas energias, ambos os efeitos fotoelétrico e Compton tornam-se sem importância comparados à formação de pares (Kaplan, 1977). 


\subsubsection{Atenuação da radiação gama com a matéria}

Tanto um feixe monocromático como um policromático de fótons que possui um pequeno intervalo de energia, apresenta uma função semelhante para a atenuação desses feixes na matéria (McCullough, 1975).

Um estreito feixe monoenergético de fótons com energia $E$ e densidade de fluxo de fótons incidente, $\phi_{0}$, (número de fótons por unidade de tempo e área) que passa através de um material absorvedor homogêneo de espessura $x$, terá uma intensidade emergente de fótons $\phi$ dada por:

$$
\phi=\phi_{0} e^{-\mu(\rho, Z, E) x}
$$

onde,

- $\mu$ é o coeficiente de atenuação linear (por unidade de comprimento);

- $\rho$ é a densidade em massa;

- $Z$ é a composição atômica do material absorvedor.

Observa-se que o $\mu$ além de depender da densidade e composição do material, também depende da energia do fóton incidente.

\subsubsection{Coeficiente de atenuação de massa}

O coeficiente de atenuação linear, $\mu$, como visto anteriormente é proporcional a densidade, $\rho$, do material absorvedor. Uma vez que a energia de ligação molecular geralmente é muito menor do que a energia envolvida na interação da radiação gama, num intervalo de energia diagnóstica, é razoável assumir que $\mu\left(\mathrm{cm}^{-1}\right)$ é diretamente proporcional a densidade $\left(\mathrm{g} . \mathrm{cm}^{-3}\right)$ (McCullough, 1975).

Assim pode-se escrever que:

$$
\phi=\phi_{0} e^{-\left(\frac{\mu(Z, E)}{\rho}\right) \rho x}
$$

onde,

- $\mu / \rho$ é o coeficiente de atenuação de massa dado em $\mathrm{cm}^{2} \cdot g^{-1}$ ou $m^{2} \cdot K g^{-1}$.

Para um composto químico ou mistura, o coeficiente de atenuação de massa pode ser calculado a partir da soma ponderada dos coeficientes dos elementos que o constituem 
(McCullough, 1975).

$$
\frac{\mu}{\rho}=\sum_{i=1}^{n} \omega_{i} \frac{\mu_{i}}{\rho_{i}}
$$

onde,

- $\omega_{i}$ é a fração em peso do i-ésimo elemento constituinte.

Para um composto com fórmula $\left(A_{i}\right)_{a_{i}}\left(A_{i+1}\right)_{a_{i+1}} \cdots\left(A_{i+n}\right)_{a_{i+n}}$, em que $a_{i}$ e $A_{i}$ representam a quantidade e a massa atômica do i-ésimo elemento respectivamente, assim a fração em peso do i-ésimo elemento pode ser escrita como:

$$
\omega_{i}=\frac{a_{i} A_{i}}{\sum_{j=1}^{n} a_{j} A_{j}}
$$

Outra maneira de representar o coeficiente de atenuação de massa é através da seção de choque total, para interações de fótons, por átomo, $\sigma_{\text {tot }}^{a}$, dada $\mathrm{em} \mathrm{cm}^{2} /$ atom ou barns/atom (1 barns equivale a $10^{-24} \mathrm{~cm}^{2}$ ).

Essa seção de choque representa a soma das seções de choque de todos os processos de espalhamento e absorção ocasionados pela interação da radiação gama com a matéra.

Dessa forma $\mu / \rho$ pode ser escrito como:

$$
\frac{\mu}{\rho}=\sigma_{\text {tot }}^{a} \frac{N_{A}}{A}
$$

onde,

- A é a massa atômica do material absorvedor;

- $N_{A}$ é o número de Avogadro;

- $\frac{N_{A}}{A}$ é dado em atom. $g^{-1}$.

\subsubsection{Coeficiente de atenuação linear em termos da densidade, composição de um composto químico e da seção de choque total para interações de fótons por átomo}

O coeficiente de atenuação linear de um composto químico ou mistura, em relação a densidade, composição química dos elementos da mistura e da seção de choque total para 
interações de fótons, por átomo é encontrado ao substituir a Eq.(3.19) em $\mu_{i} / \rho_{i}$ presente na Eq.(3.17), dessa forma tem-se (McCullough, 1975):

$$
\mu=\rho N_{A} \sum_{i=1}^{n}\left(\frac{\omega_{i}}{A_{i}} \sigma_{\text {tot }}^{a}\right)
$$

Também é possível obter o coeficiente de atenuação linear de um composto químico, em relação a densidade, composição química dos elementos da mistura e da seção de choque total, para interações de fótons, por elétron:

$$
\mu=\rho N_{A} \sum_{i=1}^{n}\left(\omega_{i} \frac{Z_{i}}{A_{i}}\right) \cdot \sigma_{t o t}^{e}
$$

\subsection{Introdução a elétrons e pósitrons}

As partículas carregadas sofrem interação com a matéria de forma diferente do que os raios-X, raios- $\gamma$ e nêutrons (Attix, 2004b).

Quando um fóton individual ou nêutron incide num material a probabilidade de ocorrer alguma interação é infima, porém, ao se tratar de partícula carregada essa probabilidade aumenta drasticamente.

A partícula carregada, cercada pelo seu campo Coulombiano, interage com alguns elétrons do meio e com praticamente todos os átomos presentes em seu caminho.

A transferência da energia cinética inicial da partícula, em cada interação, é pouquíssima, isto é, há a necessidade de uma grande quantidade de interações para a partícula carregada perder toda sua energia cinética inicial. Essa perda de energia é normalmente tratada através de um modelo referido em inglês, "Continuous Slowing-Down Approximation" (CSDA).

Há uma maneira grosseira para se caracterizar uma partícula carregada que é mediante o caminho percorrido por essa partícula, denominado em inglês pathlength, traçado pela maioria dessas partículas que possuem um determinado tipo de energia ao atravessar um meio específico.

Por causa da enorme quantidade de interações sofridas por cada partícula, o pathlength tende a se aproximar do valor médio observado para uma grande população de partículas idênticas (Attix, 2004b). 


\subsubsection{Tipos de interações por forças Coulombianas pelas partículas carregadas}

As interações das partículas carregadas ocorridas através das forças Coulombianas são caracterizadas pelo parâmetro de impacto $b$ versus o raio atômico $a$. Na Fig.(3.4) há a representação de $a$ e $b$ (Attix, 2004b).

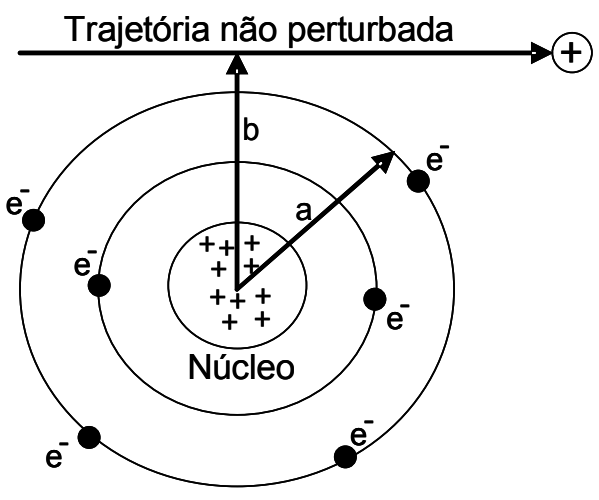

Figura 3.4: Representação do parâmetro de impacto $b$ e do raio atômico $a$.

Numa comparação entre esses dois parâmetros é possível ocorrer três tipos de interações: Colisões "Soft" $(b \gg a)$; Colisões "Hard" ou "Knock-On" $(b \sim a)$ e interações de forças Coulombianas com o campo nuclear externo $(b \ll a)$.

A seguir são apresentados cada um desses tipos de maneira mais detalhada.

\section{COLISÕES "SOFT" $(b \gg a)$}

Quando uma partícula carregada passa a uma distância razoável de um átomo, o campo de força Coulombiano dessa partícula provoca uma excitação no átomo à um nível de energia maior ou em alguns casos pode provocar até mesmo a ionização deste átomo (Attix, 2004b).

Esse tipo de interação é a que mais ocorre pois a probabilidade da partícula carregada passar a uma determinada distância do átomo é muito maior do que a de colidir com o mesmo e desse modo representam cerca de metade da energia total transferida ao meio absorvedor.

Em determinadas condições, onde a velocidade da partícula carregada ao atravessar um material dielétrico transparente, com índice de refração $n$, exceder a velocidade da luz 
nesse material, uma pequeníssima parte da energia despendida por essa partícula, através de colisões "Soft", podem ser emitidas pelo meio absorvedor na forma de uma luz violeta chamada radiação de Cerenkov.

A energia emitida na forma da radiação de Cerenkov representa uma fração menor do que $1 \%$ comparada com as demais relacionadas à colisão "Soft" podendo assim ser negligenciada em física radiológica.

\section{COLISÕES “HARD” $(b \sim a)$}

Se uma partícula carregada passar a um distância muito próxima do raio atômico de um atômo individual, isto é, se o parâmetro $b$ for da mesma ordem do raio atômico $a$, essa partícula muito provavelmente colidirá com um elétron atômico que consequentemente será emitido com um energia cinética considerável e será denominado raio delta $(\delta)$ (Attix, 2004b).

Para esse tipo de interação, num tratamento teórico, a energia de ligação atômica é negligenciada e o elétron atômico é tratado como um elétron livre.

O raio- $\delta$ emitido do átomo possui energia suficiente para sofrer adicionais interações Coulombinas e perde sua energia cinética num caminho diferente da partícula carregada primária.

As colisões "Hard" ocorrem em uma quantidade muito menor do que as colisões "Soft", porém esses dois processos contribuem de maneira comparável na fração da energia despendida no meio absorvedor, pois a energia mediante uma colisão "Hard" é bem maior que a despendida numa colisão "Soft"

Caso um elétron atômico de uma camada mais profunda for ejetado por uma colisão "Hard" provocará um mesmo efeito se esse elétron fosse removido por uma interação com fóton, ocasionando emissão de raios-X característico e/ou elétron Auger.

Assim, em colisões "Hard", parte da energia transferida para o meio pode estar a alguma distância do traçado da partícula primária, sendo transferidas por todas essas interações mencionadas anteriormente como pelos raios- $\delta$. 


\section{INTERAÇÕES COULOMBIANAS COM O NÚCLEO $(b \ll a)$}

As interações coulombianas com o núcleo ocorrem quando a partícula carregada passa muito próxima de um núcleo atômico, isto é, o parâmetro de impacto $b$ é muito menor do que o raio atômico $a$ do átomo em consideração e consequentemente acaba na maioria dos casos interagindo com o núcleo do mesmo (Attix, 2004b).

É considerada uma interação muito importante para elétrons e pósitrons. Na maioria dos casos, o elétron ou pósitron sofre espalhamento elástico e não ocorre perda de energia, tanto, através de fótons de raios-X como por excitação do núcleo, mas sim apenas por uma insignificante quantidade de energia cinética que é necessária para satisfazer a conservação do momento da colisão.

Por isso, este tipo de interação por espalhamento elástico não é um importante mecanismo de tranferência de energia para o meio absorvedor mas sim um importante meio de defletir elétrons. A seção de choque para o espalhamento elástico é proporcional a $Z^{2}$, sendo Z o número atômico do meio absorvedor.

Isto explica os diversos caminhos percorridos por um elétron em um meio absorvedor, principalmente se este meio possuir um elevado número atômico.

Há outro tipo de interação que ocorre numa quantidade muito menor que a do espalhamento elástico, em torno de 2 a $3 \%$, que é a interação radiativa inelástica que provoca a emissão de um fóton de raio-X.

Nesse caso, o elétron não é defletido, porém fornece uma fração significante, em alguns casos de até $100 \%$ de sua energia cinética para o fóton. Esse processo é chamado de radiação de Bremsstrahlung, uma palavra alemã que significa "radiação de freamento".

A seção de choque para a interação inelástica, assim como para o espalhamento elástico, é proporcional a $Z^{2}$, além disso ela é inversamente proporcional ao quadrado da massa da partícula, numa dada velocidade.

Dessa forma, a geração da radiação de Bremsstrahlung é muito mais importante quando se trata da interação inelástica de elétrons do que de outras partículas carregadas. No entanto, esta interação é irrelevante em materiais de baixo $Z$ ao se tratar de elétrons com energia menor do que $10 \mathrm{MeV}$. 


\section{INTERAÇÃO DO PÓSITRON}

O pósitron possue a mesma massa de um elétron porém apresenta carga positiva e é denominado antimatéria. Por este motivo, a interação do pósitron com a matéria é, em parte, diferente do que ocorre com o elétron (Sprawls Junior, 1995).

Basicamente essa interação apresenta duas fases: ionização e aniquilação. A primeira fase não é muito diferente da que ocorre com os elétrons. A medida que os pósitrons atravessam a matéria, atraem os elétrons dos átomos produzindo ionização. Somente uma pequena quantidade de energia é perdida pelos pósitrons em cada interação. Porém, quando o pósitron já perdeu grande parte de sua energia cinética ele colide com um elétron e ocorre um processo denominado aniquilação.

Nessa segunda fase (aniquilação), a massa de ambas as partículas são completamentes convertidas em energias. A relação entre massa e energia é dada por:

$$
E=m c^{2}
$$

A energia equivalente da massa de um elétron ou pósitron é de $511 \mathrm{keV}$. A energia que resulta desta interação é emitida na forma de dois fótons com energia de $511 \mathrm{keV}$ cada. Esse par de fótons são emitidos em direções opostas.

\subsubsection{Poder de freamento}

O poder de freamento, $(d T / d x)_{Y, T, Z}$ é definido como sendo a taxa da perda energética por unidade de comprimento percorrido $(x)$. Depende da partícula carregada $(Y)$, também da energia cinética $(T)$ dessa partícula e por fim do número atômico $(Z)$ do meio absorvedor.

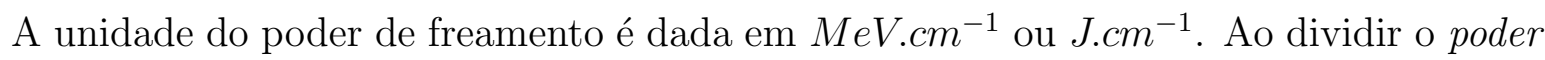
de freamento pela densidade $\rho\left(\mathrm{g} . \mathrm{cm}^{-3}\right)$ do meio absorvedor encontra-se uma quantidade denominada mass stopping power $(d T / \rho d x)$ que consequentemente possuirá unidade em $\mathrm{MeV} \mathrm{cm}^{2} \cdot \mathrm{g}^{-1}$ ou J.cm $\mathrm{cm}^{2} \cdot \mathrm{g}^{-1}$.

Ao tratar-se da perda energética de partículas carregadas, o poder de freamento pode ser subdividido em "poder de freamento de colisão" e "poder de freamento radioativo".

O "poder de freamento de colisão" é a taxa da perda energética através das colisões "Soft" e "Hard", já o "poder de freamento radioativo" é a taxa de perda energética através 
das interações Coulombianas com os núcleos.

Nas colisões radiativas a energia que é dissipada para o meio não encontra-se próxima da trajetória da partícula carregada o que não ocorre nas interações de colisão que produzem ionização e excitação e provocam assim a dissipação da energia próxima a trajetória da partícula.

\subsection{Método Monte Carlo}

O método de Monte Carlo é um método estocástico utilizado para descrever processos, sistemas ou fenômenos físicos por intermédio de uma simulação com base em números aleatórios (Zaid, 2003).

Uma das primeiras histórias conhecidas do uso de eventos aleatórios, é sobre o Dr. de Buffon que mostrou que ao jogar agulhas aleatoriamente em uma mesa, na qual estivesse desenhada linhas paralelas, seria possível obter o valor de pi $(\pi)$ experimentalmente.

A partir de então, começaram a surgir trabalhos nesta área. Em 1899, Rayleigh mostrou que o uso de um aleatório unidimensional poderia solucionar uma equação diferencial parabólica e também, em 1931, quando Kolmogorov mostrou a relação entre o processo estocástico de Markov com certas equações integro-diferenciais (Zaid, 2003).

Em sua autobiografia, Ulam, mencionou que logo após retornar para Los Alamos, em meados de 1946 a 1947, ministrou dois seminários que obtiveram grande sucesso, um deles tornou-se conhecido como o método de Monte Carlo.

A breve biografia, lista apenas um artigo de Ulam em Monte Carlo. Por volta do ano de 1948, Fermi, Metropolis e Ulam obtiveram uma estimativa de Monte Carlo para os autovalores da equação de Schrödinger. Ulam e von Neumann, em meados de 1944, batizaram o nome do método de "Monte Carlo" durante o projeto Manhatam, na segunda guerra mundial (Zaid, 2003).

O nome surgiu, por intermédio dos famosos jogos de azar, e levou o nome da conhecida cidade de Monaco onde esses jogos são populares. Ambos são considerados os precursores no desenvolvimento do método de Monte Carlo e nas suas realizações em modelos computacionais (Zaid, 2003). 


\subsubsection{Transporte de partículas pelo método de Monte Carlo}

A simulação de Monte Carlo tem por idéia geral criar um modelo o mais similar possível de um sistema real que se deseja estudar por intermédio da criação de eventos aleatórios com base na amostragem por números aleatórios de funções densidade de probabilidade (fdps) que representam tais sistemas (Zaid, 2003).

Os eventos individuais que são gerados são mais comumente referidos como "histórias". Conforme é aumentado o número de histórias a qualidade do comportamento médio do sistema aumenta o que significa que a incerteza estatística decresce.

Em termos de transporte de radiação, o processo estocástico pode ser visto como um grupo de partículas, cujas coordenadas das partículas mudam aleatoriamente a cada colisão. O comportamento das partículas é descrito em termos de grandezas macroscópicas, como o fluxo das partículas, a densidade de partículas ou a seção de choque.

Cada partícula é seguida no decorrer do seu caminho através da matéria. A ocorrência e resposta de cada interação são feitas por amostragem de funções de densidade de probabilidade apropriadas, associadas aos termos macroscópicos, por meio de números aleatórios.

Todas as partículas secundárias emitidas são armazenadas numa "pilha" para depois serem transportadas. Caso ocorra a emissão de outras partículas o processo anterior se repete até ocorrer "absorção total" ou "fuga" destas partículas, com isso uma nova história é gerada.

\subsection{Medicina Nuclear}

A medicina Nuclear foi difundida no inicio de 1950, mas as primeiras utilizações de radioisótopos aconteceram em 1946, quando o iodo radioativo foi usado para tratar câncer de tireóide. Além da cura desse tipo de câncer, o iodo radioativo também foi usado em pequenas doses para medir a função e diagnosticar doenças da tireóide (Rocha, 1976).

Desde então, a Medicina Nuclear é utilizada no tratamento de hipertiroidismo, uma patologia em que há excesso na produção de hormônios pela tiróide.

Um maior conhecimento dos processos bioquímicos e o uso do elemento radioativo como traçador de processos metabólicos levaram a um grande avanço no diagnóstico médico.

Diferentemente de um diagnóstico por raio-X no qual a radiação está externa ao pa- 
ciente, na Medicina Nuclear os radiomarcadores estão internos e detectores externos medem a radiação que esses marcadores emitem, sendo que a quantidade de radiação que o paciente é exposto é aproximadamente igual á fornecida em exames com raios-X (Rocha, 1976).

A partir de 1960, a Medicina Nuclear cresceu como uma especialidade de forma extraordinária. Inicialmente as técnicas desenvolvidas eram para estudar o fluxo sanguíneo da pequena circulação e para identificação de câncer.

No anos de 1970 mais órgãos do corpo puderam ser vizualizados, incluindo fígado, baço, localização de tumor cerebral e estudos gastrintestinais. Em 1971, a American Medical Association reconheceu oficialmente a Medicina Nuclear como uma especialidade médica.

Em 1980, radiofármacos de nova geração foram desenvolvidos para diagnosticar doenças do coração, tais como anticorpos monoclonais e FDG (2-Flúor 2-Desoxi D - Glicose), que são carreadores de elementos radioativos especialmente para células cancerígenas.

Em pequenas doses, o FDG marcado com ${ }^{18} \mathrm{~F}$ pode ser usado para identificar a existência e localização de células cancerígenas de tamanho reduzido, muito antes delas serem vistas por métodos convencionais de imagem (Rocha, 1976).

Altas taxas de doses de anticorpos monoclonais radiomarcados são usados para levar uma dose de radiação terapêutica diretamente para células cancerígenas.

A principal característica do radiofármaco é a sua ação direta no órgão de interesse, por causa da ligação ao radionuclídeo, para um determinado órgão ou tecido (Rocha, 1976).

\subsubsection{Breve histórico da dosimetria na Medicina Nuclear}

Na história da dosimetria da medicina nuclear entre os períodos de 1956 e 2006, ocorreram dois importantíssimos eventos (Stabin, 2006).

O primeiro foi o desenvolvimento do gerador de ${ }^{99 m} T c$ no ano de 1957 por W. D. Tucker e colaboradores no Laboratório Nacional de Brookhaven. O grande benefício sobreveio devido a possibilidade de se distribuir radionuclídeos a lugares distantes do seu ponto de distribuição, juntamente com a característica única de imagem do ${ }^{99 m} T c$, descoberto por Emilio Segre e Glenn Seaborg em 1938. O segundo foi o desenvolvimento do primeiro tratamento matemático genérico para cálculo de dose de radiação, elaborado por Edith Quimby e Leonidas Marinelli (Stabin, 2006). 
No ano de 1924, Georg de Hevesy, começaram a usar radiotraçadores, ao estudar a movimentação do ${ }^{210} \mathrm{~Pb}$ e ${ }^{210} \mathrm{Bi}$ em animais. Um ano depois Herrman Blumgart e Otto Yens usaram o ${ }^{214} \mathrm{Bi}$ para estudar a taxa de fluxo sanguíneo em humanos.

Dois radionuclídeos de grande importância para as aplicações médicas, ${ }^{131} I$ e ${ }^{60} C o$, foram descobertos por John Livingood e Glenn Seaborg. Tanto o ${ }^{131} I$ como ${ }^{99 m} T c$ continuam a ser vastamente utilizados em diagnóstico e terapia em estudos de medicina nuclear.

Em 1946, Allen Reid e Albert Keston descobriram o isótopo do iodo o ${ }^{125}$ I, que apresenta uma importante função nos estudos de radioimunoensaio, assim como na medicina em geral.

Em 1948, o Laboratório Abbott, iniciou a distribuição comercial de radionuclídeos e em 1950 fez a primeira distribuição do ${ }^{131} I$ como um radiofármaco. O ${ }^{131} I$ como iodeto de sódio se tornou o primeiro radiofármaco aprovado pela U.S. Food and Drug Administration (FDA) em 1951 (Stabin, 2006).

Antes de 1999, radiofármacos emissores de pósitrons já eram utilizados na rotina clínica, e a U.S. Health Care Finance Administration (HCFA) aprovou um reembolso financeiro para a aquisição de equipamentos de tomografia por emissão de pósitrons (PET) utilizado para diagnóstico e acompanhamento de muitos cânceres. Com isso, a produção e o uso de radiofármacos para PET teve um crescimento elevado.

A "câmera de cintilação", foi inventada em 1958 por Hal Anger e é também conhecida como "câmera-Anger". Ela é um dispositivo de imagiamento que permite a formação de imagens complexas de duas e três dimensões, da distribuição cinética do radiofármaco no corpo (Stabin, 2006).

O principal uso destas imagens em rotina clínica é para o diagnóstico, porém, cálculos de dose de radiação baseados em dados de imagens humanas vêm quase que exclusivamente a partir de dados obtidos com as gama câmaras de uma maneira ou de outra (Stabin, 2006).

\subsubsection{Dose Absorvida}

A dose absorvida é uma grandeza utilizada para quantificar o efeito macroscópico da irradiação de um meio, ocorrida por qualquer tipo de radiação. Definida em um ponto $P$ contido em um volume $V$ de massa $d m$, como (Sgouros, 2005):

$$
D=\frac{d \epsilon}{d m}
$$


Onde,

- de é o valor da energia depositada pela irradiação no volume V.

O valor de "de" é melhor descrito como: a diferença entre a soma das energias de todas as partículas (com ou sem carga) que entram no volume "V" com a soma das energias de todas as partículas (com ou sem carga) que saem do volume " $V "$, acrescida da energia liquida produzida por variações de massa dentro do volume (valor positivo para transformações de massa em energia e negativo para as transformações inversas) (Sgouros, 2005).

A unidade de dose absorvida adotada pelo Sistema Internacional (SI) é $(J / K g)$ que recebe o nome especial de Gray. Há também uma unidade antiga de dose absorvida o rad (radiation absorbed dose) e equivale a $10^{-2}(\mathrm{~J} / \mathrm{Kg})$.

\subsubsection{Método de Marinelli e Quimby}

Segundo Stabin (2006), o primeiro sistema dosimétrico foi desenvolvido a partir de trabalhos de Marinelli em 1948 e Quimby e Feitelberg em 1963, para emissores beta decaindo completamente no tecido. Assim obteve-se a seguinte equação para a dose pelo emissores beta:

$$
D_{\beta}=73,8 C E_{\beta} T
$$

onde,

- $D_{\beta}$ é a dose em rad (1 Gray equivale a $100 \mathrm{rad}$ );

- $C$ é a concentração de nuclídeo em microcuries por gramas $\left(\mu C i . g^{-1}\right)$;

- $E_{\beta}$ é a energia média emitida por decaimento do nuclídeo;

- $T$ é a meia vida do nuclídeo no tecido.

Para calcular a taxa de dose próxima de uma fonte pontual emissora gama, a expressão para dose foi dada por:

$$
D_{\gamma}=10^{-3} \Gamma C \int_{v} \frac{e^{-\mu r}}{r^{2}} d V
$$

onde, 
- $C$ é a atividade por unidade de massa;

- $\Gamma$ constante de taxa gama específica - fornece a taxa de exposição por desintegração em um meio infinito provocada pela fonte pontual;

- $\int \frac{e^{-\mu r}}{r^{2}} d V$ é semelhante a fração absorvida (fração de energia absorvida, em uma região alvo, por uma região fonte), que será citada posteriormente, em que $\mu$ é o coeficiente de absorção e $1 / r^{2}$ é referente a geometria da fração absorvida.

\subsubsection{O sistema MIRD (Medical Internal Radiation Dose)}

Marinelli e Quimby definiram o primeiro sistema dosimétrico, porém, o sistema que se consagrou na dosimetria médica interna e permanece até os dias atuais é o MIRD, desenvolvido pelo Comite "Medical Internal Radiation Dose" da "Society of Nuclear Medicine" (SNM), uma organização internacional fundada em 1954 para promover a ciência, tecnologia e aplicação prática da medicina nuclear ${ }^{1}$.

Informação sobre a metodologia, incluindo notação, terminologia, modelo matemático, e os dados de referência, tem sido distribuída na forma de panfletos MIRD e por meio de publicações associadas (Stabin, 2006).

Uma lista de panfletos é dada na TAB.3.1

Tabela 3.1 - Panfletos MIRD (Stabin, 2006)

\begin{tabular}{ccl}
\hline Panfletos & Data da Publicação & Informação principal \\
\hline 1,1 revisado & 1968,1976 & Discussão da técnica de dose interna MIRD \\
3 & 1968 & Fração absorvida para fótons de pequenos objetos \\
5,5 rvisado & 1969,1978 & Descrição da representação de fantons antropomórficos \\
& & Homem de referência, fração absorvida para fótons de diversos órgãos \\
7 & 1971 & Distribuição de dose ao redor de uma fonte pontual, elétrons, emissores beta \\
8 & 1971 & Fração absorvida para fótons de pequenos objetos \\
11 & 1975 & Valor $S$ para diversos radionuclídeos \\
12 & 1977 & Discussão de modelos cinéticos para dosimetria interna \\
13 & 1981 & Descrição do modelo do coração, fração absorvida para fótons \\
14,14 revisado & 1992,1999 & Dinâmica da bexiga urinária para cálculo de dose absorvida \\
15 & 1996 & Descrição do modelo de cérebro, fração absorvida para fótons \\
16 & 1999 & Esboço das melhores práticas e métodos para coleta e análise de dados cinéticos \\
17 & 1999 & Valore $S$ para fontes de voxel \\
18 & 2001 & Atividade administrada para estudos com xenônio \\
19 & 2003 & Modelo de rim multi particionado com frações absorvidas \\
\hline
\end{tabular}

\footnotetext{
${ }^{1}$ Site da Society of Nuclear Medicine: http://interactive.snm.org/index.cfm?PageID=14
} 
De todos os membros do Comitê MIRD, três merecem destaque: Robert Loevinger, Walter Snyder e Evelyn Watson, muito embora todos os outros de certa forma também contribuiram fortemente (Stabin, 2006).

Os doutores Loevinger e Snyder elaboraram as equações e os modelos das quais o sistema é organizado e estiveram à frente de muitas investigações e publicações importantes que definiram o sistema.

Evelyn Watson, trabalhando com Roger Cloutier em Oak Ridge, também esteve envolvida com diversas publicações importantes, e juntos organizaram uma série de importantes simpósios em dosimetria radiofarmacêutica. Os assuntos abordados nesses simpósios permanecem como importantes referências nos arquivos de qualquer um que trabalhe na área (Stabin, 2006).

Importantes modelos, métodos e dados relacionados à dosimetria radiofarmacêutica que não são encontrados em nenhum lugar, estão disponíveis nos artigos dessas séries de simpósios.

Para efetuar o cálculo da dose absorvida numa distribuição radionuclídica interna é necessário ter conhecimento de duas informações: (1) o número total de transições nucleares que ocorrem no órgão de interesse num período de tempo e (2) o quanto de energia é depositado, pelas diversas ocorrências de transições nucleares, por unidade de massa do órgão (Stabin, 2006).

Porém, para obter essas duas informações, é necessário o conhecimento prévio de outras:

- a quantidade da atividade injetada (Bq);

- a meia vida física do radionuclídeo injetado (constante de decaimento);

- o tipo de radiação emitida pelo radionuclídeo juntamente com sua frenquência e energia média de emissão (constante de equilíbrio de dose);

- a fração da atividade injetada que está localizada em cada tecido ou órgão (ou "região fonte") - referente a captação - função da atividade versus o tempo;

- o tempo que o radionuclídeo reside em cada órgão ou tecido; 
- o número total de transições nucleares (decaimentos) que ocorrem em cada órgão (atividade acumulada);

- a fração de energia da radiação que é absorvida no tecido ou órgão causada por ele mesmo como também por outros tecidos e órgãos, ou "regiões alvos" (a fração absorvida);

- a massa de cada tecido ou órgão (região alvo).

A seguir será apresentado os principais conceitos para se efetuar o cálculo de dose absorvida num órgão de interesse.

\section{ATIVIDADE ADMINISTRADA}

Define-se como atividade administrada, a atividade total que é fornecida a um paciente independentemente da via de administração. A unidade utilizada pelo Sistema Internacional (SI) é de bequerel $(B q)$ (1 $B q$ equivale a 1 desintegração por segundo $(d p s))$. A unidade utilizada anteriormente era o curie $(\mathrm{Ci})$ e para efeito de cálculo $37 \mathrm{MBq}$ equivale a $1 \mathrm{mCi}$ (Zanzonico, 2000).

\section{ATIVIDADE ACUMULADA}

Atividade acumulada é definida como o produto da atividade de radionuclídeo presente no órgão de interesse pelo tempo em que ele permanece no órgão, isto é, ela é proporcional ao número total de transições nucleares que ocorrem dentro do orgão (Sgouros, 2005).

A atividade acumulada representada por $\widetilde{A}$ é relacionada com a atividade $A$ pela seguinte equação:

$$
\widetilde{A}=\int_{t_{1}}^{t_{2}} A(t) d t \quad(\mu . C i-h)
$$

onde,

- $t_{1}$ e $t_{2}$ são os tempos inicial e final referente ao período de permanência do radionuclídio, em horas $(h)$.

Conhecido o termo $A(t)$ a Eq.(3.26) pode ser resolvida analiticamente, graficamente ou numericamente. 
Numa análise analítica, para encontrar o termo $A(t)$ é conveniente definir uma função de distribuição $q(t)$ que corresponde a quantidade de radionuclídeo administrado no órgão num tempo $t$, corrigida pelo decaimento físico para um tempo de referência (Loevinger et al., 1976), assim tem-se:

$$
A(t)=q(t) e^{-\lambda t} \quad(\mu . C i)
$$

onde,

- $\lambda$ é a constante de decaimento físico do radionuclídeo.

Se a função de distribuição $q(t)$ puder ser resolvida em termos de componentes exponenciais, com uma adequada precisão para o cálculo de dose, então tem-se:

$$
q(t)=\sum_{j} q_{j} e^{-\lambda_{j} t} \quad(\mu . C i)
$$

onde,

- $q_{j}$ é o valor da j-ésima componente exponencial;

- $\lambda_{j}$ é a constante de decaimento biológica do j-ésimo componente exponencial;

Agora é possível encontrar o termo $A(t)$, mostrado na Eq.(3.27), em função do $q(t)$ expresso mediante a Eq.(3.28). Com isso, esse resultado é substituido na Eq.(3.26). Assim, obtêm-se:

$$
\widetilde{A}(t)=\int_{0}^{t}\left(\sum_{j} q_{j} e^{-\lambda_{j} t}\right) e^{-\lambda t} d t \quad(\mu . C i-h)
$$

Ao resolver a integral o seguinte resultado é encontrado:

$$
\widetilde{A}(t)=\sum_{j} \frac{q_{j}}{\lambda+\lambda_{j}}\left\{1-e^{-\left(\lambda+\lambda_{j}\right) t}\right\} \quad(\mu . C i-h)
$$

Em relação a equação anterior o valor inicial da atividade pode ser zero e valores negativos do coeficiente $q_{j}$ representam a captação e valores positivos representam a eliminação do radionuclídeo no órgão.

A atividade acumulada como mencionado anteriormente pode ser resolvida graficamente, para isso deve-se considerar um cenário típico em que uma coleção de imagens, da distribuição da atividade, são armazenas em diferentes tempos depois da administração do radiofármaco. 
Ao obter um gráfico do nível de atividade num determinado órgão em função do tempo, é encontrada a curva da atividade pelo tempo para esse órgão. A integral dessa curva fornece a atividade acumulada nesse órgão (Sgouros, 2005).

\section{FRAÇÃO ABSORVIDA E FRAÇÃO ABSORVIDA ESPECÍFICA}

Se um volume alvo " $v$ " absorveu energia de uma fonte " $r$ ", a fração absorvida de " $v$ " a " $r$ " é definida como a razão entra a energia no volume " $v$ " ocasionado pela fonte " $r$ ", pela energia que é emitida pela fonte "r" (Loevinger et al., 1976).

Assim tem-se:

$$
\phi_{i}(v \leftarrow r)=\frac{m_{v} \bar{D}_{i}(v \leftarrow r)}{\widetilde{A}_{r} \Delta_{i}}
$$

onde,

- $\phi_{i}(v \leftarrow r)$ é a fração absorvida para um tipo "i" de radiação;

- $m_{v}$ é a massa referente ao volume $v$;

- $\bar{D}_{i}(v \leftarrow r)$ é a dose média no volume $v$ ocosionada pela fonte " $r$ " por um tipo " $i$ " de radiação;

- $\widetilde{A}_{r}$ é a atividade acumulada referênte à fonte $r$;

- $\Delta_{i}$ é a energia por transições nucleares referente à fonte $r$ ocosionada por um tipo "i" de radiação.

O numerador da Eq.(3.31) representa justamente a energia absorvida pelo volume $v$ e o denominador a energia emitida pela fonte. A fração absorvida possui uma limitação que consiste na necessidade da região alvo ser um volume.

Uma fórmula mais geral é obtida pela definição de fração absorvida específica.

$$
\Phi_{i}(v \leftarrow r)=\frac{\phi_{i}(v \leftarrow r)}{m_{v}} \quad\left(g^{-1}\right)
$$

A fração absorvida específica obtida em qualquer região alvo $r_{1}$ por uma região fonte $r_{2}$ é definida pela seguinte equação:

$$
\Phi_{i}\left(r_{1} \leftarrow r_{2}\right)=\lim _{v \rightarrow r_{1}} \Phi_{i}\left(v \leftarrow r_{2}\right)=\frac{\bar{D}_{i}\left(r_{1} \leftarrow r_{2}\right)}{\widetilde{A}_{2} \Delta_{i}} \quad\left(g^{-1}\right)
$$

onde, 
- $v$ é o volume contendo a região $r_{1}$ na qual não há pontos em comum entre a fonte (" $r_{2}$ ") e a região alvo (" $\left.r_{1} "\right)$, a menos que a fonte seja o volume.

A fração absorvida é insensível ao tamanho e a forma tanto da fonte como do alvo, quando a energia é em grande parte absorvida em um único alvo $(\phi \rightarrow 1)$. Já a fração absorvida específica é relativamente insensível ao tamanho e forma tanto da fonte como do alvo, quando somente uma pequena fração da energia é absorvida em um único alvo $(\phi \ll 1)$ (Loevinger et al., 1976).

\section{DISTRIBUIÇÃO DE EQUILÍBRIO}

Para uma distribuição uniforme de um radionuclídeo em um meio infinito de material absorvedor homogêneo, a energia absorvida por grama está em equilíbrio com a energia emitida por grama, e o equilíbrio da dose absorvida é dado por:

$$
D_{e q}=\widetilde{C} \sum_{i} \Delta_{i} \quad(r a d)
$$

Sendo

$$
\Delta_{i}=2,13 n_{i} \bar{E}_{i} \quad \text { g.rad/M.Ci.h }
$$

onde,

- $\widetilde{C}$ é a concentração acumulada (constante) $\left(\mu C i . h . g^{-1}\right)$;

- $\Delta_{i}$ é a energia por desintegração (transições nucleares) emitida por uma partícula de tipo " $i$ " ("constante de equilíbrio de dose");

A constante 2,13 é encontrada da seguida forma:

$$
1,602 \times 10^{-6}\left(\frac{\mathrm{erg}}{\mathrm{MeV}}\right) 10^{-2}\left(\frac{\mathrm{rad}}{\mathrm{erg} / \mathrm{g}}\right) 3,7 \times 10^{4}\left(\frac{\mathrm{dis} / \mathrm{sec}}{\mu . C i}\right) 3,6 \times 10^{3}\left(\frac{\mathrm{sec}}{\mathrm{h}}\right)
$$

A unidade desta constante é g.rad/ $\mu C i . h(M e V / d i s)$.

A Eq.(3.34) também é válida para radionuclídeo distribuídos uniformemente num meio material finito e homogêneo, o "efeito de borda" pode ser negligenciado (Loevinger et al., 1976). 


\section{EQUAÇÃO DE DOSE GERAL}

Aplicada para todo tipo de radiação esta equação pode ser obtida da seguinte forma (Loevinger et al., 1976):

$$
\bar{D}\left(r_{1} \leftarrow r_{2}\right)=\widetilde{A}_{r_{2}} \sum_{i} \Delta_{i} \Phi_{i}\left(r_{1} \leftarrow r_{2}\right) \quad(r a d)
$$

onde,

- $r_{1}$ é a região considerada alvo;

- $r_{2}$ é a região considerada fonte;

A Eq.(3.37) pode ser reescrita como:

$$
\bar{D}\left(r_{1} \leftarrow r_{2}\right)=\widetilde{A}_{r_{2}} \times S_{r_{1} \leftarrow r_{2}} \quad r a d
$$

onde,

- $S_{r_{1} \leftarrow r_{2}}$ é a dose absorvida por unidade de atividade acumulada.

O valor de $S$ é obtido mediante cálculo efetuados por códigos de Monte Carlo por intermédio de objetos simuladores antropormórficos que serão mencionados posteriormente (Sgouros, 2005).

Os valores de $S$ podem ser tabulados para facilitar o cálculo da dose absorvida. A grande vantagem está no fato do cálculo de Monte Carlo, que requer muito tempo computacional, ser executado somente uma vez, obtendo-se os valores de $S$, não precisando ser executado a todo instante para estimar a dose absorvida (Sgouros, 2005).

\subsubsection{Objeto simulador antropomórfico}

O objeto simulador antropormórfico nada mais é do que uma representação do corpo humano ou de suas partes. Sua utilidade em dosimetria interna está no fato de proporcionar o cálculo dos "fatores de conversão de dose" (FCD's), ou valor $S$, que são necessários para converter as desintegrações ocorridas numa região fonte em dose absorvida na região alvo (RADAR, 2010).

O desenvolvimento de objetos simuladores teve início com o objeto simulador de FisherSnyder, no ano de 1969. Esse objeto simulador foi construído por intermédio da combinação 
de formas geométricas conhecidas (esferas, cilíndros, cones, entre outras) para assim criar uma representação do corpo humano (RADAR, 2010).

Para encontrar os fatores de conversão de dose foi preciso reconstruir toda a geometria do objeto simulador de Fisher-Snyder em códigos de Monte Carlo. Esses códigos simulam o transporte de fótons através das várias estruturas do corpo (geometrias). As composições atômicas e densidades de cada estrutura foram adquiridas pelo relatório da ICRP para um homem de referência e que representa em média um trabalhador adulto do Hemisfério Norte (ICRP 1975) (RADAR, 2010).

Cristy e Eckerman (1987) desenvolveram uma série de objetos simuladores antropomórficos para uma grande variabilidade de indivíduos com diferentes idades e tamanhos. Seis objetos simuladores foram desenvolvidos representando crianças e adultos de ambos os sexos (RADAR, 2010).

Outros autores propuseram modelos mais detalhados de alguns órgãos ou estruturas, incluindo o cérebro, olhos, cavidade peritonial, próstata, osso, reto, e pequenas esferas para representar tumores (RADAR, 2010).

Atualmente, mediante o avanço das imagens médicas tomográficas, tem surgido novos modelos de objeto simulador, como visto na FIG.3.5.

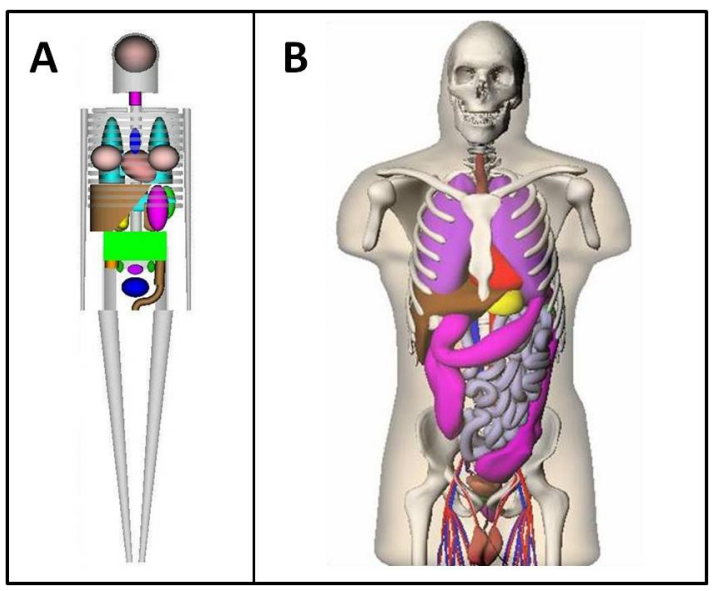

Figura 3.5: Comparação de um modelo de um objeto simulador antropomórfico antigo (A) com um modelo usado atualmente (B) (RADAR, 2010). 


\subsubsection{Softwares de dosimetria interna baseado em objetos simuladores}

O software MIRDOSE por muito tempo foi amplamente utilizado pela comunidade de Medicina Nuclear como base para apresentar a estimativa de dose interna (Stabin, 2006).

Esse código automatiza o cálculo de dose interna para um grande número de radiofármacos por intermédio do objeto simulador de corpo inteiro do sistema MIRD o qual foi implementado no código.

Também executa uma rápida comparação de cálculo para diferentes casos, estima a contribuição de dose para diferentes órgãos e efetua cálculo de dose na região da medula.

O código foi totalmente reescrito na linguagem de programação Java, porém suas funções básicas foram mantidas e outras foram extendidas. Esse código foi nomeado de OLINDA/EXM (Organ Level Internal Dose Assessment with Exponencial Modelling) (Sgouros, 2005; Stabin, 2006; Tsougos, 2009).

Nesse código foram implementados mais objetos simuladores de orgãos, houve um aumento considerável do número de radionuclídeos e foi disponibilizada a capacidade de realizar mínimos ajustes para a dose de um paciente específico indicada pelo padrão de objetos simuladores.

Há também o MABDOSE que permite utilizar formas esféricas representando tumores, dentro do objeto simulador descrito nos sistema MIRD. Uma versão atualizada do MABDOSE é o código DOSE3D (Bardiès et al., 1996; Clairand et al., 1999).

O software DOSE3D (Clairand et al., 1999) é baseado no código de Monte Carlo e possue a finalidade de calcular os valores $S$ dos órgão do objeto simulador antropomórfico matemático estipulado por Cristy e Eckerman.

A geometria do objeto simulador foi desenvolvida por meio da geometria combinatorial e a atividade nos órgãos fontes são consideradas uniformemente distribuidas.

\subsubsection{Dosimetria Interna mediante imagens médicas nucleares 3D}

Atualmente, quase todos tratamentos radioterápicos realizados em Medicina Nuclear apresentam uma atividade fixa administrada ao paciente. Caso haja alguma modificação, o médico a fará de forma empírica modificando-a de acordo com as características do paciente, como idade e tamanho e por resultados clínicos (Tsougos et al., 2009).

Contudo, estudos clínicos revelam que esta abordagem leva a erros da ordem de 30-100 
\% ou até mais. A principal razão de tais erros é que a dose absorvida não está somente em função da atividade administrada, ela também apresenta uma alta correlação com outros fatores que estão relacionados às características intrínsecas ao paciente, como a anatomia e as variações funcionais (Tsougos et al., 2009).

Imagens tomográficas, utilizadas em diagnóstico, desempenham um papel crucial para fornecer informações anatômicas e funcionais do paciente.

Em relação a anatomia destacam-se imagens de Tomografia Computadorizada (CT) e Imagem por Ressonância Magnética (RMI) as quais evidenciam informações da localização, tamanho, volume dos órgão e tumores.

Já com relação as informações funcionais, as modalidades que se destacam são Tomografia por emissão de fóton único (SPECT) e Tomografia por emissão de pósitron (PET) utilizadas com radioisótopos emissores de gama e pósitrons respectivamente.

É importante mencionar que em muitos casos o radioisótopo do agente radioterápico não apresenta esses dois tipos de emissão e nessa situação é necessário administrar o mesmo fármaco porém com radioisótopo diferente para se adquirir uma imagem. Nesse caso, é necessário correlacionar o comportamento da imagem e o agente radioterápico. Assim, se for utilizada imagens radionuclídicas adequadas é possivel observar pequenas variações na concentração de atividade no tumor (Tsougos et al., 2009).

Há equipamentos que possuem tanto a possibilidade de fornecer informações anatômicas como funcionais, os chamados equipamentos híbridos, como exemplo o PET/CT que praticamente vem substituindo o PET. Essa nova modalidade vem sendo utilizada no desenvolvimento de sistemas de dosimetria específica para paciente em Medicina Nuclear.

Existem, em especial, dois requisitos para se realizar a dosimetria por intermédio de imagens 3D:

1. É necessário um estudo das imagens tomográficas 3D para definir a anatomia e obter os parâmetros do tecido, como densidade e fração em peso dos elementos químicos do tecido que serão fornecidos, por exemplo, pelo CT ou MRI e por fim definir a distribuição espacial da atividade interna ao paciente que será fornecida, por exemplo, pelo PET ou SPECT;

2. É necessário um software que implemente o cálculo da fração absorvida (point kernel ou Monte Carlo) para estimar a distribuição espacial da dose absorvida; 
Mediante a idéia descrita acima, diversos softwares foram desenvolvidos: "3D-internal dosimetry" (3D-ID) (Clairand et al., 1999), "Radionuclide treatment planning and absorbed dose estimation system" (RTDS) (An Liu et al., 1999), "The Royal Marsden Dosimetry Package" (RMDP) (Guy et al., 2003), VoxelDose (Gardin et al., 2003), "Tool for personalized internal dose assessment" (OEDIPE) (Chiavassa et al., 2005), "Dose planning method" (DPM) (Wilderman et al., 2007), "Patient-specific 3-dimensional radiobiologic dosimetry" (3D-RD) (Hobbs et al., 2009).

\subsubsection{Cálculo de dose através de informações nucleares e dose kernels}

Dose kernels são definidos como a dose absorvida num ponto, $r$, a um determinada distância da fonte. Geralmente considera-se uma fonte pontual num meio homogêneo.

Dessa forma a dose absorvida é calculada mediante métodos de convolução que assumem o corpo do paciente como sendo uniforme. Os valores de Hounsfield adquiridos do CT são usados para definir diferentes regiões e por intermédio dessas informações valores de dose kernels são calculados para outros materiais utilizando método de Monte Carlo.

A dose kernels apresenta a seguinte fórmula (Tsougos et al., 2009):

$$
k(r)=\left(\frac{\operatorname{dose}(r)}{4 \pi r^{2}}\right)\left(\frac{n_{\text {dec }}}{n_{\text {total }}}\right) \times 1,0602 \times 10^{-8} \quad\left[\frac{c G y}{B q-s}\right]
$$

onde,

- $n_{\text {dec }}$ é o número de fótons por decaimento;

- $n_{\text {total }}$ é o número total histórias por simulação;

- $1,0602 \times 10^{-8}$ é um fator de conversão dado em $M e V / g-c G y$.

Para calcular a dose absorvida, deve ser fornecida a distribuição da atividade, geralmente dada por uma imagem funcional. A dose é determinada pela convolução desses kernels com a atividade fornecida pelas imagens funcionais.

O grande problema desse método é a dificuldade de incorporar tecidos não homogêneos até mesmo por intermédio de imagens anatômicas conhecidas. O kernel pode ser somente gerado assumindo um meio homogêneo e infinito (Tsougos et al., 2009). 


\subsubsection{Cálculo de dose com base em códigos de Monte Carlo}

A dosimetria mediante códigos de Monte Carlo possui três requisitos básicos (Tsougos et al., 2009):

1. Adquirir uma imagem de CT ou MRI para definir o mapa de atenuação (geometria do paciente);

2. Adquirir uma imagem de SPECT ou PET (se possível, com regiões de interesse selecionadas) para definir o mapa de atividade (descrição da fonte);

3. Utilizar o código de Monte Carlo para calcular a distribuição de dose 3D.

Caso seja permitido pelo código é possível implementar geometrias semelhantes as imagens tomográficas 3D, que possuem voxels (elementos de volume) os quais compõem a imagem como um todo.

Incialmente as posições dos fótons podem ser uniformemente distribuídas em cada voxel. Cada fóton é então emitido numa direção aleatória e com energia amostrada de acordo com o espectro de emissão do radionuclídeo.

A diferenciação dos meios é feita pela densidade e composição do tecido encontrado em cada voxel, esses dados podem ser adquiridos do CT. Dada a seção de choque do meio e conhecendo-se a energia da partícula, o código de Monte Carlo calcula a deposição de energia da partícula ou fornece a direção e a distância $T$ para a próxima interação (Tsougos et al., 2009).

O processo continua até a partícula escapar da geometria do paciente ou até a partícula perder sua energia a menos de um limiar pré selecionado, por exemplo, $10 \mathrm{keV}$, e a partir deste ponto a partícula é assumida ser absorvida localmente (Tsougos et al., 2009).

A dose pode ser dada pela seguite expressão (Tsougos et al., 2009):

$$
\operatorname{Dose}(x, y, z)=\frac{E}{V}\left[\left(\frac{\mu_{a b}}{\rho}(E)\right)_{m e i o}\right] \times T_{x, y, x}
$$

onde,

- $V$ é o volume alvo dados em $\mathrm{cm}^{3}$;

- $x, y, z$ são as coordenadas no voxel alvo; 
- E é a energia do fóton dada em $\mathrm{MeV}$;

- $\frac{\mu_{a b}}{\rho}(E)$ é o coeficiente de absorção de energia em massa dado em $\mathrm{cm}^{2} \cdot g^{-1}$;

- $T_{x, y, z}$ é o caminho percorrido através do voxel dado em $\mathrm{cm}$.

\subsubsection{Problemas que podem afetar o cálculo da dose mediante imagens médicas}

Para realizar a quantificação da dose absorvida de maneira precisa por intermédio de imagens médicas e pelo método de Monte Carlo, é de extrema importância a análise correta dessas imagens.

A seguir serão descritas as principais modalidades que deverão ser analisadas:

\section{Câmara de cintilação (Gama Câmara)}

Na FIG.3.6 observa-se um esquema dos componentes da Gama-Câmara.

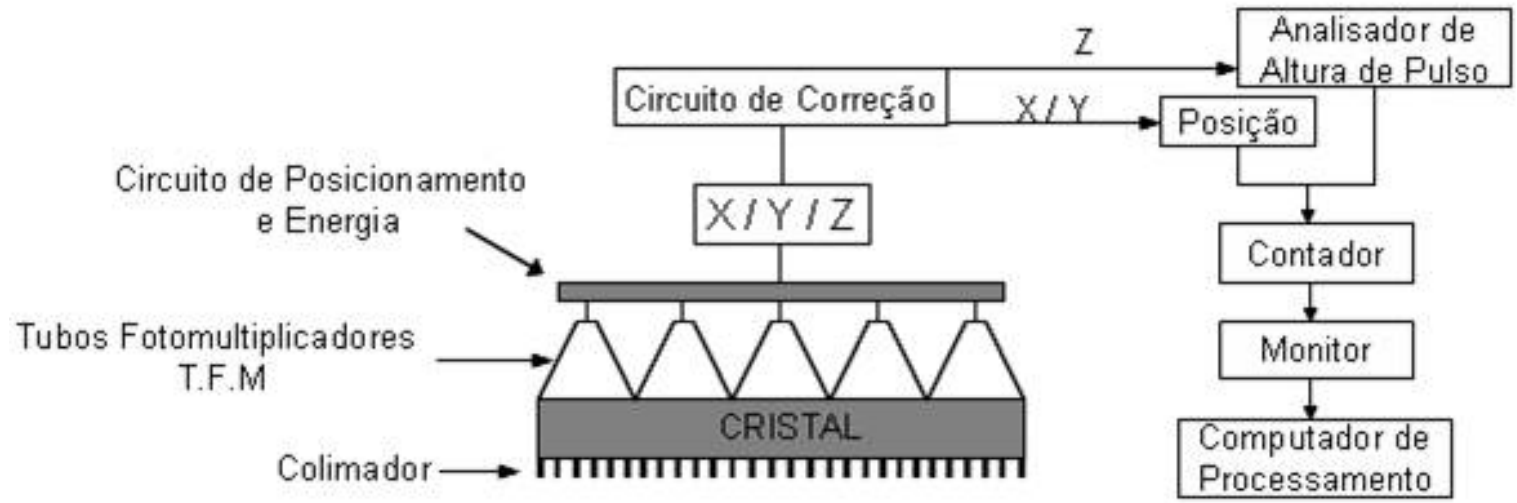

Figura 3.6: Esquema dos componentes da câmara de cintilação.

Cada componente possui uma função específica, no entanto suas interligações têm finalidade de converter os raios- $\gamma$ em uma imagem, a qual será observada no monitor.

Nesta modalidade há quatro fatores que afetam a qualidade da imagem:

- resolução;

- atenuação; 
- espalhamento;

- ruído estatístico.

A resolução esta relacionada com a habilidade em distinguir duas fontes radioativas pontuais como entidades distintas, isto é, ao grau de "borramento" nas bordas dos objetos. Ela depende da resolução intrínseca (cristal + fotomultiplicadora) e da resolução do colimador (Sprawls Junior, 1995).

A atenuação esta relacionada com a capacidade dos tecidos de atenuar a radiação, portanto o sinal detectado não é o sinal real. Existem diversos métodos para efetuar a correção destas imagens, um deles é o método de Chang de $1^{\mathrm{a}}$ ordem (Chang, 1978).

Já o espalhamento que ocorre devido ao efeito Compton prejudica na localização da fonte radioativa e no espectro obtido. Uma das maneiras de se resolver o problema é por meio do analisador de altura de pulso que será mencionado posteriormente.

O ruído está relacionado com a estatística de emissão dos raios gamas e para diminuir esse erro é necessário aumentar a contagem na região a ser imageada.

A seguir será discutida cada componente; antes disso é preciso ter conhecimento de que a gama câmara apresenta duas características muito importantes: a sensibilidade e o campo de visão (Field of View - FOV).

Apenas uma pequena fração de fótons emitidos pela fonte radioativa contribui para a formação da imagem. Isto porque somente os fótons que passam através do colimador são absorvidos pelo cristal, sendo que o resto é perdido, isto é, os que foram absorvidos pelo colimador. Essa característica é geralmente referida como sensibilidade.

A sensibilidade de uma câmara pode ser descrita em termos do número de fótons detectados e usados na imagem para cada unidade de radioatividade $(\mu \mathrm{Ci})$.

O campo de visão é importante por determinar o quanto o corpo do paciente pode ser retratado de uma vez.

Colimadores: Os colimadores possuem o objetivo de projetar a imagem de um material radioativo na superfície do cristal.

Geralmente são constituídos por metais, que apresentam alta eficiência na absorção de fótons, como o chumbo e tungstênio. Com exceção do Pinhole, todos os colimadores 
possuem centenas de furos, os quais são separados por septos, ordenados ao longo de todo o FOV (Sprawls Junior, 1995).

Dessa forma cada ponto na superfície do cristal tem uma direção vista de somente um ponto na superfície do corpo. Quanto maior for à sensibilidade causada por um colimador maior será o "blur" (borrão) na imagem. Uma forma de representar o "blur" é com base em uma imagem de um objeto pontual. Esta imagem conterá um objeto circular em que sua intensidade será mais intensa no centro e diminuirá gradativamente conforme se direciona para a periferia (Sprawls Junior, 1995).

Há vários tipos de colimadores utilizados na gama câmara e se diferenciam por suas espessuras, números e tamanhos dos furos e pelo caminho em que ele orienta. Essas características afetam a sensibilidade da câmara, a magnitude do FOV e o "blur" da imagem. A energia do fóton também é um fator muito importante para a escolha do colimador.

Cristal: O cristal apresenta duas funções principais, a de absorver fótons e a de converter a radiação em luz, mediante o processo de cintilação. Os cristais usados estão normalmente no formato de discos e o seu diâmetro e espessura têm grande importância na captação da imagem (Sprawls Junior, 1995).

Para uma espessura relativamente fina, a eficiência do detector e a sensibilidade da câmara são reduzidas. Isto ocorre, pois os fótons passam através do cristal sem interagirem com este e nesse caso há a vantagem da diminuição do "blur". A medida que a espessura do cristal aumenta, especialmente para fóton de alta energia, a sensibilidade também aumenta, no entanto o "blur" na imagem é maior. Assim a espessura do cristal tem influência direta na relação entre a sensibilidade e a qualidade da imagem. Normalmente a espessura está entre $1 / 4$ a $1 / 2$ de polegadas.

O cristal de cintilação possui uma outra característica que influencia na sensibilidade, o chamado tempo morto. Esse tempo é definido da seguinte forma: o raio- $\gamma$ excita um elétron presente no átomo do cristal, o qual subirá para uma camada de energia superior, no entanto esse elétron fica instável nessa camada, sendo assim ele perde energia emitindo fótons de luz e volta para camada de onde saiu. O tempo decorrido do instante que o elétron foi excitado até o instante que ele voltou a sua camada de origem é o tempo morto. 
Nomeia-se assim, pois durante esse tempo o raio- $\gamma$ não consegue provocar excitação nesse átomo. Dessa maneira quanto maior o tempo morto menor será a sensibilidade.

O diâmetro do cristal estabelece o FOV básico, o qual é modificado pelo tipo de colimador e pela distância entre a câmara e a fonte a ser captada (Sprawls Junior, 1995)..

Tubos Fotomultiplicadores: Os Tubos Fotomultiplicadores (TFM) são geralmente arranjados numa disposição hexagonal e o número contido no cristal depende do seu diâmetro e da área do cristal. Eles possuem a função de converter os fótons de luz em pulsos elétricos e amplificar esses pulsos.

A disposição dos TFM em todo o cristal possibilita detectar onde cada fóton é absorvido. Essa informação é necessária para transferir a imagem formada no cristal para o visor (Sprawls Junior, 1995).

Formação da Imagem: Para a formação da imagem, a gama câmara por meio de um circuito eletrônico, se utiliza dos pulsos dos TFM. Primeiramente, o circuito eletrônico apresenta a função de captar todos os pulsos elétricos criados por um único fóton, que interagiu com o cristal, e em seguida usá-los para calcular ou determinar a localização da interação dentro da área da imagem (Sprawls Junior, 1995).

Depois desse processo, o circuito produz dois novos pulsos que descrevem a localização do fóton no plano $X Y$. Um dos pulsos representa a localização do fóton na horizontal $(X)$ e o outro representa a localização na posição vertical $(Y)$.

A segunda função do circuito é combinar todos os pulsos dos TFM em um único pulso elétrico cuja amplitude representa a energia do fóton. Logo em seguida esse pulso passa no analisador de altura de pulso (AAP) (Sprawls Junior, 1995).

Podem ser realizadas imagens estáticas onde as contagens são acumuladas em uma única imagem até que um nível pré-determinado de contagens seja atingido ou até que um tempo pré-determinado seja transcorrido, ou imagens dinâmicas em que a aquisição é semelhante àquela de imagens estáticas, exceto pelo fato de que várias imagens sequenciais são adquiridas. Há também um tipo de imagem chamada de aquisição sincronizada (Gated) que é a aquisição de dados de imagem sincronizada com algum sinal fisiológico (Sprawls Junior, 1995)..

A imagem reconstruída representa a distribuição e concentração relativa dos elementos 
radioativos presentes nos órgãos imageados. Um dos problemas deste tipo de imagem é a sobreposição, pelo fato de ser feita em somente uma projeção (Sprawls Junior, 1995).

Analisador de altura de pulso (AAP): Há um grande problema em quantificar a radiação de uma fonte primária no interior de um paciente ou da amostra, pois existem outras fontes que serão detectadas, por exemplo, a radiação Cósmica, provinda de nuclídeos radioativos em determinados materiais e a contaminação radioativa presente no ambiente, chamada radiação de fundo.

Existe a ocorrência de interação Compton pelos fótons da própria fonte primária com materiais fora do campo da fonte, e essa radiação espalhada pode também ser detectada. Caso o sistema de imagem responda a essa radiação espalhada, o resultado será o surgimento de áreas ao redor da fonte primária, o que dificulta a determinação do tamanho real, da forma e da atividade da fonte.

Em casos específicos há a necessidade de administrar ao paciente dois tipos de materiais radioativos, e dessa forma o sistema deve seletivamente responder para cada fonte num tempo apropriado.

Um sistema de contagem pode se tornar seletivo, pela adição de um espectrômetro de energia posicionado depois do detector e do amplificador. O espectrômetro é um AAP, o qual trabalha com o pulso elétrico produzido pelo detector. O propósito do AAP é selecionar o pulso criado pela fonte de radiação escolhida e rejeitar os demais, associados com as outras fontes de radiação.

Os pulsos de um detector de cintilação não serão de tamanhos semelhantes, pois a maioria dos materiais radioativos emitem fótons gama de diversas energias. Além desse fator, há também a interação Compton, energias que escapam do cristal e fatores estatísticos dentro do cristal e do TFM, os quais variam o tamanho dos pulsos.

Para simplificar, considera-se que o material radioativo emite todos os fótons com a mesma energia, se comportando tal como uma fonte monoenergética. Num sistema ideal de detecção, esses fótons deveriam produzir uma série de pulsos de mesmo tamanho e o espectro desses pulsos deveria ser uma única linha posicionada na sua relativa energia.

Infelizmente, um sistema detector real não produz um espectro que representa precisamente o espectro de energia do fóton. Há diversos fatores que afetam o espectro, e agora 
será considerado alguns desses fatores, para mostrar suas relações com o uso apropriado do AAP.

Um fóton é absorvido no cristal e cria um conjunto de fótons de luz, no entanto, sempre há uma variação nesse número de fótons de luz produzidos. Também, nem todos os fótons de luz associados com uma cintilação, são necessariamente absorvidos pelo TFM, alguns são absorvidos pelo próprio cristal e seu número é influenciado pela localização no interior do cristal.

O número de elétrons gerados também flutua a cada dinodo. Assim, o pulso elétrico, que sai do ânodo, varia no tamanho, consequentemente ocorre flutuações.

A maioria dos eventos ocorre entre a absorção do fóton gama e a formação do pulso elétrico, sendo ilustrado na FIG.3.7.

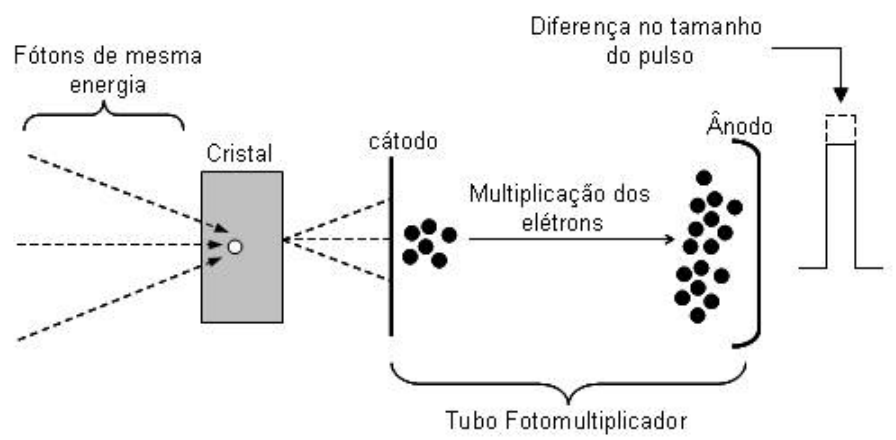

Figura 3.7: Fatores que produzem variação no tamanho do pulso do detector.

As variações que ocorrem no tamanho dos pulsos provocam mudanças na forma do espectro alargando o seu pico. Uma importante característica do sistema do detector é a quantidade de variações no tamanho dos pulsos.

Essa característica é conhecida como resolução energética do sistema de detecção e é geralmente expressada em termos da LMH (Largura a Meia Altura). A LMH é a largura a meia altura medida do pico máximo, e geralmente é expressa em porcentagem da média do tamanho dos pulsos (energia do fóton). Na FIG.3.8 observa-se um pulso típico e o resultado de seu espectro.

A LMH pode ser considerada como uma expressão da variação "média" no tamanho dos pulsos, e o sistema detector ideal deve ter uma LMH igual a zero.

$$
L M H=\frac{l m a}{m t p} \times 100
$$



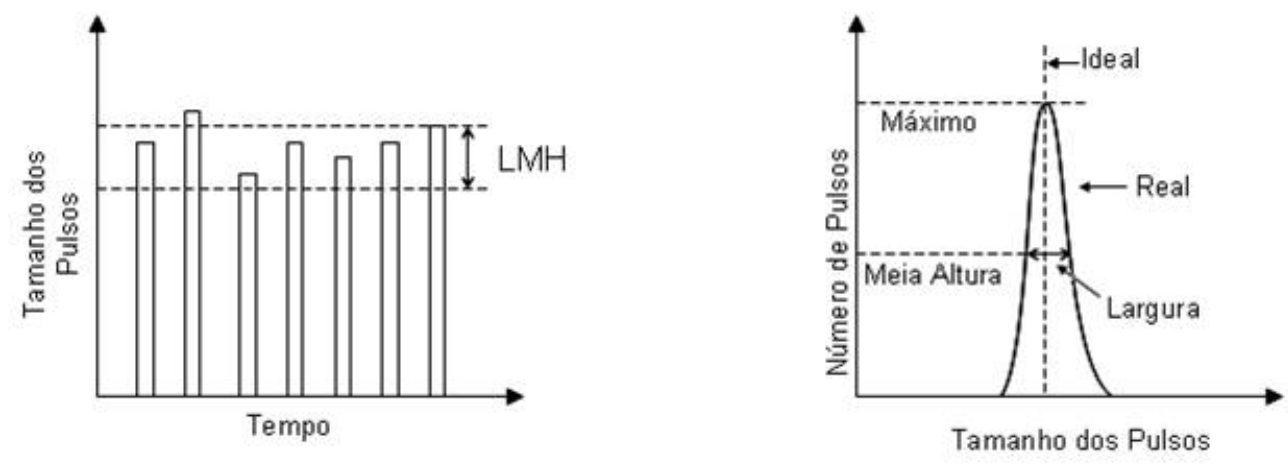

Figura 3.8: Espectro produzido por uma fonte radioativa monoenergética por um típico detector.

onde,

- lma é a largura a meia altura;

- mtp é a média do tamanho de pulsos.

A resolução energética do sistema de detecção depende da qualidade do cristal, do TFM, e da estabilidade do amplificador de pulsos. Sérias perdas na potencialidade da resolução energética podem ser resultantes de condições do cristal, como quebra do mesmo ou inadequada transmissão de luz entre o cristal e o TFM (Sprawls Junior, 1995).

Uma resolução energética pobre, ou alto valor da LMH, indica que existe variação considerável nos tamanhos dos pulsos associados com o fóton monoenergético da fonte primária, o qual provoca problemas para o AAP discriminar os pulsos da fonte primária dos demais pulsos.

A aquisição de fótons espalhados, gerados pelo efeito Compton com o tecido, prejudica a imagem, e o resultado não será fidedigno em relação à distribuição do material radioativo. Por isso, deve-se excluir os fótons provenientes desse tipo de interação. O processo de exclusão pode ser feito, pois as energias desses fótons espalhados são diferentes das energias dos fótons primários (Sprawls Junior, 1995).

Os fótons espalhados dentro do corpo incrementam uma componente no espectro final. Se o ângulo de espalhamento for muito pequeno, esses fótons terão energias próximas a do fóton primário. Isso causa flutuações estatísticas dentro do detector e essas flutuações provocam sobreposição entre a componente do espalhamento e a do fotopico do espectro. Fótons que se espalham numa direção contrária ao fóton primário, adquirem uma energia 
muito baixa. Há também, fótons que sofrem diversas interações Compton antes de deixar o corpo, o que provoca uma grande diminuição de sua energia em relação ao fóton primário (Sprawls Junior, 1995).

A forma da curva do espalhamento Compton e sua relativa amplitude dependem de uma série de fatores, sendo que o principal é o tipo de tecido circunvizinho ao material radioativo.

Caso a interação Compton ocorra dentro do cristal, forma-se um espectro que para o detector representará a energia depositada dentro de si, significando a diferença entre a energia do fóton primário e a energia do fóton espalhado. Assim, quanto menor o ângulo de espalhamento, menor será a energia depositada.

Outro fator que modificará o espectro final é a ocorrência do efeito fotoelétrico fora do cristal, como,por exemplo, no colimador. Devido ao seu alto número atômico, normalmente chumbo, há uma alta predominância de produção de raio-x característico, com energia em torno de $77 \mathrm{KeV}$, o que contribui na formação de outra componente no espectro.

No caso do raio-x ser formado dentro do cristal, também haverá uma diferença na componente do espectro. Porém, somente ocorrerá se houver escape do fóton de raio-x do cristal. A energia depositada no cristal é a diferença entre a energia do fóton primário e a energia de escape do fóton de raio-x.

O espectro de energia do fóton adquirido através de um sistema de detectores baseia-se na soma de muitas componentes produzidas por diferentes tipos de interações onde, cada componente possui sua relativa contribuição, com suas devidas ponderações, como já foram discutidas.

Em diversos casos, a composição do espectro pode ser considerada como a soma de componente desejada e indesejada. O fotopico é frequentemente avaliado como um componente desejável, pois representa fótons emitidos diretamente da fonte radioativa. Um exemplo de uma componente indesejada é o espalhamento Compton já mencionado.

A espectrometria é um processo que permite o operador selecionar e usar uma fração específica de um determinado espectro. O tipo de espectrometria usado na gama câmara é o AAP (Analisador de Altura de Pulso).

A característica mais importante do AAP é que ele pode ser arranjado para somente aceitar pulsos de um intervalo de altura delimitado. Os tamanhos dos pulsos que passam 
através do AAP são determinados pelo posicionamento de dois controles, a linha base e a janela, os quais formaram a delimitação desejada.

A escala da altura de pulso utilizada pelo AAP é arbitrária, mas para poder exemplificar o significado da linha base e da janela, deverá assumir um intervalo de 0 a 100 unidades para a escala de altura de pulso.

Pela própria calibração dos componentes do detector e amplificador, a escala do AAP pode ser feita para corresponder a um intervalo de energia de um fóton específico.

Suponha que essa energia esteja num intervalo de 0 a $200 \mathrm{keV}$. O procedimento a ser feito é ajustar o ganho do detector e do amplificador de modo que um fóton de $200 \mathrm{keV}$ de energia produza uma altura de pulso de 100 unidades. Dessa forma, as demais energias poderão estar relacionadas com o intervalo de unidades determinado.

Para poder delimitar um intervalo desejado, deve-se ajustar primeiramente a linha base, que representa o limite inferior da altura de pulso que o operador deseja, isto é, a altura indicada para linha base representa a menor altura aceita pelo AAP e a janela, controla a amplitude. Assim delimita-se a fração do espectro que será usada na elaboração da imagem cintilográfica.

Quando o raio- $\gamma$ se espalha, perde parte de sua energia. Assim, em teoria, os raios- $\gamma$ espalhados podem ser identificados por intermédio de suas energias. Porém, as câmaras de cintilação têm resolução energética relativamente baixa (Sprawls Junior, 1995).

Tipicamente, a resolução energética de uma câmara de cintilação é aproximadamente $10 \%$, isto é, para a energia do radionuclídeo, ${ }^{99 m} \mathrm{Tc}$, que é de $140 \mathrm{keV}$, o espectro de energia detectado terá a forma de uma gaussiana com a largura total à meia altura igual a aproximadamente $14 \mathrm{keV}$. O propósito da discriminação de energia que é executado pelo analisador de altura de pulso é coletar a maioria das contagens sem espalhamento e rejeitar o máximo possível aquelas, cujo desvio poderá interferir na qualidade das imagens.

Devido à baixa resolução energética da câmara, solicita-se a utilização de uma janela relativamente grande para aceitar a maioria dos eventos sem espalhamento (Sprawls Junior, 1995).

Porém, enquanto uma janela de $20 \%$ elimina uma grande quantidade de espalhamento, ainda permite que um número considerável de raios- $\gamma$ espalhados seja exibido.

Portanto para se escolher a largura da janela, terá que se levar em consideração a 
quantidade de fótons espalhados que serão eliminados sem prejudicar demasiadamente a resolução energética. Uma janela mal determinada, que não abrange o intervalo desejado de energia, por estar fora desse intervalo ou pelo fato de ser pequena demais, acarreta numa redução na sensibilidade da câmara (Sprawls Junior, 1995).

\section{Tomografia por emissão de fóton único - SPECT}

A tomografia por emissão de fóton único - SPECT é uma modalidade tomográfica em medicina nuclear e uma das vantagens em relação as imagens convencionais é o aumento na sensibilidade para detectar lesões. Isto ocorre porque a sobreposição neste tipo de imagem é quase que totalmente removida, devido a maior quantidade de projeções e também por adquirir imagens em fatias (slices) (Sprawls Junior, 1995).

O sistema SPECT utiliza a gama câmera, discutida anteriormente, para formar a imagem tomográfica. Para realizar a aquisição da imagem a câmara cintilográfica é rotacionada em torno do paciente. Definindo-se $\theta$ como o ângulo de rotação, o transcorrer da rotação pode ser subdividido em dois passos, começando por $\theta=0^{\circ}$ :

1. A câmera cintilográfica, posicionada em $\theta$, armazena os dados da projeção da radiação emitida pelo paciente num determinado período;

2. A câmera cintilográfica é rotacionada à $\theta+\theta_{f}$, em que $\theta_{f}$ é um ângulo fixo.

Cada projeção é composta pelas contagens acumuladas ao longo da direção $\theta$ provocada pelos fótons emitidos os quais não foram absorvidos ou espalhados ao atravessar o paciente (Sprawls Junior, 1995).

Essas projeções são manipulados para gerar uma figura bidimensional no qual o eixo horizontal representa a posição de detecção contendo a contagem acumulada e o eixo vertical a posição angular $\theta$ do detector no momento dessa aquisição. Esta figura recebe o nome de sinograma.

Através do sinograma e por meio de métodos matemáticos de reconstrução, forma-se a imagem tomográfica de um corte. Depois de adquirir dados de uma fatia (slice) a mesa onde o paciente se encontra move-se para que outra fatia possa ser reconstruída. Esse processo é realizado até se obter a imagem do órgão desejado (Sprawls Junior, 1995). 


\section{Tomografia por emissão de pósitron - PET}

O sistema PET é baseado em elementos radioativos emissores de pósitron $\left(\beta^{+}\right)$. Como já mencionado na seção 3.2, no instante em que um pósitron interage com um elétron do meio, ocorre um processo denominado de aniquilação o que resulta na emissão de dois fótons de mesma energia (511 keV) em direção opostas (Powsner et al., 2006).

O processo de reconstrução é praticamente similar ao usado no SPECT, a única exeção é o fato de que sempre se realizará a correção da atenuação.

\section{VANTAGENS}

Essa modalidade apresenta três grandes vantagens:

Sensibilidade: Não são requeridos colimadores para o sistema PET devido ao processo de detecção por coincidência que será discutido posteriormente. Por tal motivo esse sistema possui uma alta sensibilidade (no mínimo um fator de 100) em comparação ao sistema SPECT e câmara de cintilação (Powsner et al., 2006).

Resolução: O processo de detecção da aniquilação somente irá ocorrer caso dois detectores registrem o sinal da interação com esses fótons, provenientes da aniquilação, no mesmo "instante". Quando um destes fótons chegar em um dos detectores será dado um tempo, denominado "janela de coincidência", para que o outro fóton seja detectado no detector oposto (Powsner et al., 2006).

Essa reação ocorrerá ao longo de uma linha imaginária denominada linha de resposta (line of response - LOR) ilustrada na FIG.3.9.

Podem ocorrer basicamente quatro tipos de eventos:

- "coincidência verdadeira" em que os dois fótons da aniquilação são detectados simultaneamente. Evento detectado;

- "coincidência espalhada" em que no mínimo um dos fótons é espalhado, por interação Compton, no mesmo plano de detecção. Evento detectado;

- "coincidência falsa ou aleatória" em que existe a possibilidade de um evento ser detectado no qual os dois fótons detectados não fazem parte do mesmo processo de 


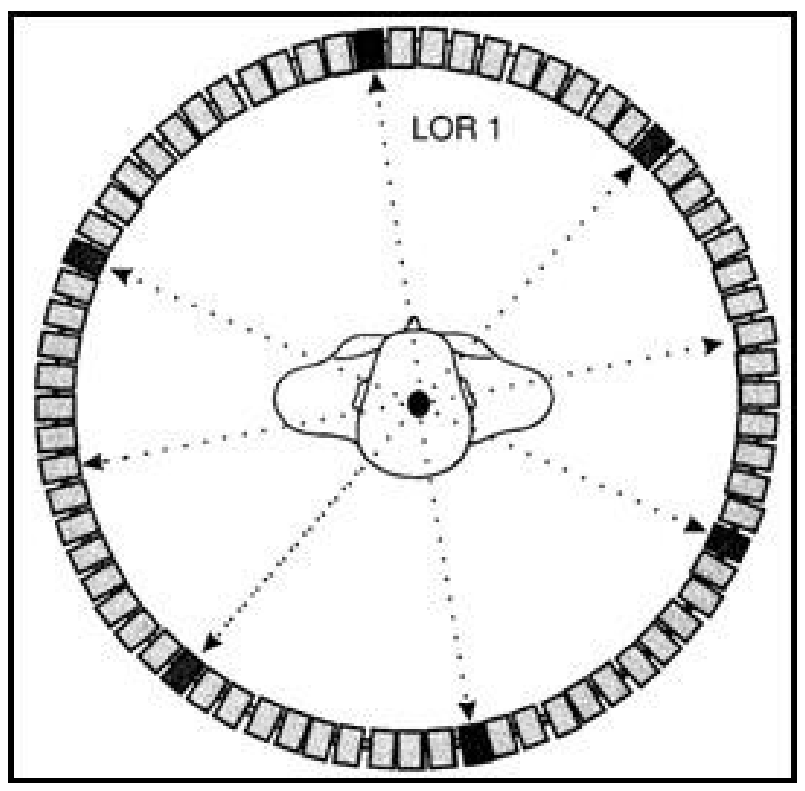

Figura 3.9: Demonstração da linha de resposta LOR (Adaptada de Sprawls Junior et al., 1995).

aniquilação ou até mesmo nem são provenientes de aniquilação. Evento detectado;

- "eventos isolados (single)" em que um dos fótons é espalhado para fora do plano de detecção ou absorvido, sendo o evento rejeitado. A detecção pode ocorrer se um outro fóton colidir com o detector quando a janela de coincidência estiver aberta.

No intuito de melhorar a resolução da imagem alguns sistemas medem o chamado "tempo de vôo" que consiste em medir o tempo de chegada de cada fóton. Caso o processo de aniquilação ocorra exatamente no centro do anel de detectores, ambos os tempos serão iguais, caso contrário um dos fótons chegará primeiro e a diferença do tempo será proporcional a diferença da distância percorrida pelos fótons. Isso pode ser usado para calcular a posição do evento ao longo da linha de resposta (LOR).

Como esse tempo é da ordem de nanosegundos, infelizmente, devido a limitações eletrônicas, o cálculo da posição não é preciso o que resulta numa redução da resolução espacial nessa técnica.

Radiofármacos: A principal vantagem das imagens de PET em relação à de SPECT e câmara de cintilação é o fato dos emissores de pósitron $\left({ }^{18} \mathrm{~F},{ }^{15} \mathrm{O},{ }^{13} \mathrm{~N},{ }^{11} \mathrm{C}\right)$ serem elementos naturais em muitas moléculas biológicas e isso permite verficar as propriedades fisiológicas 
de uma órgão com a ajuda desses radionuclídeos por intermédio da imagem.

\section{CORREÇÃO DA ATENUAÇÃO}

Devido a alta energia dos fótons provenientes da aniquilação e do uso da detecção por coincidência, a correção de atenuação em imagens de PET é mais simples e mais precisa do que em imagens de SPECT (Powsner et al., 2006).

O coeficiente de atenuação para fótons de $511 \mathrm{keV}$ é praticamente uniforme para os vários tipos de tecidos do corpo (gordura, músculo e osso) em comparação aos de baixa energia encontrados no SPECT. Também independe da localização da ocorrência do evento de aniquilação.

A atenuação em imagens PET é compensada mediante modelos matemáticos que utilizam dados de transmissão (fonte externa). Dependendo da câmera a fonte de transmissão pode ser um emissor de pósitron, uma fonte de fóton de alta energia ou até mesmo uma fonte de raios-x (Powsner et al., 2006).

\section{Tomografia Computadorizada - CT}

A Tomografia Computadorizada (CT) difere das imagens radiográficas convencionais em diferentes aspectos, sendo o maior deles o processo pelo qual ela realiza a formação da imagem (Sprawls Junior, 1995).

A formação da imagem inicia-se com a fase de varredura ilustrada na FIG.3.10.

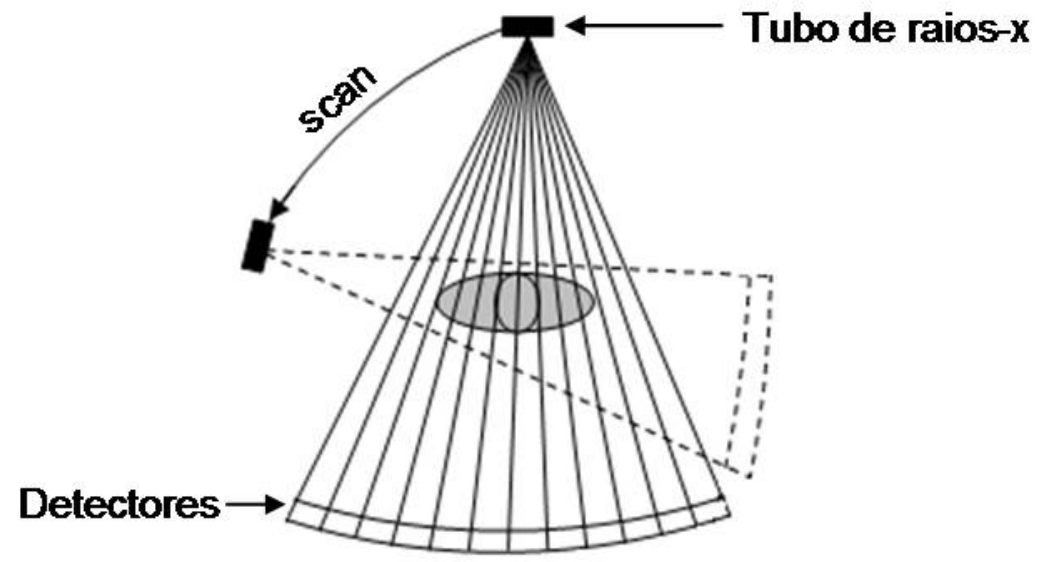

Figura 3.10: Esquema da fase de varredura 
Durante esta fase, um fino feixe de raios-x em forma de leque é projetado em direção a uma das secções do corpo em que serão realizadas as imagens. Atrás do paciente encontrase um conjunto de detectores agrupados que possuem a finalidade de medir a intensidade do feixe que atravessou o paciente (Sprawls Junior, 1995).

Como citado na seção 3.1, quando uma determinada quantidade de fótons atravessa um objeto ocorre um processo denominado atenuação, devido a interação da radiação gama com a matéria. Revisando, tem-se que para um feixe monoenergético:

$$
\phi=\phi_{0} e^{-\mu(\rho, Z, E) x}
$$

onde,

- $\mu$ é o coeficiente de atenuação linear (por unidade de comprimento);

- $\rho$ é a densidade em massa;

- $Z$ é a composição atômica do material absorvedor;

- $x$ é a distância percorrida no material absorvedor.

A resposta $\lambda$ de um único detector, considerando que um feixe monoenergético tenha somente atravessado uma região, isto é, sempre considerando o mesmo coeficiente de atenuação linear $(\mu)$, tem-se:

$$
\lambda=\ln \left(\frac{\phi_{0}}{\phi}\right)=\mu(\rho, Z, E) x
$$

Utilizando a idéia anterior, só que para um feixe policromático que atravessa diversos tipos de tecidos (diferentes $\mu$ ) a resposta do detector será:

$$
\lambda=\ln \left(\frac{S_{i}(E)}{S_{d}(E)}\right)=\int \mu(\rho, Z, E) d s
$$

onde,

- $S_{i}(E)$ é a densidade espectral da energia dos fótons incidentes;

- $S_{d}(E)$ a densidade espectral da energia dos fótons que saem do objeto;

- $\int \mu(\rho, Z, E)$ é referente a somatória dos $\mu_{s}$ que o feixe policromático atravessa. 
Num caso real, o feixe é policromático e atravessa um conjunto de tecidos do corpo do paciente (diferentes $\mu$ ). Para se obter o $S_{d}(E)$, isto é, o espectro de saída, é preciso saber que existem basicamente três tipos diferentes de detectores:

1. A resposta de um detector é proporcional ao número total de fótons incidentes;

2. A resposta é proporcional à energia total do fóton;

3. A resposta é equivalente a deposição de energia por unidade de massa.

Pelo fato da resposta do detector também depender da sua sensibilidade em relação à energia dos fótons, para simplificar, é assumido que a sensibilidade do detector é constante durante o intervalo de interesse da energia (Kak et al., 1988).

O $\mu$ varia ao longo do caminho, porque a medida que o fóton interage com o meio, ele transfere sua energia. Como o $\mu$ é função da energia e aumenta a medida que a energia diminui, para energias altas tem-se valores altos de $\mu$. Portanto, a atenuação de fótons de baixa energia é maior que para os fótons de alta energia, desta forma, o espectro desloca para a direita. Em outras palavras, a energia média associada com o espectro de saída, $S_{d}(E)$, é maior do que a associada com o espectro incidente, $S_{i}(E)$. Este fenômeno é chamado de endurecimento do feixe (Kak et al., 1988).

Para resolver esse problema McCullough (1975), introduziu o conceito de energia efetiva de um scanner de CT, definida como a energia monocromática que ao atravessar um determinado material provocará o mesmo coeficiente de atenuação se no caso fosse medido por um scanner. O conceito de energia efetiva somente é válido caso os espectros de saída sejam os mesmos para todas as projeções (Kak et al., 1988).

Com isso é possível realizar uma correção no valor de $\lambda$, de forma que o valor do coeficiente de atenuação fique independente da localização podendo assim ser considerado como valor médio $(\bar{\mu})$ de acordo com a função espectral $S_{d}(E)$ (Kak et al., 1988). Assim tem-se:

$$
\bar{\mu}(s)=\frac{\int \widehat{S}_{d}(E) \mu(E, s) d E}{\int \widehat{S}_{d}(E) d E}
$$

onde,

- $\widehat{S}_{d}(E)$ é a função espectral que chega ao detector. 
Generalizando, este processo é realizado para todos os detectores do conjunto, localizados atrás do paciente. Assim é obtido os dados de uma projeção.

Para gerar a imagem de toda secção, o tubo de raios-x gira ao redor do corpo realizando diversas projeções que permitirão a fomação do sinograma assim como nas imagens de medicina nuclear. Por fim, os sinogramas são utilizados para a reconstrução da imagem.

Quando a imagem de tomografia computadorizada é digitalizada os valores dos coeficientes de atenuação lineares são substituídos por um valor denominado unidade de Hounsfield $(\mathrm{H})$ ou número de CT. Para o corpo humano a escala de Hounsfield possui um intervalo de aproximadamente -1000 a 1000, sendo que o centro da escala equivale à água, a extremidade positiva equivale ao osso e a negativa ao ar (Sprawls Junior, 1995). A relação entre $\bar{\mu}$ e a unidade de Hounsfield é dado por:

$$
H=\left(\frac{\bar{\mu}}{\bar{\mu}_{\mathrm{H}_{2} \mathrm{O}}}-1\right) \times 1000
$$

onde,

- $\bar{\mu}$ coeficiente de atenuação do tecido;

- $\bar{\mu}_{H_{2} O}$ coeficiente de atenuação da água.

A razão $\bar{\mu} / \bar{\mu}_{H_{2} O}$ depende fracamente da função espectral $\widehat{S}_{d}(E)$ e a unidade de Hounsfield depende fortemente do sistema de CT.

No caso deste trabalho um dos objetivos é encontrar $\bar{\mu} / \bar{\mu}_{H_{2} O}$ com base na unidade de Hounsfield, isto é, o processo inverso do tomógrafo. Isto foi proposto para se obter a composição e densidade dos tecidos.

O cálculo de dose pelo método de Monte Carlo mediante imagens tomográficas - 3D do paciente, como citado anteriormente, necessita das informações da geometria do paciente, da densidade e composição do tecido, as quais serão obtidas por intermédio da unidade de Hounsfield aquirida do CT.

O método mais comum para determinar a unidade de Hounsfield correspondente ao tecido humano é adquirir imagens de objetos simuladores, similares ao tecidos, ou de tecidos de animais.

Dessa forma, os números de Hounsfield são agrupados de acordo com o tipo de tecido a fim de atribuir a composição química e a fração em peso dos elementos químicos, baseado 
nas publicações da Comissão Internacional de unidades e medidas de Radiação (ICRU) ou a Comissão Internacional de Proteção Radiológica (ICRP) (Jiang et al., 2007).

Um dos problemas que ocorrem ao medir a unidade de Hounsfield de um tipo de tecido é que este valor pode estar contido num intervalo de outro tipo de tecido, pois alguns intervalos se sobrepõem (Jiang et al., 2007). 
Capítulo 4

\section{MATERIAIS E MÉTODOS}

\subsection{MATERIAIS}

\subsubsection{Linguagem de programação Java}

Java é uma linguagem de programação resultante de um projeto desenvolvido em 1991 por um grupo de engenheiros da empresa Sun Microsystem. Inicialmente, esses engenheiros tinham a missão de criar uma linguagem que seria utilizada em diversos aparelhos, tais como fornos e telefones. Eles deveriam criar um linguagem que permitisse a comunicação entre os aparelhos de uma casa e que gerasse pequenos códigos para serem executados nos diversos aparelhos (Deitel et al., 2005).

Os engenheiros responsáveis pelo projeto, optaram por utilizar a linguagem $\mathrm{C}++$ em conjunto a um conceito de máquina virtual que é implementada mediante um software, e possui a finalidade de executar programas da mesma forma que um computador real. A opção por essa linguagem deve-se ao fato dela ser muito poderosa e ter a vantagem de ser orientada a objetos. Quanto ao conceito de máquinas virtuais, foi a solução encontrada para a execução em diversas arquiteturas (Deitel et al., 2005).

Em princípio a linguagem seria desenvolvida para ambientes residenciais com a finalidade de permitir que aparelhos eletrodomésticos fossem capazes de se comunicar entre si. Atualmente, tornou-se uma das linguagens mais conhecidas e utilizadas do mundo (Deitel et al., 2005).

A linguagem Java pode ser utilizada em três frentes de programação distintas:

1. Programas criados por intermédio de recursos oferecidos somente pelo Java, denominados applets. Devem ser inseridos em páginas da Web, pois não podem ser execu- 
tados sozinhos. Uma vez inseridos em uma página HTML, são executados de forma automática quando a página é aberta. Para que a execução do applet não tenha erro, a página deve ser aberta em um navegador que esteja habilitado para a linguagem Java;

2. Os aplicativos escritos em outras linguagens podem ser facilmente traduzidos para a linguagem Java. A maior vantagem do aplicativo escrito na lingugem Java é o fato dele poder ser executado em quase todos os sistemas operacionais;

3. Uso da linguagem em sistemas embutidos que são aqueles utilizados em outros aparelhos eletrônicos diferentes dos microcomputadores.

Java é um linguagem orientados a objetos. O assunto referente a orientação a objetos é muito complexo e extenso o que foge do escopo deste trabalho, porém ele será resumidamente descrito.

Os programas desenvolvidos com base na orientação a objetos são compostos por grupos de objetos que se comunicam entre si. Esses objetos podem representar entidades concretas, assim como uma bola de futebol, ou abstratas, como uma estratégia de um jogo. Aquilo que um objeto sabe sobre si é conhecido como atributo e o que ele sabe fazer é conhecido como método (comportamento) e é por meio dos métodos que os objetos se comunicam entre si(Deitel etal., 2005).

Numa linguagem orientada a objetos a responsável por descrever os atributos e métodos de tais objetos é a classe, isto é, a classe é quem descreve o objeto e diversos objetos podem ser construídos por uma única classe.

A essência desse tipo de programação é a possibilidade de alterar ou substituir partes de um sistema sem que haja riscos de ocorrências de erros. Isso somente ocorre devido a alguns conceitos de orientação a objetos como abstração, encapsulamento, herança e polimorfismo, apresentados brevemente a seguir (Deitel et al., 2005).

- Abstração: Isolar aspectos que sejam importantes a um determinado propósito e descartar os demais. Em se tratando de desenvolvimento de sistemas, abstração significa focalizar dois fatores essenciais que são: o que é um objeto e o que ele faz?

- Encapsulamento: É uma técnica que faz os atributos da classe serem ocultos, pois assim, estes podem ser somente lidos ou alterados por métodos da classe. 
- Herança: É um mecanismo que permite compartilhar atributos e métodos entre classes por meio de um relacionamento hierárquico. Assim, uma classe definida de forma genérica (superclasse) pode ser dividida sucessivamente em termos de outras classes denominadas de classes derivadas ou subclasses. Cada subclasse possui suas propriedades particulares, porém herda todas as propriedades de sua superclasse, isto é, as propriedades da superclasse não precisam ser repetidas em cada subclasse. Este conceito pode reduzir drasticamente a repetição de código em um programa, sendo uma das principais vantagens da orientação a objetos.

- Polimorfismo: Com base em herança, as subclasses herdam os métodos da superclasse e neste contexto o polimorfismo é um mecanismo em que um mesmo método herdado pode se comportar de forma diferente entre as subclasses. Polimorfismo também implica que uma determinada operação de uma classe pode ser implementada por mais de um método dentro dessa classe. Nesse caso a linguagem java seleciona o método correto a partir do nome da operação, classe do objeto e argumentos para a operação.

Assim, devido as caracteristicas citadas, programas que se baseiam na orientação a objetos são facilmente alterados em algum momento posterior para uma melhor adaptação às necessidades apresentadas.

Outra característica é o fato de ser interpretada e compilada. Para que programas que utilizam a linguagem de programação Java sejam executados, é necessária a realização de dois processos distintos: compilação e interpretação. Esses processos, no entanto, ocorrem de maneira única e separada em outras linguagens, em que os programas ou são compilados, ou interpretados (Deitel et al., 2005).

Em Java, a compilação é um processo em que o programa é transformado em um código denominado bytecode que por sua vez pertence a uma máquina virtual com o nome JVM (Java Virtual Machine). O bytecode gerado, que possui extensão “.class", é então interpretado posteriormente por um interpretador contido na JVM. A compilação do programa em java, é realizada somente uma vez, porém sua interpretação ocorre a cada execução desse programa.

Graças a essa independência, em relação ao processo de compilação, a execução dos programas Java podem ocorrer em qualquer plataforma para as quais a JVM seja suportada 
(Deitel et al., 2005).

A linguagem de programação Java conta com IDEs (ambiente de desenvolvimento integrado, do inglês Integrate Development Environment) que são ambientes de desenvolvimento gráfico capazes de auxiliar no desenvolvimento de programas de maneira adequada (Deitel et al., 2005).

A IDE utilizada no trabalho foi o software Netbeans que possui como vantagens, a fácil instalação e execusão em diferentes sistemas operacionais, incluindo Windows, Linux, Mac OS X e Solaris (Netbeans, 2010).

\subsubsection{Software ImageJ}

O ImageJ é um software escrito em Java e de domínio público desenvolvido para processamento de imagem. Originalmente foi produzido pelo NIH (National Institute of Health). Pode ser executado como um applet ou ser baixado através da internet. Por ser um software Java ele é multiplataforma (ImageJ, 2010).

É possível através do ImageJ exibir, processar e salvar imagens, além de ler muitos formatos de imagens como TIFF, GIF, JPEG, BMP, DICOM, FITS e "raw".

O ImageJ foi projetado com uma arquitetura aberta que fornece extensibilidade através de plugins Java, que é uma funcionalidade a mais no ImageJ que pode ser desenvolvida ou não pelos seus criadores. Assim plugins personalizados para processamento de imagens podem ser desenvolvidos e acoplados ao ImageJ (ImageJ, 2010).

\subsubsection{Software MCNP5}

O código MCNP5 é um programa computacional baseado no Método de Monte Carlo para simulação do transporte de radiação no meio. Na sua atual versão, permite a simulação da interação de três tipos de radiação com a matéria: nêutron, fóton e elétron; e possui certas vantagens que o tornam atrativo em aplicações médicas. A faixa possível de energia de fótons e elétrons possíveis estende-se entre $1 \mathrm{keV}$ até $100 \mathrm{MeV}$ (Booth et al.; 2003).

Em relação à geometria, este código possui uma vasta flexibilidade de modelagens geométricas que permitem o uso simultâneo de recursos de geometria combinatorial, com superfícies de até quarto grau em conjunto com recursos de estruturas repetidas, permitindo 
a reprodução geométrica exata de figuras digitalizadas como é caso de imagens médicas (Booth et al.; 2003).

O código MCNP5 tem sido utilizado com sucesso na solução de muitos problemas na área de física médica, sendo que um número crescente de pesquisadores tem adotado este sistema em cálculos de dosimetria numérica aplicada aos planos de tratamento em radioterapia, braquiterapia e radioimunoterapia (Solberg et al., 2001).

\subsubsection{Sistema de Construção de Manequins Segmentados - SCMS}

O software SCMS é uma ferramenta computacional para construção de modelos anatômicos representados por elementos discretos de volume denominados voxels semelhantes às imagens digitais, por exemplo, a de Tomografia Computadorizada (CT). O modelo geométrico da anatomia é chamado de "phantom segmentado" ou "phantom baseado em voxel".

O SCMS interpreta as imagens e fornece um arquivo de entrada para ser usado no código MCNP5 que realizará a simulação do transporte de radiação. Há um arquivo de entrada com o nome SINP que contém as informações sobre o arquivo da imagem e opções do usuário. Na versão 1.0, só é possível ler imagens em formato ASCII.

O arquivo MCNPINP é o principal arquivo de saída do SCMS, é ele o arquivo de entrada para o MCNP5. Apenas algumas modificações são necessárias e devem ser fornecidas pelo usuário para completar o arquivo de entrada: (1) o valor da energia ou espectro no cartão SDEF; (2) o número de histórias de partículas a serem simuladas e (3) a composição dos tecidos que por padrão são: M1 - tecido mole, M2 - tecido pulmonar e M3 - tecido ósseo.

Inicialmente o SCMS foi desenvolvido em linguagem FORTRAN e atualmente está sendo reescrito em JAVA, juntamente com outras atualizações necessárias.

\subsubsection{Padrão DICOM - Digital Imaging and Communications in Medicine}

$\mathrm{O}$ advento dos equipamentos que possibilitam as aquisições de imagens computadorizados de pacientes, proporcionaram às clínicas de diagnóstico um grande benefício pois são técnicas de diagnósticos não invasivas. No entanto, cada fabricante utilizava um formato específico para fornecer as imagens digitais e as informações do paciente, provindas do equipamento. Isso, acabou criando limitações na comunicação entre diferentes equipamen- 
tos e consequentemente limitou o uso desses dados (DICOM,2009; DICOM 2010).

Com base nisto, em 1983, o American College of Radiology (ACR) e o National Eletrical Manufactures Associations (NEMA), criaram uma comissão com a finalidade de discutir e desenvolver um padrão que favorecesse a transferência de imagens digitais e de suas informações entre equipamentos de diferentes fabricantes. O comitê especificava como o padrão, basicamente três fatores:

- Proporcionar transferências de informações de imagens digitais, independente do fabricante;

- Facilitar o desenvovimento e a expansão do sistema PACS (Picture Archiving and Communication Systems) o qual interage com outros sistemas de informações hospitalares;

- Permitir a formação de um banco de dados de informação diagnóstica que poderá ser acessado por uma grande variedade de equipamentos.

Assim após muitos esforços, em 1993, o padrão DICOM foi criado tendo como seu principal objetivo, a transferência de imagens médicas e de informações referentes ao paciente entre clínicas e outros ambientes hospitalares. Nele há todos os aspectos de aquisição, visualização, armazenamento, consulta, recuperação, fluxo de informação entre sistemas e impressão de imagens médicas (DICOM,2009; DICOM 2010).

O DICOM é assessorado pelo "DICOM Standards Committe" da NEMA e mediante esse comitê sofre atualizações. O requisito primordial das atualizações é manter a compatibilidade com as versões anteriores (DICOM 2010).

Atualmente, o DICOM é utilizado em praticamente todas as clínicas médicas ou por profissionais da saúde que trabalhe com imagens médicas (DICOM,2009; DICOM 2010).

\subsection{MÉTODOS}

\subsubsection{Desenvolvimento do software ICCT ( Image Converter for Computer Tomography ) e do ACPS (Attenuation Correction PET/SPECT)}

O software SCMS que possui a finalidade de transmitir as informações provenientes do paciente para o MCNP5 foi desenvolvido em sua primeira versão em linguagem FORTRAN. 
Esta versão não reconhece imagens em formato DICOM, mas somente arquivos em formato ASCII. Além dos dados geométricos transformados numa matriz de voxels, o arquivo ASCII deve conter informações sobre a composição dos tecidos que compõe o objeto estudado. Entretanto, estas informações precisam ser extraídas e processadas das imagens em formato DICOM.

Com este intento, desenvolveu-se o software ICCT (Image Convertor for Computer Tomography) para conversão dos números de Hounsfield em informações de densidade e composição. A linguagem escolhida foi o JAVA e futuramente será realizada a integração da nova versão do software SCMS.

O SCMS também precisa obter a fonte interna ao paciente e fornecer a especificação da fonte para o MCNP5. Assim, o software ACPS (Attenuation Correction PET/SPECT) foi desenvolvido para corrigir a atenuação ocorrida em imagens SPECT e PET e transmitir a localização da fonte, em valores relativos, para o SCMS.

Considerando essas modificações a linguagem JAVA foi escolhida para desenvolver os softwares ICCT e ACPS. Por fim, os mesmos foram implementados como plugins do ImageJ.

\subsubsection{Metodologia de conversão da unidade de Hounsfield em parâmetros do tecido}

O método utilizado para conversão da unidade de Hounsfield $(H)$ advindas das imagens de CT do paciente em densidade e composição química dos tecidos, foi proposto por Schneider et al. (2000). Este método foi desenvolvido inicialmente para ser utilizado na dosimetria de terapia de prótons.

Antes de mencionar esse método é válido analisar a função que relaciona os parâmetros dos tecidos: a densidade $(\rho)$ e a fração em peso do i-ésimo elemento de um composto químico do tecido $\left(\omega_{i}\right)$ com a unidade de Hounsfield $(H)$.

Esta função é obtida com base nas Eq.(3.20), Eq.(3.45) e (3.46), comentadas no capítulo de Fundamentos Teóricos, e dada pela seguinte equação:

$$
\frac{1}{\bar{\mu}_{H_{2} O}} \frac{\bar{\mu}}{\rho}=\frac{1}{\bar{\mu}_{H_{2} O}} N_{A} \sum_{i=1}^{n}\left(\omega_{i} \frac{Z_{i}}{A_{i}} \cdot \bar{\sigma}_{i}^{e}\right)
$$

onde, 
- $\bar{\sigma}_{i}^{e}$ é a seção de choque média por elétron do i-ésimo elemento que compõe o tecido;

- $\omega_{i}$ é a fração em peso do i-ésimo elemento que compõe o tecido;

- $A_{i}$ é a massa atômica do i-ésimo elemento que compõe o tecido;

- $Z_{i}$ é o número atômico do i-ésimo elemento que compõe o tecido;

- $N_{A}$ é o número de Avogadro;

- $\rho$ é a densidade do tecido.

Observa-se que do lado esquerdo dessa equação há uma dependência somente da densidade $(\rho)$ e do direito somente da fração em peso do i-ésimo elemento que compõe o tecido $\left(\omega_{i}\right)$.

A partir dessa observação, é possível obter um gráfico que relaciona o lado esquerdo da Eq.(4.1) $\left(\mathrm{cm}^{3} \cdot \mathrm{g}^{-1}\right)$, representado por $\chi$, com a densidade $\rho\left(\mathrm{g} \cdot \mathrm{cm}^{-3}\right)$. Com isso estabelecese uma relação entre os seguintes parâmetros: unidade de Hounsfield $(H), \rho$ e $\omega_{i}$. Na FIG.(4.1) é apresentado o gráfico que apresenta esta relação.

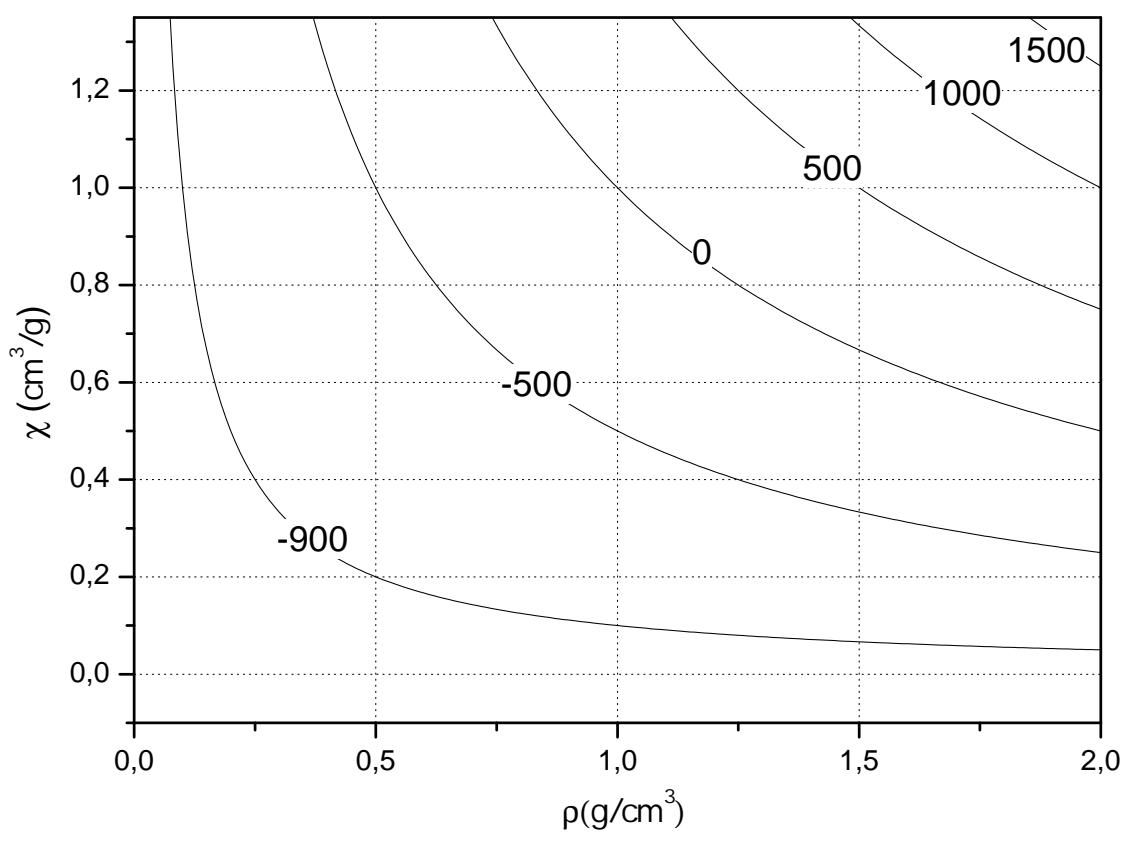

Figura 4.1: Correlação da unidade de Hounsfield com os parâmetros do tecido $\left(\rho, \omega_{i}\right)$.

O eixo da ordenada depende somente da fração em peso do i-ésimo elemento que compõe o tecido $\left(\omega_{i}\right)$ e o eixo da abscissa somente da densidade $(\rho)$. As hipérboles representam 
curvas de igual unidade de Hounsfield $(H)$, com o valor de cada uma delas apresentado no gráfico.

Assim, observa-se que a correlação de diferentes densidades com diferentes frações em pesos $(f p)$ podem resultar em um mesmo valor de Hounsfield $(H)$.

Para avaliar a possibilidade de se adquirir os parâmetros dos tecidos $\left(\rho, \omega_{i}\right)$ através da unidade de Hounsfield é necessário calcular os valores de $H$ para maioria dos tecidos do corpo humano e assim determinar as regiões nesse espaço de parâmetro que eles represen$\operatorname{tam}$ (FIG.(4.1)).

Para este trabalho foram utilizados 71 tipos de tecidos com suas composições adquiridas da literatura (Woodard et al., 1986 ; White et al., 1987).

Na TAB.(4.1) apresentam-se as densidades e as frações em peso dos elementos químicos dos tecidos moles e na TAB.(4.2), apresentam-se as mesmas informações para os tecidos esqueléticos. A partir destas tabelas é possível obter os valores da unidades de Hounsfield para cada tecido e também levantar as curvas de $\chi$ em função de $\rho$ como apresentado na FIG.4.2.

Tabela 4.1 - Composição dos tecidos moles: densidade $(\rho)$ e as frações em pesos $\left(\omega_{i}(f p)\right)$ de cada elemento dos tecidos (Woodard et al., 1986 ; White et al., 1987).

\begin{tabular}{|c|c|c|c|c|c|c|c|c|c|c|c|c|c|}
\hline \multirow[b]{2}{*}{ Tecido Esquelético } & \multirow[b]{2}{*}{$\rho\left(\mathrm{g} / \mathrm{cm}^{3}\right)$} & \multicolumn{12}{|c|}{$\omega_{i}(f p)$} \\
\hline & & $\mathrm{H}$ & $\mathrm{C}$ & $\mathrm{N}$ & $\mathrm{O}$ & $\mathrm{P}$ & $\mathrm{Ca}$ & $\mathrm{Na}$ & $\mathrm{Mg}$ & $\mathrm{S}$ & $\mathrm{Cl}$ & $\mathrm{K}$ & $\mathrm{Fe}$ \\
\hline Pulmão preenchido de sangue & 0,26 & 10,3 & 10,5 & 3,1 & 74,9 & 0,2 & - & 0,2 & - & 0,3 & 0,3 & 0,2 & - \\
\hline Tecido adiposo 3 & 0,93 & 11,6 & 68,1 & 0,2 & 19,8 & - & - & 0,1 & - & 0,1 & 0,1 & - & - \\
\hline Tecido adiposo 2 & 0,95 & 11,4 & 59,8 & 0,7 & 27,8 & - & - & 0,1 & - & 0,1 & 0,1 & - & - \\
\hline Tecido adiposo 1 & 0,97 & 11,2 & 51,7 & 1,3 & 35,5 & - & - & 0,1 & - & 0,1 & 0,1 & - & - \\
\hline Glândula mamária 1 & 0,99 & 10,9 & 50,6 & 2,3 & 35,8 & 0,1 & - & 0,1 & - & 0,1 & 0,1 & - & - \\
\hline Glândula mamária 2 & 1,02 & 10,6 & 33,2 & 3,0 & 52,7 & 0,1 & - & 0,1 & - & 0,2 & 0,1 & - & - \\
\hline Cérebro (fluído cérebro espinhal) & 1,01 & 11,1 & - & - & 88,0 & - & - & 0,5 & - & - & 0,4 & - & - \\
\hline Glândula adrenal & 1,03 & 10,6 & 28,4 & 2,6 & 57,8 & 0,1 & - & 0,0 & - & 0,2 & 0,2 & 0,1 & - \\
\hline Intestino grosso (parede) & 1,03 & 10,6 & 11,5 & 2,2 & 75,1 & 0,1 & - & 0,1 & - & 0,1 & 0,2 & 0,1 & - \\
\hline Urina & 1,02 & 11,0 & 0,5 & 1,0 & 86,2 & 0,1 & - & 0,4 & - & - & 0,6 & 0,2 & - \\
\hline Vesícula biliar & 1,03 & 10,8 & 6,1 & 0,1 & 82,2 & - & - & 0,4 & - & - & 0,4 & - & - \\
\hline Sistema linfático & 1,03 & 10,8 & 4,1 & 1,1 & 83,2 & - & - & 0,3 & - & 0,1 & 0,4 & - & - \\
\hline Pâncreas & 1,04 & 10,6 & 16,9 & 2,2 & 69,4 & 0,2 & - & 0,2 & - & 0,1 & 0,2 & 0,2 & - \\
\hline Próstata & 1,04 & 10,5 & 8,9 & 2,5 & 77,4 & 0,1 & - & 0,2 & - & 0,2 & - & 0,2 & - \\
\hline Cérebro (massa branca) & 1,04 & 10,6 & 19,4 & 2,5 & 66,1 & 0,4 & - & 0,2 & - & 0,2 & 0,3 & 0,3 & - \\
\hline Testículos & 1,04 & 10,6 & 9,9 & 2,0 & 76,6 & 0,1 & - & 0,2 & - & 0,2 & 0,2 & 0,2 & - \\
\hline Cérebro (massa cinza) & 1,04 & 10,7 & 9,5 & 1,8 & 76,7 & 0,3 & - & 0,2 & - & 0,2 & 0,3 & 0,3 & - \\
\hline Músculo estriado 1 & 1,05 & 10,1 & 17,1 & 3,6 & 68,1 & 0,2 & - & 0,1 & - & 0,3 & 0,1 & 0,4 & - \\
\hline
\end{tabular}


Tabela 4.1 - Continuação

\begin{tabular}{|c|c|c|c|c|c|c|c|c|c|c|c|c|c|}
\hline \multirow[b]{2}{*}{ Tecido Esquelético } & \multirow[b]{2}{*}{$\rho\left(g / \mathrm{cm}^{3}\right)$} & \multicolumn{12}{|c|}{$\omega_{i}(f p)$} \\
\hline & & $\mathrm{H}$ & $\mathrm{C}$ & $\mathrm{N}$ & $\mathrm{O}$ & $\mathrm{P}$ & $\mathrm{Ca}$ & $\mathrm{Na}$ & $\mathrm{Mg}$ & $\mathrm{S}$ & $\mathrm{Cl}$ & K & $\mathrm{Fe}$ \\
\hline Estômago & 1,05 & 10,4 & 13,9 & 2,9 & 72,1 & 0,1 & - & 0,1 & - & 0,2 & 0,1 & 0,2 & - \\
\hline Coração 1 & 1,05 & 10,3 & 17,5 & 3,1 & 68,1 & 0,2 & - & 0,1 & - & 0,2 & 0,2 & 0,3 & - \\
\hline Rins 1 & 1,05 & 10,2 & 16,0 & 3,4 & 69,3 & 0,2 & 0,1 & 0,2 & - & 0,2 & 0,2 & 0,2 & - \\
\hline Tireóide & 1,05 & 10,4 & 11,9 & 2,4 & 74,5 & 0,1 & - & 0,2 & - & 0,1 & 0,2 & 0,2 & - \\
\hline Aorta & 1,05 & 9,9 & 14,7 & 4,2 & 69,8 & 0,4 & 0,4 & 0,2 & - & 0,3 & - & 0,1 & - \\
\hline Coração 2 & 1,05 & 10,4 & 13,9 & 2,9 & 71,8 & 0,2 & - & 0,1 & - & 0,2 & 0,2 & 0,3 & - \\
\hline Rins 2 & 1,05 & 10,3 & 13,2 & 3,0 & 72,4 & 0,2 & 0,1 & 0,2 & - & 0,2 & 0,2 & 0,2 & - \\
\hline Fígado 1 & 1,05 & 10,3 & 15,6 & 2,7 & 70,1 & 0,3 & - & 0,2 & - & 0,3 & 0,2 & 0,3 & - \\
\hline Músculo estriado 2 & 1,05 & 10,2 & 14,3 & 3,4 & 71,0 & 0,2 & - & 0,1 & - & 0,3 & 0,1 & 0,4 & - \\
\hline Músculo estriado 3 & 1,05 & 10,2 & 11,2 & 3,0 & 74,5 & 0,2 & - & 0,1 & - & 0,3 & 0,1 & 0,4 & - \\
\hline Coração 3 & 1,05 & 10,4 & 10,3 & 2,7 & 75,6 & 0,2 & - & 0,1 & - & 0,2 & 0,2 & 0,3 & - \\
\hline Glândula mamária 3 & 1,06 & 10,2 & 15,8 & 3,7 & 69,8 & 0,1 & - & 0,1 & - & 0,2 & 0,1 & - & - \\
\hline Rins 3 & 1,05 & 10,4 & 10,6 & 2,7 & 75,2 & 0,2 & 0,1 & 0,2 & - & 0,2 & 0,2 & 0,2 & - \\
\hline Ovários & 1,05 & 10,5 & 9,3 & 2,4 & 76,8 & 0,2 & - & 0,2 & - & 0,2 & 0,2 & 0,2 & - \\
\hline Lente ocular & 1,07 & 9,6 & 19,5 & 5,7 & 64,6 & 0,1 & - & 0,1 & - & 0,3 & 0,1 & - & - \\
\hline Fígado 2 & 1,06 & 10,2 & 13,9 & 3,0 & 71,6 & 0,3 & - & 0,2 & - & 0,3 & 0,2 & 0,3 & - \\
\hline Traquéia & 1,06 & 10,1 & 13,9 & 3,3 & 71,3 & 0,4 & - & 0,1 & - & 0,4 & 0,1 & 0,4 & - \\
\hline Baço & 1,06 & 10,3 & 11,3 & 3,2 & 74,1 & 0,3 & - & 0,1 & - & 0,2 & 0,2 & 0,3 & - \\
\hline Coração preenchido de sangue & 1,06 & 10,3 & 12,1 & 3,2 & 73,4 & 0,1 & - & 0,1 & - & 0,2 & 0,3 & 0,2 & 0,1 \\
\hline Sangue & 1,06 & 10,2 & 11,0 & 3,3 & 74,5 & 0,1 & - & 0,1 & - & 0,2 & 0,3 & 0,2 & 0,1 \\
\hline Fígado 3 & 1,07 & 10,1 & 12,6 & 3,3 & 72,7 & 0,3 & - & 0,2 & - & 0,3 & 0,2 & 0,3 & - \\
\hline Pele 1 & 1,09 & 10,0 & 25,0 & 4,6 & 59,4 & 0,1 & - & 0,2 & - & 0,3 & 0,3 & 0,1 & - \\
\hline Pele 2 & 1,09 & 10,0 & 20,4 & 4,2 & 64,5 & 0,1 & - & 0,2 & - & 0,2 & 0,3 & 0,1 & - \\
\hline Pele 3 & 1,09 & 10,1 & 15,8 & 3,7 & 69,5 & 0,1 & - & 0,2 & - & 0,2 & 0,3 & 0,1 & - \\
\hline Tecidos conectivos & 1,12 & 9,4 & 20,7 & 6,2 & 62,2 & - & - & 0,6 & - & 0,6 & 0,3 & - & - \\
\hline
\end{tabular}

Tabela 4.2 - Composição dos tecidos esqueléticos: densidade $(\rho)$ e as frações em peso $\left(\omega_{i}(f p)\right)$ de cada elemento dos tecidos (Woodard et al., 1986 ; White et al., 1987).

\begin{tabular}{|c|c|c|c|c|c|c|c|c|c|c|c|c|c|}
\hline \multirow[b]{2}{*}{ Tecido Esquelético } & \multirow[b]{2}{*}{$\rho\left(\mathrm{g} / \mathrm{cm}^{3}\right)$} & \multicolumn{12}{|c|}{$\omega_{i}(f p)$} \\
\hline & & $\mathrm{H}$ & $\mathrm{C}$ & $\mathrm{N}$ & $\mathrm{O}$ & $\mathrm{P}$ & $\mathrm{Ca}$ & $\mathrm{Na}$ & $\mathrm{Mg}$ & $\mathrm{S}$ & $\mathrm{Cl}$ & $\mathrm{K}$ & $\mathrm{Fe}$ \\
\hline Medula amarela & 0,98 & 11,5 & 64,4 & 0,7 & 23,1 & - & - & 0,1 & - & 0,1 & 0,1 & - & - \\
\hline Medula amarela / vermelha & 1 & 11,0 & 52,9 & 2,1 & 33,5 & 0,1 & - & 0,1 & - & 0,2 & 0,2 & 0,1 & 0,1 \\
\hline Medula vermelha & 1,03 & 10,5 & 41,4 & 3,4 & 43,9 & 0,1 & - & - & - & 0,2 & 0,2 & 0,2 & 0,1 \\
\hline Cartilagem & 1,1 & 9,6 & 9,9 & 2,2 & 74,4 & 2,2 & - & 0,5 & - & 0,9 & 0,3 & - & - \\
\hline Esterno & 1,25 & 7,8 & 31,6 & 3,7 & 43,8 & 4,0 & 8,5 & - & 0,1 & 0,2 & 0,1 & 0,1 & 0,1 \\
\hline Sacro (homem) & 1,29 & 7,4 & 30,2 & 3,7 & 43,8 & 4,5 & 9,8 & - & 0,1 & 0,2 & 0,1 & 0,1 & 0,1 \\
\hline D6, L3 incl. cartilagem (homem) & 1,3 & 7,3 & 26,5 & 3,6 & 47,3 & 4,8 & 9,8 & 0,1 & 0,1 & 0,3 & 0,1 & 0,1 & - \\
\hline Coluna vertebral inteira (homem) & 1,33 & 7,1 & 25,8 & 3,6 & 47,2 & 5,1 & 10,5 & 0,1 & 0,1 & 0,3 & 0,1 & 0,1 & - \\
\hline D6, L3 excl. cartilagem (homem) & 1,33 & 7,0 & 28,7 & 3,8 & 43,7 & 5,1 & 11,1 & - & 0,1 & 0,2 & 0,1 & 0,1 & 0,1 \\
\hline
\end{tabular}


Tabela 4.2 - Continuação

\begin{tabular}{|c|c|c|c|c|c|c|c|c|c|c|c|c|c|}
\hline \multirow[b]{2}{*}{ Tecido Esquelético } & \multirow[b]{2}{*}{$\rho\left(\mathrm{g} / \mathrm{cm}^{3}\right)$} & \multicolumn{12}{|c|}{$\omega_{i}(f p)$} \\
\hline & & $\mathrm{H}$ & $\mathrm{C}$ & $\mathrm{N}$ & $\mathrm{O}$ & $\mathrm{P}$ & $\mathrm{Ca}$ & $\mathrm{Na}$ & $\mathrm{Mg}$ & $\mathrm{S}$ & $\mathrm{Cl}$ & $\mathrm{K}$ & $\mathrm{Fe}$ \\
\hline Úmero (cabeça) & 1,33 & 7,1 & 37,9 & 2,6 & 34,2 & 5,6 & 12,2 & 0,1 & 0,1 & 0,2 & - & - & - \\
\hline Fêmur (cabeça) & 1,33 & 7,1 & 37,9 & 2,6 & 34,2 & 5,6 & 12,2 & 0,1 & 0,1 & 0,2 & - & - & - \\
\hline Fêmur (trocanter conical) & 1,36 & 6,9 & 36,6 & 2,7 & 34,7 & 5,9 & 12,8 & 0,1 & 0,1 & 0,2 & - & - & - \\
\hline C4 incl. cartilagem (homem) & 1,38 & 6,6 & 24,3 & 3,7 & 47,1 & 5,7 & 11,9 & 0,1 & 0,1 & 0,3 & 0,1 & 0,1 & - \\
\hline Sacro (mulher) & 1,39 & 6,6 & 27,1 & 3,8 & 43,5 & 5,8 & 12,5 & 0,1 & 0,1 & 0,3 & 0,1 & 0,1 & - \\
\hline Úmero & 1,39 & 6,7 & 35,2 & 2,8 & 35,2 & 6,2 & 13,5 & 0,1 & 0,1 & 0,2 & - & - & - \\
\hline $2^{\mathrm{a}}, 6^{\mathrm{a}}$ Costela (homem) & 1,41 & 6,4 & 26,3 & 3,9 & 43,6 & 6,0 & 13,1 & 0,1 & 0,1 & 0,3 & 0,1 & 0,1 & - \\
\hline Osso inominado (homem) & 1,41 & 6,3 & 26,2 & 3,9 & 43,6 & 6,1 & 13,2 & 0,1 & 0,1 & 0,3 & 0,1 & 0,1 & - \\
\hline C4 excl. cartilagem (homem) & 1,42 & 6,3 & 26,1 & 3,9 & 43,6 & 6,1 & 13,3 & 0,1 & 0,1 & 0,3 & 0,1 & 0,1 & - \\
\hline Fêmur (osso total) & 1,42 & 6,3 & 33,3 & 2,9 & 36,2 & 6,6 & 14,3 & 0,1 & 0,1 & 0,2 & - & - & - \\
\hline Fêmur & 1,43 & 6,3 & 33,1 & 2,9 & 36,3 & 6,6 & 14,4 & 0,1 & 0,1 & 0,2 & - & - & - \\
\hline Osso inominado (mulher) & 1,46 & 6,0 & 25,0 & 3,9 & 43,5 & 6,6 & 14,3 & 0,1 & 0,1 & 0,3 & 0,1 & 0,1 & - \\
\hline Clavícula, escápula & 1,46 & 6,0 & 31,3 & 3,1 & 37,0 & 7,0 & 15,2 & 0,1 & 0,1 & 0,2 & - & - & - \\
\hline Úmero (osso total) & 1,46 & 6,0 & 31,4 & 3,1 & 36,9 & 7,0 & 15,2 & 0,1 & 0,1 & 0,2 & - & - & - \\
\hline Úmero (eixo cilíndrico) & 1,49 & 5,8 & 30,1 & 3,2 & 37,4 & 7,2 & 15,8 & 0,1 & 0,2 & 0,2 & - & - & - \\
\hline $10^{\mathrm{a}}$ Costela (homem) & 1,52 & 5,6 & 23,5 & 4,0 & 43,4 & 7,2 & 15,6 & 0,1 & 0,1 & 0,3 & 0,1 & 0,1 & - \\
\hline Crânio & 1,61 & 5,0 & 21,2 & 4,0 & 43,5 & 8,1 & 17,6 & 0,1 & 0,2 & 0,3 & - & - & - \\
\hline Mandíbula & 1,68 & 4,6 & 19,9 & 4,1 & 43,5 & 8,6 & 18,7 & 0,1 & 0,2 & 0,3 & - & - & - \\
\hline Fêmur (eixo cilíndrico) & 1,75 & 4,2 & 20,4 & 3,8 & 41,5 & 9,3 & 20,2 & 0,1 & 0,2 & 0,3 & - & - & - \\
\hline Osso cortical & 1,92 & 3,4 & 15,5 & 4,2 & 43,5 & 10,3 & 22,5 & 0,1 & 0,2 & 0,3 & - & - & - \\
\hline
\end{tabular}

Através da FIG.(4.2) é possível observar que na faixa de valores de Hounsfield entre -100 e 0, assim como para a faixa acima de 300, os valores estão dispostos numa direção ortogonal ao da hipérbole, mostrando que estes tecidos podem ser bem resolvidos mediante o número de CT. Entretanto, os valores contidos entre 0 à 100 unidades de Hounsfield estão dispostos numa direção tangencial ao da hipérbole o que caracteriza serem pobremente resolvidos pelo número de $\mathrm{CT}$.

Observou-se também que a grande maioria dos tecidos apresentados nas TAB.4.1 e TAB.4.2 são bem caracterizados pelo CT e isto possibilita encontrar uma maneira de correlacionar a unidade de Hounsfield com os parâmetros do tecido $\left(\rho, \omega_{i}\right)$.

\section{Cálculo das unidades de Hounsfield}

O cálculo do número de Hounsfield, de forma direta, utilizando as Eq.(3.20), Eq.(3.45) e (3.46), juntamente com os valores tabulados das seções de choques, não é possível, pois a função espectral $\widehat{S}_{d}(E)$ que é o espectro detectado, é desconhecida. 


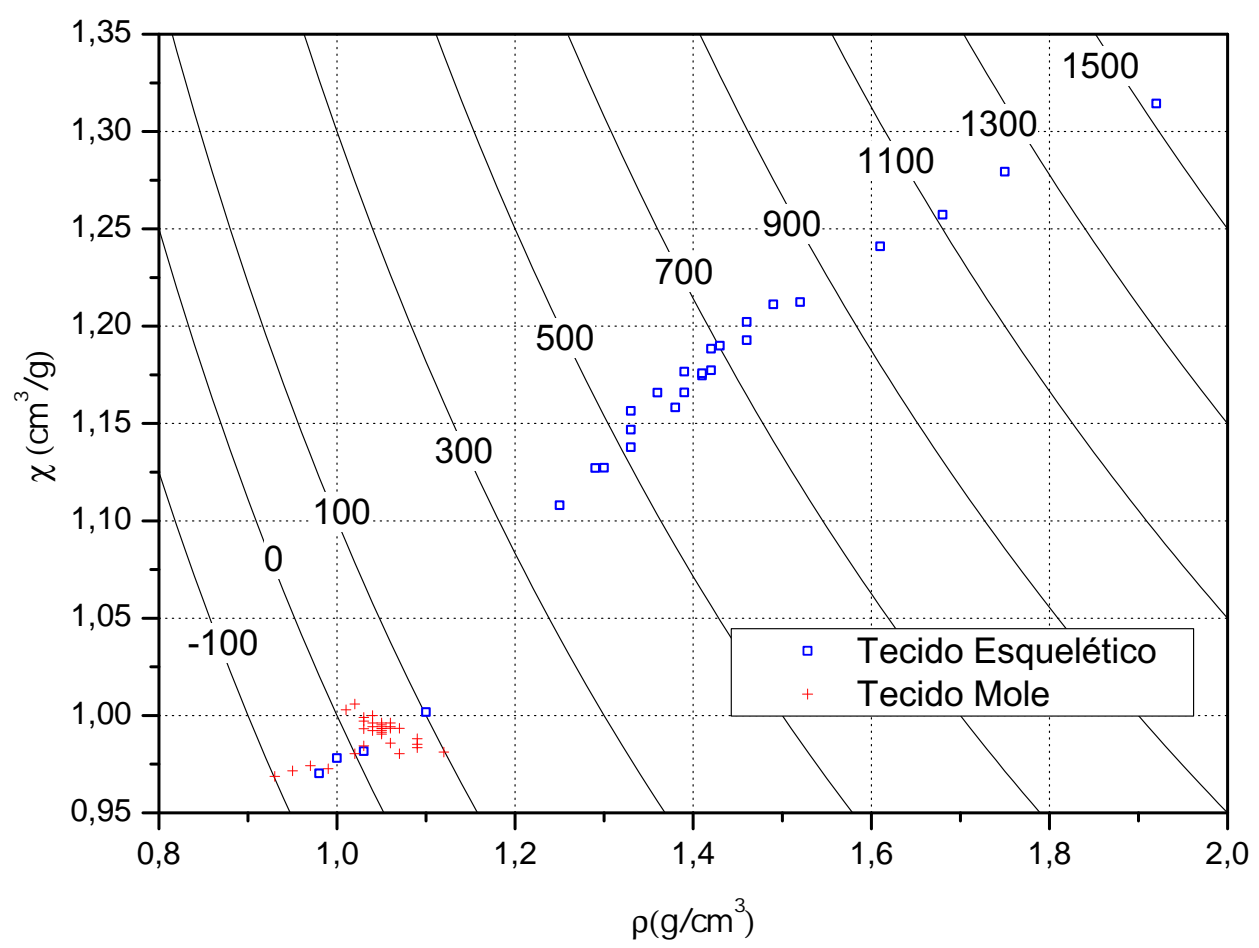

Figura 4.2: Correlação da unidade de Hounsfield com os parâmetros do tecido $\left(\omega_{i}, \rho\right)$.

No intuito de resolver esse problema, foram apresentados trabalhos que propuseram a substituição da seção de choque por uma fórmula empírica que mais se aproxime do sistema real em estudo (Watanabe, 1999 ; Schneider et al., 2000). Rutherford et al. (1976) mostraram que, para o intervalo de energia que é utilizado em raio-X diagnóstico $(50 \mathrm{keV}$ $\leq E \leq 100 \mathrm{keV}$ ) e levando em consideração os elementos contidos no corpo humano, a seção de choque total por elétron pode ser aproximada por:

$$
\sigma_{\text {tot }}^{e}=K^{K N}+K^{s c a} \hat{Z}^{1,86}+K^{p h} \tilde{Z}^{3,62}
$$

sendo:

$$
\hat{Z}=\left[\sum_{i}^{N} a_{i} Z_{i}^{1,86}\right]^{\frac{1}{1,86}}, \tilde{Z}=\left[\sum_{i=1}^{N} a_{i} Z_{i}^{3,62}\right]^{\frac{1}{3,62}} \quad \text { e } a_{i}=N_{A} \omega_{i} \frac{Z_{i}}{A_{i}} \cdot \frac{1}{N_{A} \sum \omega_{i} \frac{Z_{i}}{A_{i}}}
$$

onde,

- $\hat{Z}$ e $\tilde{Z}$ são os números atômicos efetivos;

- $K^{K N}, K^{\text {sca }}$ e $K^{p h}$ são os coeficientes de Klein-Nishina, espalhamento coerente e absorção fotoelétrica, respectivamente; 
- $\omega_{i}$ é a fração em peso do elemento $Z_{i}$;

- $a_{i}$ é a fração percentual de elétrons do elemento $Z_{i}$;

- $N$ é o número de elementos químicos.

Caso todos os elementos químicos de um composto sejam considerados, então:

$$
\sum_{i=1}^{N} a_{i}=1
$$

Assim, considerando que os tecidos são compostos somente pelos elementos químicos citados nas TAB.4.1 e TAB.4.2, substituindo $\sigma_{i, t o t}^{e}$ da Eq.(3.21) pela Eq.(4.2) e, por fim, calculando o coeficiente de atenuação linear médio obtem-se:

$$
\bar{\mu}=\rho N_{A} \sum\left(\omega_{i} \frac{Z_{i}}{A_{i}}\right)\left[\bar{K}^{K N}+\bar{K}^{s c a} Z^{1,86}+\bar{K}^{p h} Z^{3,62}\right]
$$

onde,

- $\bar{K}^{K N}, \bar{K}^{s c a}, \bar{K}^{p h}$ são os valores médios em relação à função espectral $\widehat{S}_{d}(E)$;

Considerando $k_{1} \equiv \bar{K}^{s c a} / \bar{K}^{K N}, k_{2} \equiv \bar{K}^{p h} / \bar{K}^{K N}$ e formulando a equação $\bar{\mu} / \bar{\mu}_{H_{2} O}\left(k_{1}, k_{2}\right)$ por meio da Eq.(4.4) obtem-se:

$$
\frac{\bar{\mu}}{\bar{\mu}_{H_{2} O}}=\frac{\rho}{\rho_{H_{2} O}} \times \frac{\sum_{i=1}^{N}\left[\left(\frac{\omega_{i}}{A_{i}}\right)\left(Z_{i}+k_{1} Z^{2,86}+k_{2} Z^{4,62}\right)\right]}{\left(\frac{\omega_{H}}{A_{H}}\right)\left(1+k_{1}+k_{2}\right)+\left(\frac{\omega_{O}}{A_{O}}\right)\left(8+8^{2,86} k_{1}+8^{4,62} k_{2}\right)}
$$

onde,

- $\omega_{H}$ é a fração em peso do elemento químico hidrogênio na água;

- $\omega_{O}$ é a fração em peso do elemento químico oxigênio na água.

Os valores de $k_{1}$ e $k_{2}$ são determinados experimentalmente. Primeiramente, é necessário ter uma série de objetos simuladores, juntamente com suas correspondentes frações em pesos da composição química e densidades.

Ao realizar as medidas das unidades de Hounsfield de cada objeto simulador, através das imagens de CT, e utilizar as composições químicas e densidades na Eq.(4.5) é possível obter por intermédio do ajuste por mínimos quadrados os valores de $k_{1}$ e $k_{2}$. Em suma, a expressão abaixo deve ser minimizada, onde $M$ é o número de objetos simuladores: 


$$
S=\sum_{n=1}^{M}\left[\left(\frac{\bar{\mu}}{\bar{\mu}_{H_{2} O}}\left(k_{1}, k_{2}\right)\right)_{n}-\left(\frac{H_{\text {medido }}}{1000}+1\right)_{n}\right]
$$

Vale lembrar que os valores de $k_{1}$ e $k_{2}$ são dependentes do tomógrafo $(\mathrm{CT})$ e portanto, não podem ser utilizados por outros equipamentos.

Após obter os valores de $k_{1}$ e $k_{2}$ é possível encontrar a unidade de Hounsfield de um tecido mediante as Eq.(4.5) e Eq.(3.46)

\section{Algoritmo de cálculo de $k_{1}$ e $k_{2}$}

O cálculo de $k_{1}$ e $k_{2}$, como já citado anteriormente, é realizado minimizando a Eq.(4.6). Para isto, é preciso efetuar dois passos: (1) fazer a derivada parcial de $S$ em relação à $k_{1}$, $\partial S / \partial k_{1}$, e igualar a zero e (2) fazer a derivada parcial de $S$ em relação à $k_{2}, \partial S / \partial k_{2}$, e igualar a zero.

Ao realizar esse procedimento obtem-se duas equações:

$$
\begin{aligned}
& \frac{\partial S}{\partial k_{1}}=T_{1}+T_{2} k_{1}+T_{3} k_{2}+T_{4} k_{1} k_{2}+T_{5} k_{2}^{2}=0 \\
& \frac{\partial S}{\partial k_{2}}=F_{1}+F_{2} k_{1}+F_{3} k_{2}+F_{4} k_{1} k_{2}+F_{5} k_{1}^{2}=0
\end{aligned}
$$

onde,

- $T_{1}$ à $T_{5}$ e $F_{1}$ à $F_{5}$ são constantes.

Em razão da grande extensão dessas constantes, foi necessário apresentá-las de outra maneira. Assim, todas as constantes são aqui representadas mediante as Eq.(4.9) e Eq.(4.10).

$$
\begin{aligned}
& X(\alpha)=\left[\sum_{i=1}^{M} \rho_{i} \cdot\left[\sum_{j=1}^{N}\left(\frac{\omega_{j} / 100}{A_{j}}\right) Z_{j}^{\alpha}\right]\right]-\left[\frac{\omega_{H}}{A_{H}}+8^{\alpha} \frac{\omega_{O}}{A_{O}}\left[\frac{H_{\text {medido }}}{1000}+1\right]\right] \\
& Y(\alpha ; \beta)=\left[\sum_{i=1}^{M} \rho_{i} \cdot\left[\sum_{j=1}^{N}\left(\frac{\omega_{j} / 100}{A_{j}}\right) Z_{j}^{\alpha}\right]\right] \cdot\left[\frac{\omega_{H}}{A_{H}}+8^{\beta} \frac{\omega_{O}}{A_{O}}\right]- \\
& {\left[\sum_{i=1}^{M} \rho_{i} \cdot\left[\sum_{j=1}^{N}\left(\frac{\omega_{j} / 100}{A_{j}}\right) Z_{j}^{\beta}\right]\right] \cdot\left[\frac{\omega_{H}}{A_{H}}+8^{\alpha} \frac{\omega_{O}}{A_{O}}\right]}
\end{aligned}
$$

onde,

- $M$ é o número de objetos simuladores; 
- $N$ é o número de elementos químicos.

Assim, com base nas Eq.(4.9) e Eq.(4.10) é possível encontrar as constantes $T_{1}$ à $T_{5}$ e $F_{1}$ à $F_{5}$. Dessa forma, as Eq.(4.7) e Eq.(4.8), são reescritas da seguinte forma:

$$
\begin{array}{rl}
\frac{\partial S}{\partial k_{1}}= & X(1) \cdot Y(2,86 ; 1)+X(2,86) \cdot Y(2,86 ; 1) k_{1}+ \\
& {[X(4,62) \cdot Y(2,86 ; 1)+X(1) \cdot Y(2,86 ; 4,62)] k_{2}+} \\
& X(2,86) \cdot Y(2,86 ; 4,62) k_{1} k_{2}+X(4,62) \cdot Y(2,86 ; 4,62) k_{2}^{2}=0 \\
\frac{\partial S}{\partial k_{2}=} \quad & X(1) \cdot Y(4,62 ; 1)+[X(4,62) \cdot Y(4,62 ; 1)+X(1) \cdot Y(4,62 ; 2,86)] k_{1}+ \\
& X(4,62) \cdot Y(4,62 ; 1) k_{2}+X(4,62) \cdot Y(4,62 ; 2,86) k_{1} k_{2}+ \\
X & X(2,86) \cdot Y(4,62 ; 2,86) k_{1}^{2}=0
\end{array}
$$

Conhecida a composição química, a densidade e os valores de Hounsfield dos objetos simuladores, o algorítmo inicia o cálculo desse sistema de equações não lineares, obtendo como resultado os valores de $k_{1}$ e $k_{2}$.

Antes de se iniciar o cálculo do sistema, a variável $k_{2}$ foi isolada da Eq.(4.11) ficando em função de $k_{1}$ e implementada no algorítmo. Resumidamente, esta equação é apresentada a seguir, por intermédio das constantes $T_{1}$ à $T_{5}$ :

$$
k_{2}=\frac{-\left(T_{3}+T_{4} k_{1}\right)+\sqrt{\left(T_{3}+T_{4} k_{1}\right)^{2}-4\left(T_{5}\right)\left(T_{1}+T_{2} k_{1}\right)}}{2 T_{5}}
$$

Como já foi mencionado, $k_{2} \equiv \bar{K}^{p h} / \bar{K}^{K N}$, portanto o valor negativo de $k_{2}$ é descartado como se pode perceber na Eq.(4.13). Assim, com a Eq.(4.13) o algorítmo segue os seguintes passos para encontrar os valores de $k_{1}$ e $k_{2}$.

- A Eq.(4.13) é substituída na Eq.(4.12);

- Aplica-se o método de Newton-Raphson (Ruggiero et al., 1996) para encontrar o valor de $k_{1}$;

- Valor de $k_{1}$ é substituído na equação Eq.(4.13) para encontrar o valor de $k_{2}$. 


\section{Método de Schneider e colaboradores}

O método de Schneider et al. (2000) é baseado numa calibração estequiométrica do número de CT com a densidade e as frações em pesos dos elementos pertencentes aos tecidos.

Primeiramente é suposto que os tecidos podem ser decompostos em duas componentes que apresentam diferentes frações em peso. Assim é possível representar diferentes tecidos, confinados entre essas duas componentes, mediante as frações em pesos e funções de interpolação.

A primeira componente é representada por $\left(\rho_{1}, \omega_{1, i}, H_{1}\right)$, a segunda por $\left(\rho_{2}, \omega_{2, i}, H_{2}\right)$ e a componente desejada por $\left(\rho, \omega_{i}, H\right)$, sendo $H_{1}<H_{2}$.

Definindo $W_{1}$ como a fração em peso da primeira componente e $W_{2}$ a fração da segunda componente, tem-se que $W_{2}=1-W_{1}$, isto é, considera-se que o tecido é formado "somente" por essas duas componentes.

Desta forma a relação de $\omega_{i} \operatorname{com} W_{1}$ é:

$$
\omega_{i}=W_{1} \omega_{1, i}+W_{2} \omega_{2, i}=W_{1}\left(\omega_{1, i}-\omega_{2, i}\right)+\omega_{2, i}
$$

E a relação de $\rho$ com $W_{1}$ é:

$$
\rho=\frac{m}{V}=\frac{m}{\frac{m_{1}}{\rho_{1}}+\frac{m_{2}}{\rho_{2}}}=\frac{m}{\frac{m W_{1}}{\rho_{1}}+\frac{m W_{2}}{\rho_{2}}}=\frac{m}{\frac{W_{1}}{\rho_{1}}+\frac{W_{2}}{\rho_{2}}}=\frac{\rho_{1} \rho_{2}}{W_{1}\left(\rho_{2}-\rho_{1}\right)+\rho_{1}}
$$

Substituindo essas duas equações anteriores em:

$$
\bar{\mu}=\rho N_{A} \sum_{i=1}^{n}\left(\frac{\omega_{i}}{A_{i}} \cdot \bar{\sigma}_{i}^{a}\right)
$$

Tem-se que:

$$
\begin{aligned}
& \bar{\mu}=\frac{\rho_{1} \rho_{2}}{W_{1}\left(\rho_{2}-\rho_{1}\right)+\rho_{1}} N_{A} \sum_{i=1}^{n}\left(\frac{W_{1}\left(\omega_{1, i}-\omega_{2, i}\right)+\omega_{2, i}}{A_{i}} \cdot \bar{\sigma}_{i}^{a}\right) \\
& =\frac{\rho_{1} \rho_{2}}{W_{1}\left(\rho_{2}-\rho_{1}\right)+\rho_{1}} N_{A}\left[W_{1} \sum_{i=1}^{n}\left(\frac{\omega_{1, i}-\omega_{2, i}}{A_{i}} \cdot \bar{\sigma}_{i}^{a}\right) \sum_{i=1}^{n}\left(\frac{\omega_{2, i}}{A_{i}} \cdot \bar{\sigma}_{i}^{a}\right)\right]
\end{aligned}
$$

Com base na Eq.(4.16), obtem-se:

$$
\bar{\mu}=\frac{\rho_{1} \rho_{2}}{W_{1}\left(\rho_{2}-\rho_{1}\right)+\rho_{1}}\left[W_{1}\left(\frac{\bar{\mu}_{1}}{\rho_{1}}-\frac{\bar{\mu}_{2}}{\rho_{2}}\right)+\frac{\bar{\mu}_{2}}{\rho_{2}}\right]
$$


Mediante a equação anterior e a Eq.(3.46) é possível obter a relação de $W_{1}$ com $H$ dada por:

$$
W_{1}=\frac{\rho_{1}\left(H_{2}-H\right)}{H\left(\rho_{2}-\rho_{1}\right)+\left(H_{2} \rho_{1}-H_{1} \rho_{2}\right)}
$$

O cálculo da obtenção da Eq.(4.19) é apresentado no Apêndice 7. Por fim é feita a substituição de $W_{1}$ nas Eq.(4.14) e Eq.(4.15) obtendo a relação de $\omega_{i}$ e $\rho$ com $H$. Dessa forma, encontra-se as seguintes relações:

$$
\begin{gathered}
\rho=\frac{H\left(\rho_{2}-\rho_{1}\right)+H_{2} \rho_{1}-H_{1} \rho_{2}}{H_{2}-H_{1}} \\
\omega_{i}=\frac{\rho_{1}\left(H_{2}-H\right)}{H\left(\rho_{2}-\rho_{1}\right)+H_{2} \rho_{1}-H_{1} \rho_{2}}\left(\omega_{1, i}-\omega_{2, i}\right)+\omega_{2, i}
\end{gathered}
$$

Sendo que $H_{1} \leq H \leq H_{2}$. Assim dado um valor de $H$, de um meio composto de duas componentes, é possível de maneira distinta determinar tanto a densidade do composto como a fração em peso de cada elemento do composto, supondo-se que os dados dos componentes sejam conhecidos.

\section{Estipulação das componentes do tecido esquelético}

Os tecidos esqueléticos podem ser decompostos principalmente de medula óssea e tecido ósseo em diferentes proporções (Woodard et al., 1982), exceto poucos tecidos que são compostos por cartilagem.

Assim Schneider et al. (2000) propõem que a primeira componente seja a medula amarela/vermelha ( $m e$ ) e a segunda o osso cortical (oc), apresentados na TAB.(4.2). Dessa forma, as Eq.(4.20) e Eq.(4.21) são reescritas da seguinte maneira:

$$
\begin{gathered}
\rho=\frac{H\left(\rho_{o c}-\rho_{m e}\right)+H_{o c} \rho_{m e}-H_{m e} \rho_{o c}}{H_{o c}-H_{m e}} \\
\omega_{i}=\frac{\rho_{m e}\left(H_{o c}-H\right)}{H\left(\rho_{o c}-\rho_{m e}\right)+H_{o c} \rho_{m e}-H_{m e} \rho_{o c}}\left(\omega_{m e, i}-\omega_{o c, i}\right)+\omega_{o c, i}
\end{gathered}
$$

\section{Estipulação das componentes do tecido mole}

O tecido mole é composto principalmente por três componentes (água, gordura, proteína) com isso não é possível utilizar o método de interpolação em todo o intervalo do tecido 
mole. Para resolver esta situação Schneider et al. (2000) propuseram dividir o intervalo do tecido mole para assim poder utilizar o método da interpolação.

Para realizar essa subdivisão, na FIG.(4.3) há um gráfico que apresenta a proporção de água e de gordura nos tecidos moles versus o valor de Hounsfield calculado. Os dados das proporções foram extraídos da literatura(White et al., 1986).

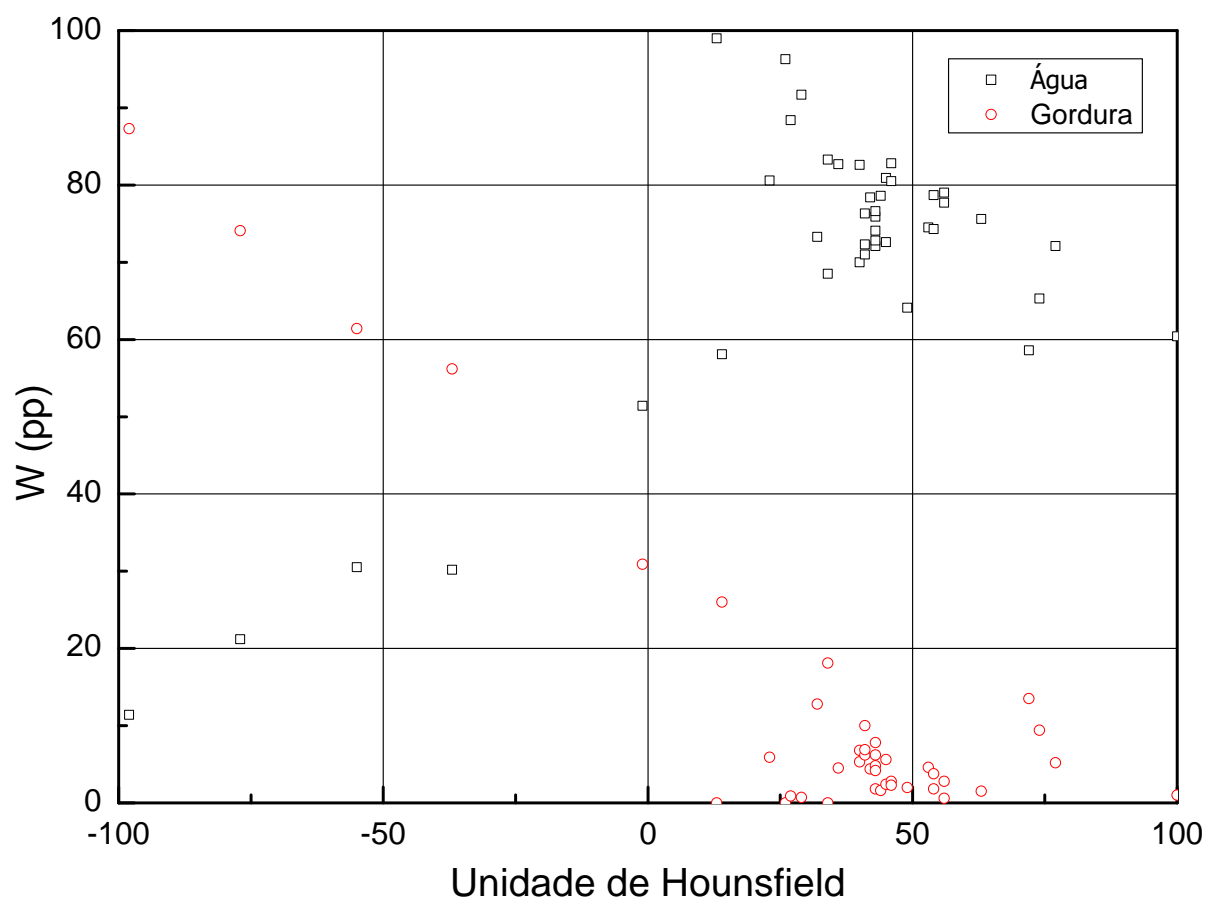

Figura 4.3: Proporção de água e de gordura em tecidos moles versus o valor de Hounsfield calculado.

Ao analisar o gráfico da FIG.(4.3) é possível observar que para valores entre -100 à 13 unidades de Hounsfield, a proporção de gordura decresce linearmente à medida que o valor de Hounsfield aumenta, o que indica uma boa região para se aplicar o método da interpolação.

Esta região está confinada entre o tecido adiposo $3(t a)$ e a glândula adrenal $(g a)$, representa pelas seguintes equações:

$$
\begin{gathered}
\rho=\frac{H\left(\rho_{g a}-\rho_{t a}\right)+H_{2} \rho_{t a}-H_{t a} \rho_{g a}}{H_{g a}-H_{t a}} \\
\omega_{i}=\frac{\rho_{t a}\left(H_{g a}-H\right)}{H\left(\rho_{g a}-\rho_{t a}\right)+H_{g a} \rho_{t a}-H_{t a} \rho_{g a}}\left(\omega_{t a, i}-\omega_{g a, i}\right)+\omega_{g a, i}
\end{gathered}
$$


Acima de 13 unidades de Hounsfield os tecidos apresentam uma alta proporção de água e apesar disso é observado um decréscimo global à medida que o valor de Hounsfield aumenta, o que também torna esta uma boa região para se aplicar o método da interpolação.

Este intervalo está compreendido entre a parede do intestino grosso $(i g)$ e tecido conectivo $(t c)$, representado pelas seguintes equações:

$$
\begin{gathered}
\rho=\frac{H\left(\rho_{t c}-\rho_{i g}\right)+H_{t c} \rho_{i g}-H_{i g} \rho_{t c}}{H_{t c}-H_{i g}} \\
\omega_{i}=\frac{\rho_{i g}\left(H_{t c}-H\right)}{H\left(\rho_{t c}-\rho_{i g}\right)+H_{t c} \rho_{i g}-H_{i g} \rho_{t c}}\left(\omega_{i g, i}-\omega_{t c, i}\right)+\omega_{t c, i}
\end{gathered}
$$

\subsubsection{Influência da composição dos tecidos no cálculo da dose absorvida}

A fim de avaliar a influência da composição dos tecidos no cálculo da dose absorvida, simulou-se um experimento com o objetivo de estimar as diferenças na dose absorvida para duas situações: (1) em um dos 24 grupos estipulados pelo ICCT e (2) em um tecido com a composição fornecida pela literatura, sendo este representado pelo grupo do ICCT. Com base nesses resultados, verificou-se a diferença na dose absorvida em relação ao tecido fornecido pela literatura.

A densidade $\left(\mathrm{g}_{\mathrm{cm}} \mathrm{cm}^{-3}\right)$ do tecido fornecida pela literatura foi substituída pela densidade do respectivo grupo estipulado mediante o ICCT, para que assim, não ocorra influência da densidade no cálculo da dose absorvida.

Foram empregadas as seguintes fontes de radiação para a simulação: fótons com energia de 0,14 MeV e $1 \mathrm{MeV}$; e uma fonte de elétrons com energia de $1 \mathrm{MeV}$. O tipo da fonte e suas energias foram escolhidos devido as características dos radionuclídeos utilizados em Medicina Nuclear.

Para cada tecido foi calculado a diferença da dose absorvida para as três fontes, por intermédio do código MCNP5, com a utilização do estimador (tally) *F8, para efetuar o cálculo da energia depositada dentro de um simulador cuja geometria é um cubo.

Para simular tal procedimento foi construído, no MCNP5, um cubo com aresta de 2 $m m$ que possui a finalidade de conter os tecidos e a fonte de radiação, uniformemente distribuída por todo esse cubo. Essa cubo está contido numa esfera de água de diâmetro $1 \mathrm{~cm}$. Com base nessa configuração foi realizado o cálculo da energia depositada média no interior do cubo. Na FIG.4.4 mostra-se o esquema dessa configuração. 


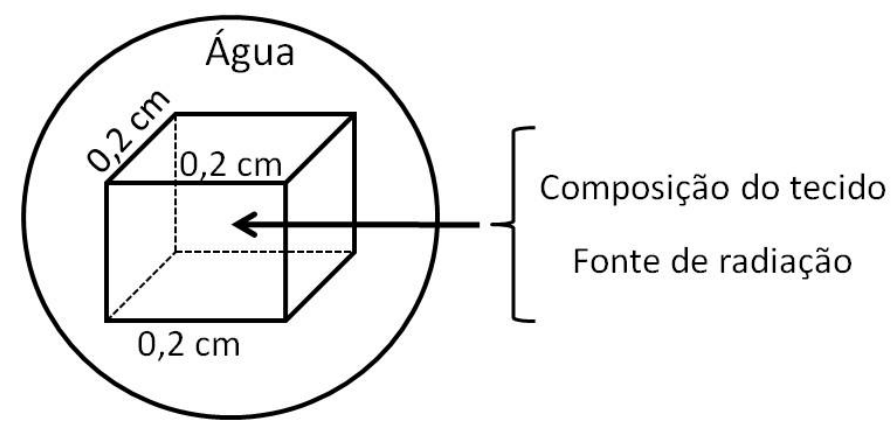

Figura 4.4: Esquema da configuração para o cálculo da energia depositada no MCNP5.

\subsubsection{Análise da influência da quantidade de tecidos no cálculo da dose absorvida}

Para analisar a influência da quantidade de tecidos no cálculo da dose absorvida, simulou-se um experimento com a finalidade de calcular a dose absorvida numa determinada geometria, referente ao corpo humano. Desta forma, foi selecionada uma região de interesse em diversas imagens, em que uma delas está ilustrada na FIG.4.5 e esta região foi processada através de duas metodologias:

METODOLOGIA 1: subdividiu-se a imagem, com auxílio da unidade de Hounsfield $(H)$, em 4 tipos de tecido: ar, pulmão, tecido mole e tecido esquelético; METODOLOGIA 2: o ICCT, através de sua metodologia que será mencionada na seção 5.1, subdivide a imagem em no máximo 24 tipos de tecidos.

Foram utilizadas nove imagens de CT de um paciente, cedidas pelo Hospital do Coração (Hcor). Na FIG.4.5 observa-se uma das imagens utilizadas.

Foram consideradas duas fontes cilíndricas situadas entre a $3^{a}$ e $7^{a}$ imagens: (1) uma fonte de elétrons com energia de $1 \mathrm{MeV}$ e (2) uma fonte de fótons com energia de $1 \mathrm{MeV}$.

Foi calculada a energia depositada (em $\mathrm{MeV}$ ) em cada pixel somente nas imagens 3,4 e 5 (formando um grupo de imagem), para ambas as metodologias, utilizando o estimador (tally) ${ }^{*} \mathrm{~F} 8$ do MCNP5. Ou seja, foram calculadas as energias depositadas no grupo de imagens (imagem 3, 4 e 5) com os tecidos subdivididos em 4 tipos e no grupo de imagens com os tecidos subdivididos em mais tipos. Foi então calculada a diferença da energia depositada nos dois grupos, com isso avaliou se a subdivisão em mais ou menos tecidos, interfere ou não no cálculo de dose, e em caso positivo, o quanto interfere.

A dose foi calculada transformando a energia deposita, dada em $\mathrm{MeV}$, em Joule $(J)$ e 

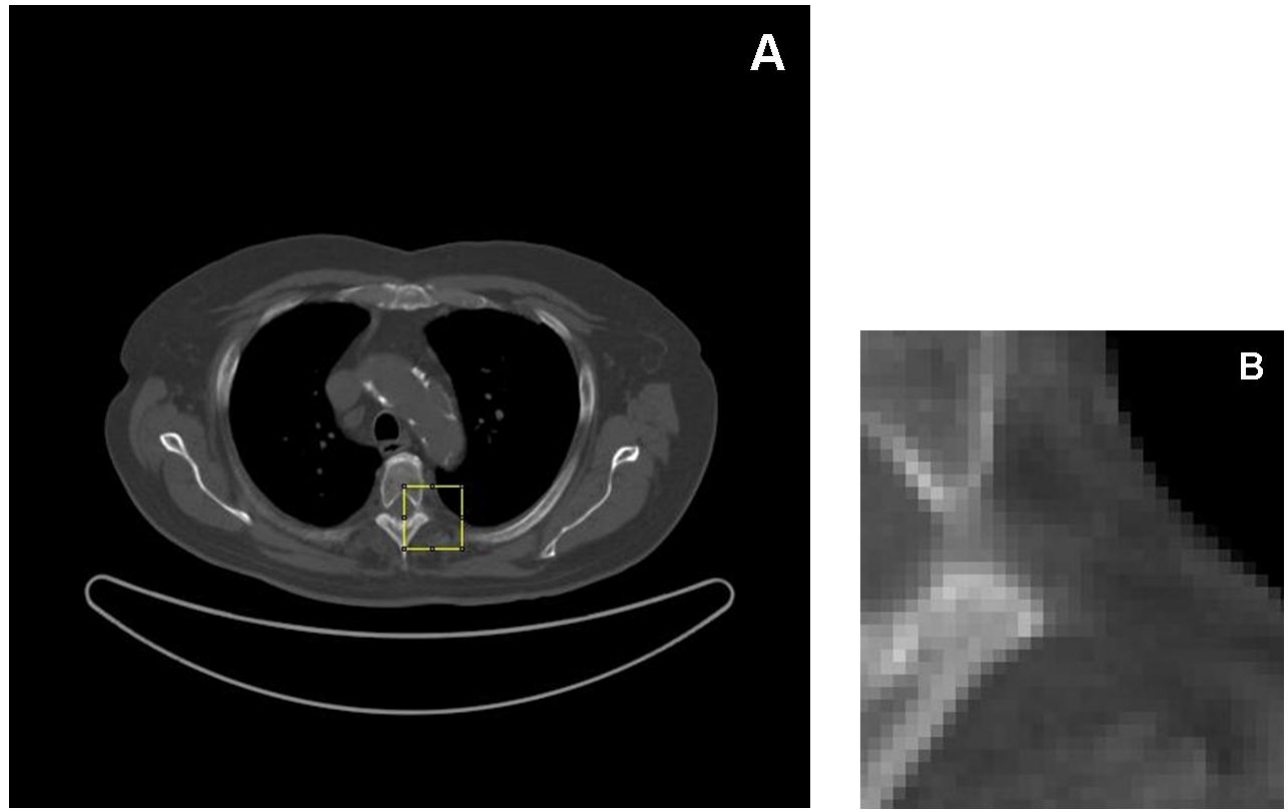

Figura 4.5: Uma das imagens de CT utilizada nas metodologias, com detalhe da região de interesse para o cálculo da distribuição de dose (A) e detalhe ampliado da região de interesse (B).

dividindo-a pela densidade do pixel.

\subsubsection{Método de Chang de $1^{a}$ ordem}

No presente método, os pixels da imagem serão considerados homogêneos por convenção. Isto é, quando for mencionado um meio homogêneo significará que todos os pixels pertencentes a este meio, terão o mesmo valor de coeficiente de atenuação, ao contrário de um meio heterogêneo onde cada pixel terá um valor diferente de coeficiente de atenuação.

A seguir será discutido o método de Chang de $1^{a}$ ordem para resolver dois problemas, um em relação ao meio homogêneo e o outro em relação a um meio heterogêneo (Chang, 1978).

De uma forma geral, esse método corrige o processo de atenuação ocorrido em imagens SPECT ou PET multiplicando-as por uma matriz de correção, denominada aqui de $C(x, y)$ (Chang, 1978). Para os meios homogêneos, essa matriz é formada com base na seguinte expressão:

$$
C(x, y)=\frac{1}{\frac{1}{M} \sum_{i=1}^{M} e^{-\mu L\left(x, y, \theta_{i}\right)}}
$$

onde, 
- $M$ é o número de projeções;

- $\mu$ é o coeficiente de atenuação linear do meio homogêneo;

- $L\left(x, y, \theta_{i}\right)$ é o comprimento do raio de projeção no ângulo $\theta_{i}$, dentro do meio atenuante.

Antes de se iniciar o processo de formação da matriz é necessário delimitar uma região de interesse na imagem (ROI - Region of Interest), que normalmente é circular. Essa região representará, com um certo grau de precisão, o contorno do corpo do paciente naquela determinada seção.

Após esse processo, forma-se uma matriz de mesma dimensão da imagem original, e assim, por meio do ROI delimitado, os elementos da matriz que estiverem fora desta região receberão valor igual a zero e os que estiverem dentro receberão valor diferente de zero, por exemplo, valor igual a um.

Tendo por base o que foi citado, o processo de construção da matriz de correção basicamente ocorre em três etapas:

1. A primeira etapa consiste em encontrar de forma lógica, elementos diferentes de zero na matriz inicial;

2. Na segunda etapa, quando um elemento é encontrado inicia-se o cálculo de $C(x, y)$, mediante a Eq.(4.28);

3. Por fim, após efetuado o cálculo da $2^{a}$ etapa o valor contido na matriz de correção, que neste caso vale um, é substituído por $C(x, y)$ e a seguir o algorítmo volta a $1^{a}$ etapa tendo esse o ponto inicial;

4. Esse processo é realizado sucessivamente até ao final da matriz.

O procedimento para o cálculo de $C(x, y)$ segue as seguintes etapas:

1. É definido o ângulo da primeira projeção $\left(\theta_{i}\right)$;

2. Com base em $\left(\theta_{i}\right)$ é feita a medida da distância entre o elemento da matriz, situado em $(x, y)$, até a borda delimitada pelo ROI. Essa distância é o comprimento do raio de projeção no ângulo $\theta_{i}$, designada por $L\left(x, y, \theta_{i}\right)$; 
3. O valor de $L\left(x, y, \theta_{i}\right)$ é então multiplicado pelo tamanho do píxel em $\mathrm{cm}$, representado por " $d$ ";

4. O valor da etapa anterior é multiplicado por -1 e pelo coeficiente de atenuação $(\mu)$ do meio;

5. É efetuado o cálculo da exponencial da etapa anterior, isto é, $e^{-\mu L\left(x, y, \theta_{i}\right) d}$;

6. Soma-se o valor encontrado na etapa 5 , referente a projeção $\theta_{i}$, com o valor referente a projeção anterior. No início, o valor da projeção anterior é igual a zero;

7. O ângulo $\theta_{i}$ é então redefinido para a nova projeção;

8. O procedimento da etapa 1 à 7 é repetido para todas as projeções obtendo-se como valor final equivalente a $\sum_{i=1}^{M} e^{-\mu L\left(x, y, \theta_{i}\right) d}$;

9. O valor obtido pela etapa anterior é então dividido pelo número de projeção representado por $M$;

10. Por fim calcula-se a inversa do valor obtido na etapa anterior obtendo assim o valor de $C(x, y)$.

Para exemplificar alguns parâmetros, na FIG.4.6 é mostrada uma representação simples desse processo com a utilização de quatro projeções.

O formato quadriculado na imagem indica os pixels. O ROI é representado pelo círculo traçado em preto. No centro da FIG.4.6, em azul, encontra-se a localização de um suposto fóton e as setas que dele emergem em direção às quatro projeções são referentes a direção de detecção. O comprimento do raio de projeção é indicado por $L$.

Para a resolução do meio heterogêneo, essa matriz é formada com base na seguinte expressão:

$$
C(x, y)=\frac{1}{\frac{1}{M} \sum_{i=1}^{M} e^{-\left[\sum_{j=1}^{N} \mu_{j}\right] L\left(x, y, \theta_{i}\right)}}
$$

onde,

- $M$ é o número de projeções;

- $N$ é o número de pixel do ponto $(x, y)$ até a borda delimida pelo ROI, numa dada projeção; 


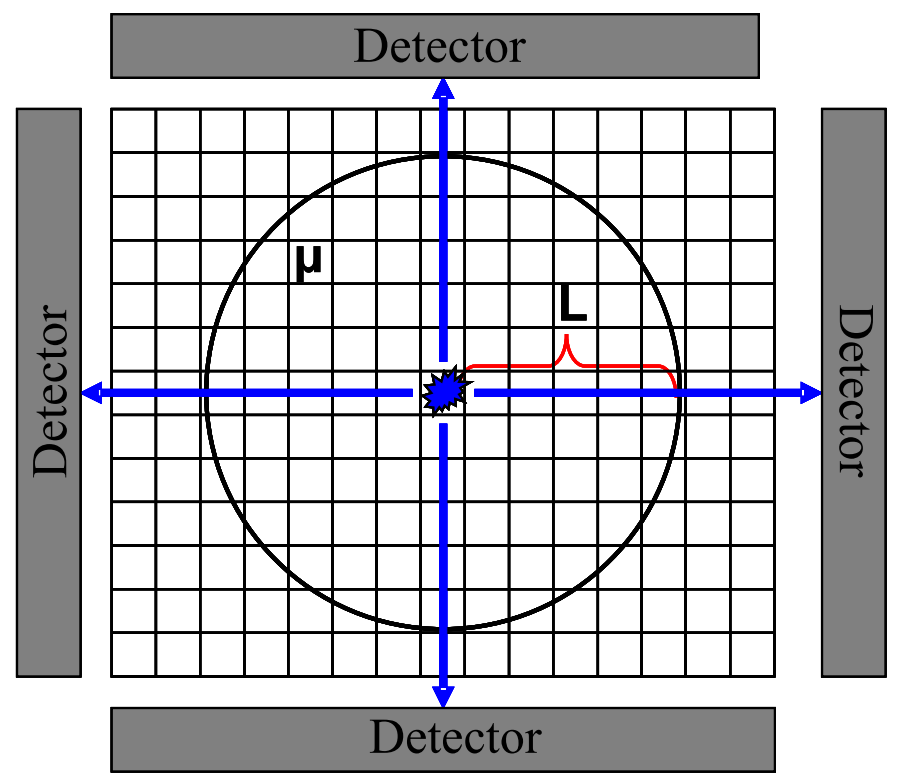

Figura 4.6: Representação do processo de cálculo de $C(x, y)$ com a utilização de quatro projeções.

- $\mu_{j}$ é o coeficiente de atenuação linear do pixel;

- $L\left(x, y, \theta_{i}\right)$ é o comprimento do raio de projeção no ângulo $\theta_{i}$, dentro do meio atenuante.

O processo de formação da matriz de correção, para esse problema, é praticamente o mesmo do anterior. A única mudança que ocorre, como é possível observar mediante a Eq.(4.29), é em relação ao coeficiente de atenuação $(\mu)$. Então na etapa 4, do cálculo de $C(x, y)$, deve haver uma somatória dos $\mu$ em todo o comprimento $L\left(x, y, \theta_{i}\right)$.

Os coeficientes de atenuação em cada pixel são obtidos mediante a imagem de CT. Porém há um problema em se utilizar esse método, pois o coeficiente de atenuação depende da energia, de maneira que um fóton com energia de $75 \mathrm{keV}$ obterá um coeficiente de atenuação diferente no tecido do que um fóton com $140 \mathrm{keV}$, por exemplo, que é o caso do ${ }^{99 m} T c$.

Dessa forma, os coeficientes de atenuação obtidos pelas imagens de CT devem ser escalonados para a energia do fóton em que se realiza a imagem. Para isso, foi assumido que o coeficiente de atenuação varia linearmente entre a energia efetiva do feixe de CT e a energia do fóton da imagem (Tsui et al., 1989).

Com isso, é possível estimar o coeficiente de atenuação linear em cada pixel, pela 
seguinte expressão:

$$
\mu_{E}(x, y)=\frac{\mu_{E}^{H_{2} O}}{\mu_{C T}^{H_{2} O}} \cdot \mu_{C T}(x, y)
$$

onde,

- $\mu_{E}$ é o coeficiente de atenuação em relação a energia desejada;

- $\mu_{C T}$ é o coeficiente de atenuação em relação a energia efetiva do CT;

- $\mu_{E}^{\mathrm{H}_{2} \mathrm{O}}$ é o coeficiente de atenuação na água em relação a energia desejada;

- $\mu_{C T}^{\mathrm{H}_{2} \mathrm{O}}$ é o coeficiente de atenuação na água em relação a energia efetiva do CT. 
Capítulo 5

\section{RESULTADOS E DISCUSSÃO}

\subsection{Software Conversor de Imagens de Tomografia Computadorizada - ICCT}

O software ICCT é composto por cinco módulos. Cada módulo possui uma funcionalidade que em conjunto possuem a finalidade de extrair informações da geometria e composição dos tecidos do corpo do paciente, mediante imagens de CT. Essas informações serão fornecidas para o software SCMS e MCNP5 que irão, com base nessas e em outras informações, calcular a distribuição de dose interna no paciente. Para isso, o ICCT gera quatro arquivos em formato ASCII; três deles são formatados para o software SCMS e um para o software MCNP5.

Na FIG.5.1 está apresentado de forma geral cada um dos módulo e suas respectivas funções:

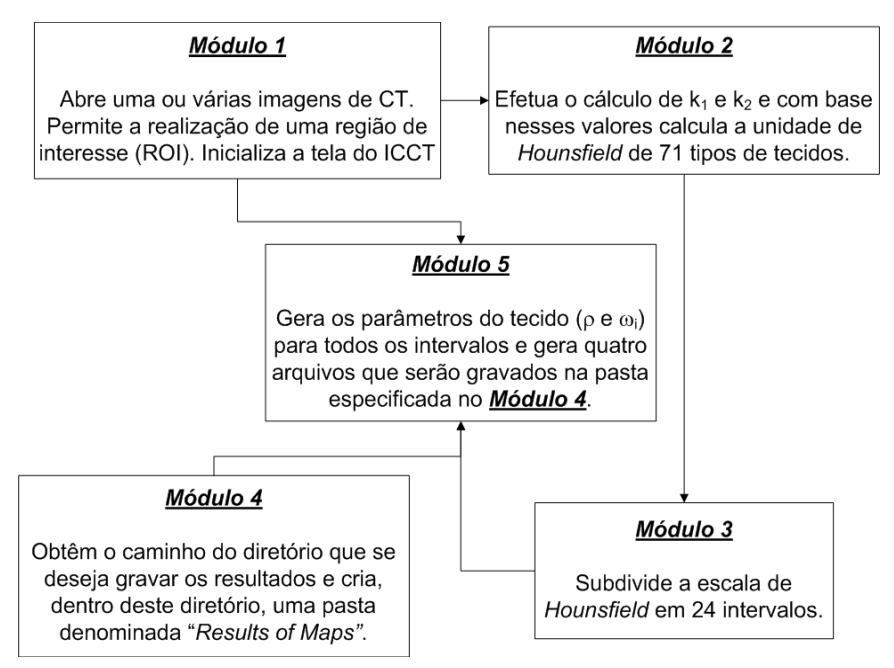

Figura 5.1: Apresentação geral dos módulos do ICCT e suas respectivas funções. 
O Módulo 1 possui duas funções principais: (1) abrir as imagens de CT, possibilitando a delimitação de uma região de interesse, e (2) inicializar a tela do ICCT.

Na FIG.5.2 observa-se um grupo de imagens aberta e uma região de interesse (ROI) selecionada na imagem.

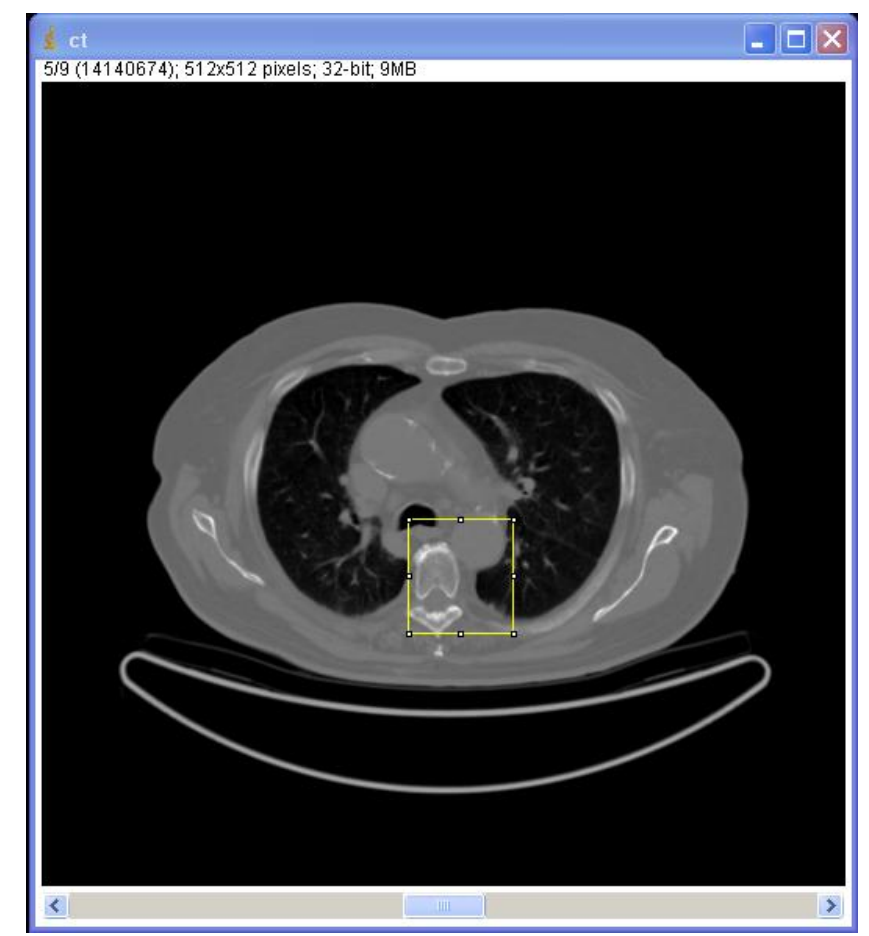

Figura 5.2: Apresentação de um grupo de imagens abertas com uma região de interesse selecionada.

É possivel observar que as imagens estão abertas uma por cima da outra, como se fosse uma "pilha de imagens". Quando delimitada, a região de interesse é extendida para todas as imagens. Caso nenhum ROI seja efetuado, toda a imagem será processada.

Na FIG.5.3 é apresentada a tela inicial do software ICCT e o fluxograma desse módulo é apresentado na FIG.5.4.

Os passos efetuados por esse módulo são:

1. Abrir as imagens de CT e possibilitar a delimitação de uma região de interesse;

2. Inicializar a tela do ICCT; 


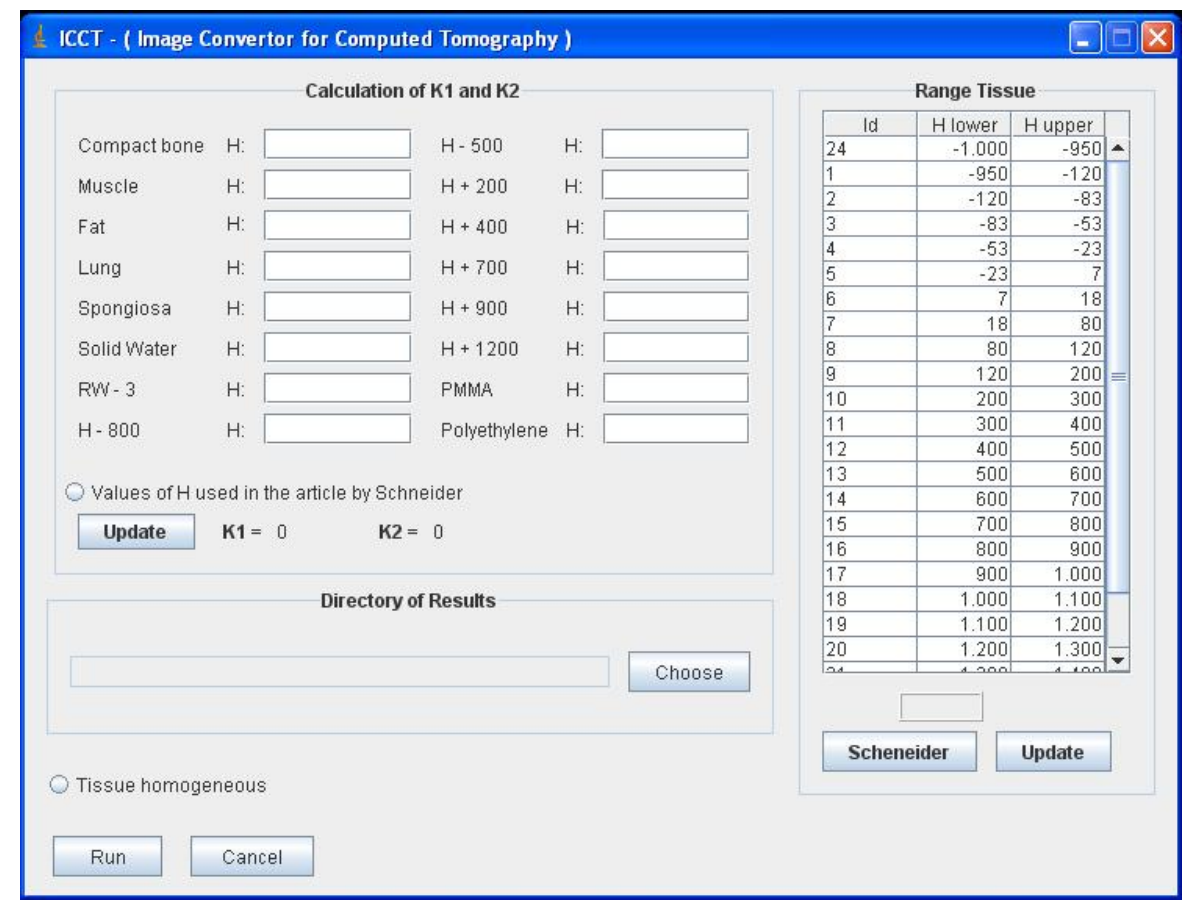

Figura 5.3: Tela do software ICCT.

\section{Módulo 1}

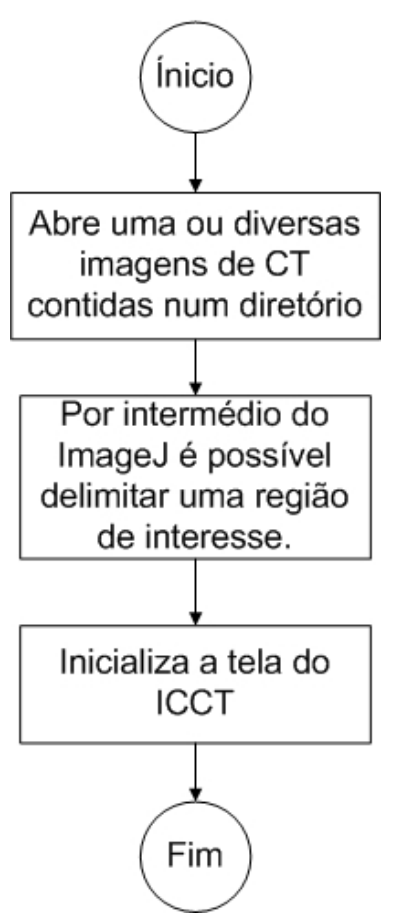

Figura 5.4: Fluxograma do Módulo 1 
O Módulo 2 apresenta duas funções principais: (1) efetuar o cálculo de $k_{1}$ e $k_{2}$ mediante um grupo de 16 objetos simuladores, cujas composições foram extraídas da literatura (Schneider et al., 2000) e (2) calcular a unidade de Hounsfield de 71 tipos de tecidos. O Módulo 1 é acessado na região da tela do ICCT nomeada de "Calculation of $k_{1} e k_{2}$ ".

As composições dos 16 objetos simuladores estão contidas na TAB.5.1.

Tabela 5.1 - Composição dos Objetos Simuladores: densidade $(\rho)$ e as frações me peso $\left(\omega_{i}(f p)\right)$ de cada elemento.

\begin{tabular}{lccccccccccc}
\hline & & \multicolumn{1}{c}{$\omega_{i}(f p)$} \\
\cline { 3 - 11 } Objetos Simuladores & $\rho\left(\mathrm{g} / \mathrm{cm}^{3}\right)$ & $\mathrm{H}$ & $\mathrm{C}$ & $\mathrm{N}$ & $\mathrm{O}$ & $\mathrm{Mg}$ & $\mathrm{Si}$ & $\mathrm{Cl}$ & $\mathrm{Ca}$ & $\mathrm{Ti}$ & $\mathrm{Sn}$ \\
\hline Osso Compacto & 1,84 & 3,1 & 31,26 & 0,99 & 37,57 & - & - & 0,05 & 27,03 & - & - \\
Músculo & 1,05 & 8,1 & 67,17 & 2,42 & 19,85 & - & - & 0,14 & 2,32 & - & - \\
Gordura & 0,92 & 8,5 & 72,88 & 2,24 & 16,25 & - & - & 0,13 & - & - & - \\
Pulmão & 0,3 & 8,36 & 60,43 & 1,67 & 17,33 & 11,36 & 0,72 & 0,13 & - & - & - \\
Esponjosa & 1,14 & 7,9 & 63,79 & 4,23 & 9,88 & - & - & - & 14,2 & - & - \\
Água Sólida & 1,035 & 8,09 & 67,22 & 2,4 & 19,84 & - & - & 0,13 & 2,32 & - & - \\
RW - 3 & 1,045 & 7,59 & 90,41 & - & 0,8 & - & - & - & - & 1,2 & - \\
H - 800 & 0,23 & 7,96 & 64,21 & - & 16,29 & - & 11,48 & - & - & - & 0,06 \\
H - 500 & 0,47 & 8,04 & 45,93 & - & 19,41 & - & 26,48 & - & - & - & 0,14 \\
H + 200 & 1,04 & 7,7 & 31,5 & - & 22,99 & - & 35,66 & - & 1,96 & - & 0,19 \\
H + 400 & 1,12 & 6,35 & 28,07 & - & 27,38 & - & 29,4 & - & 8,64 & - & 0,16 \\
H + 700 & 1,36 & 4,59 & 23,63 & - & 33,09 & - & 21,28 & - & 17,33 & - & 0,06 \\
H + 900 & 1,43 & 3,72 & 21,41 & - & 35,93 & - & 17,21 & - & 21,64 & - & 0,09 \\
H + 1200 & 1,65 & 2,4 & 18,07 & - & 40,21 & - & 11,1 & - & 28,16 & - & 0,06 \\
PMMA & 1,19 & 8,0 & 60,0 & - & 32,0 & - & - & - & - & - & - \\
Polietileno & 0,94 & 14,4 & 85,6 & - & - & - & - & - & - & - & - \\
\hline
\end{tabular}

Os passos seguidos pelo Módulo 2 são:

1. Armazenar os valores de Hounsfield dos objetos simuladores;

2. Efetuar o cálculo de $k_{1}$ e $k_{2}$, mediante o método descrito em Materiais e Métodos na subseção 4.2.2;

3. Apresentar o resultado na tela, numa região pré definida, situada ao lado do botão "Update"; 
4. Calcular a unidade de Hounsfield dos 71 tipos de tecidos.

Todos os tecidos que foram efetuados os cálculos estão contidos na TAB.4.1 e TAB.4.2.

Na FIG.5.5 é apresentado o fluxograma correspondente a esse módulo.

\section{Módulo 2}

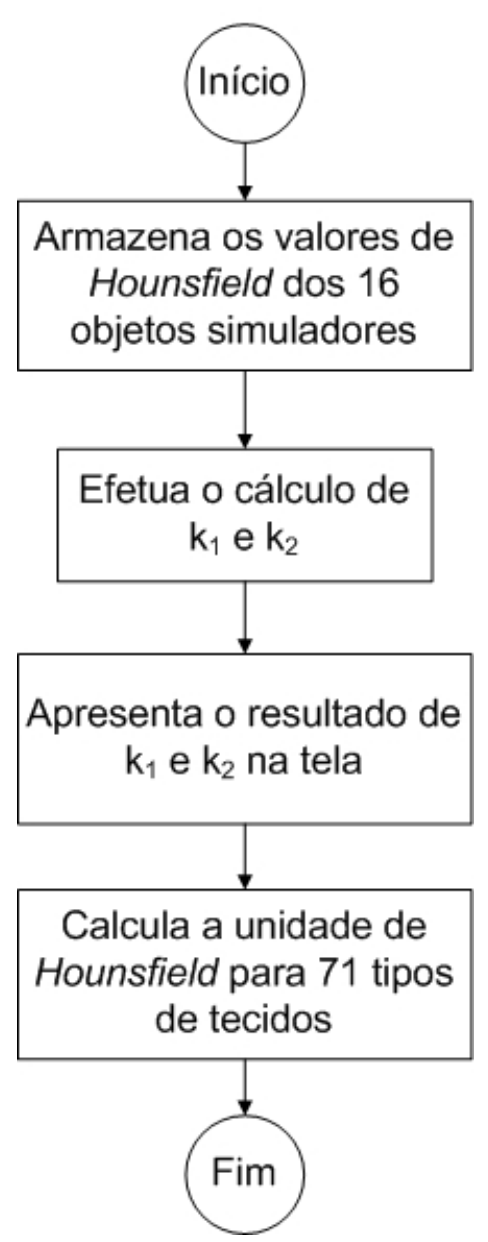

Figura 5.5: Fluxograma do Módulo 2.

O Módulo 3 apresenta uma função em especial: subdividir os tecidos do corpo em diferentes intervalos na escala de Hounsfield. Esse módulo esta situado na região da tela principal chamda"Tissue Range".

O principal motivo da necessidade de subdividir a escala de Hounsfield é devido a imprecisão ocorrida entre o valor medido e o calculado.

Assim, para determinar a quantidade dos intervalos é necessário analisar dois pontos importantes: (1) o tempo de cálculo da dose por intermédio do método de Monte Carlo, 
que aumenta a medida que o número de intervalos aumenta e (2) ao passo que a quantidade de intervalos diminui, maior é a imprecisão na determinação da composição do tecido o que prejudica o cálculo da dose.

De início, optou-se po subdividir a escala de Hounsfield da mesma forma sugerida por Schneider et al. (2000) e manter a quantidade de intervalos constante, possibilitando fazer somente determinados ajustes na largura entre os intervalos.

Assim, a escala de Hounsfield foi subdividida em 24 grupos: um grupo para o ar com valores de $H$ entre -1000 a -950; um grupo para o tecido pulmonar, com valores de $H$ entre -949 a -120; sete grupos de tecidos moles com valores de $H$ entre -119 a 120 e 15 grupos para os tecidos ósseos com valores de $H$ entre 121 a 1600.

A primeira coluna da tabela presente nesse módulo contêm os índices dos materiais ("tecidos"), a segunda e a terceira coluna contêm os limiares inferiores e superiores na escala de Hounsfield, respectivamente.

É permitido ajustar somente os limiares superiores, porém há algumas restrições:

- O número de Hounsfield calculado pelo ICCT, do pulmão preenchido com sangue, deve estar presente no intervalo do $I D=1$ (Identificador do tecido);

- O número médio de Hounsfield dos 35 tipos de tecidos, calculados pelo ICCT, situados entre a parede do intestino grosso e o tecido conectivo, deve estar presente no intervalo do $I D=7$;

- O número de Hounsfield calculado pelo ICCT, do tecido conectivo, deve estar presente no intervalo do $I D=8$.

Essas restrições estão relacionadas ao modo que o ICCT efetua a conversão da unidade de Hounsfield em parâmetros do tecido e serão entendidas no Módulo 5.

Caso alguma restrição seja violada aparecerá um aviso de erro conforme apresentado na FIG.5.6.

Este aviso de erro informa em qual ID a restrição foi violada e qual o valor de Hounsfield que deveria estar contido neste intervalo.

O botão "Schneider" presente neste módulo pode ser utilizado caso se tenha feito alguma modificação nos limiares e por algum motivo queira-se voltar para os valores empregados por Schneider et al. (2000). 


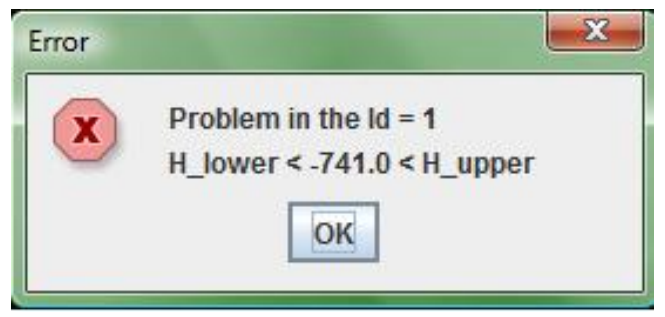

Figura 5.6: Aviso de erro emitido pelo ICCT.

Os passos efetuados pelo Módulo 3 são:

1. Verificar se $k_{1}$ e $k_{2}$ foram calculados;

2. Verificar se todos os limiares superiores estão preenchidos;

3. Verificar se a ordenação dos limiares superiores contidos na terceira coluna estão em ordem crescente;

4. Calcular as unidades de Hounsfield de 71 tecidos listados na TAB.4.1 e TAB.4.2;

5. Verificar as restrições presentes no ID 1, 7 e 8;

6. Armazenar os limiares inferiores e superiores num vetor bidimensional denominado range;

7. Inserir a palavra "Done" num local pré determinado, situado abaixo da tabela.

A FIG.5.7 ilustra o fluxograma correspondente a esse módulo.

O Módulo 4 é utilizado para salvar os dados gerados pelo ICCT numa pasta especificada pelo usuário. Este módulo esta situado na região chamada "Directory of Results". Nesse diretório será gerada uma pasta denominada "Results of Maps" onde os dados gerados pelo ICCT serão salvos.

Os passos efetuados por este módulo são:

1. Armazenar o caminho do diretório em que se dejesa salvar os resultados;

2. Criar um pasta denominada "Results of Maps" dentro do diretório especificado.

O fluxograma desse módulo é apresentado na FIG.5.8. 


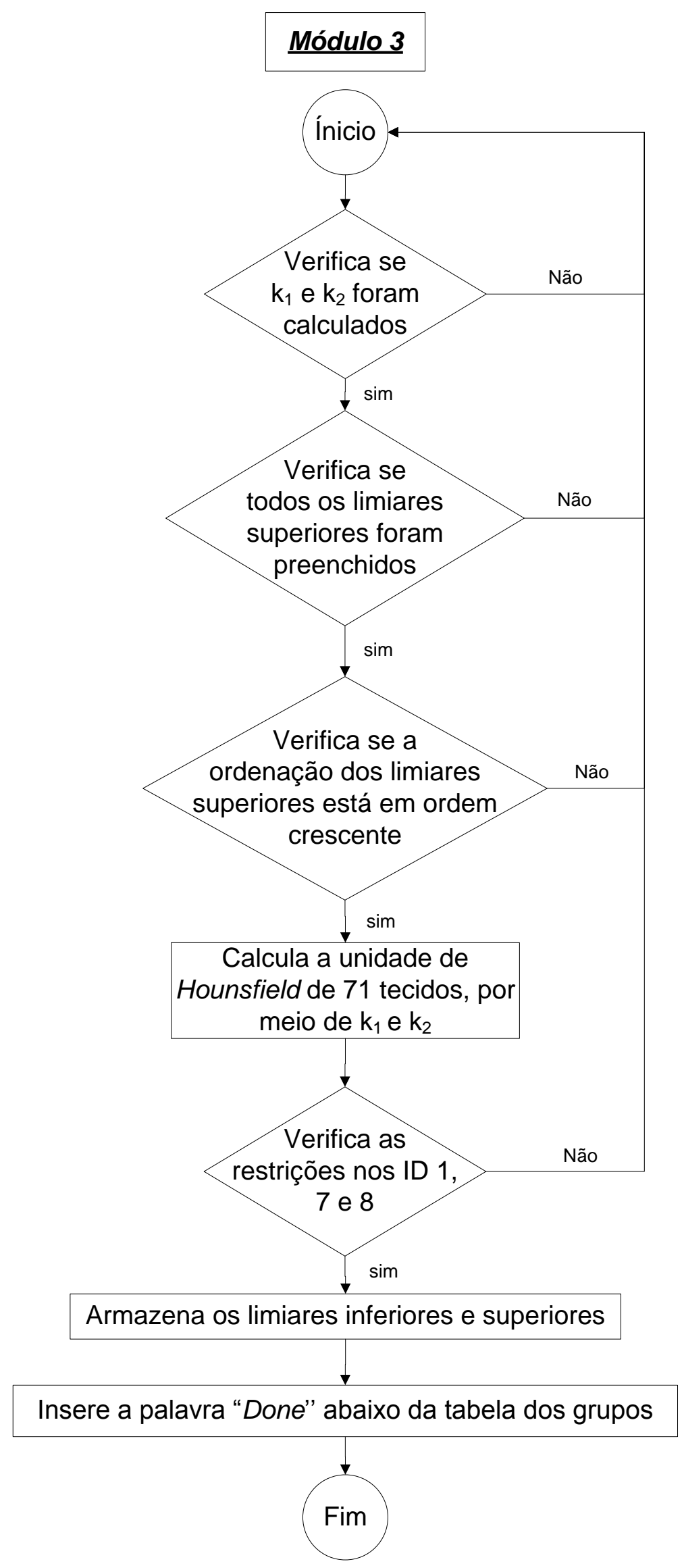

Figura 5.7: Fluxograma do Módulo 3. 


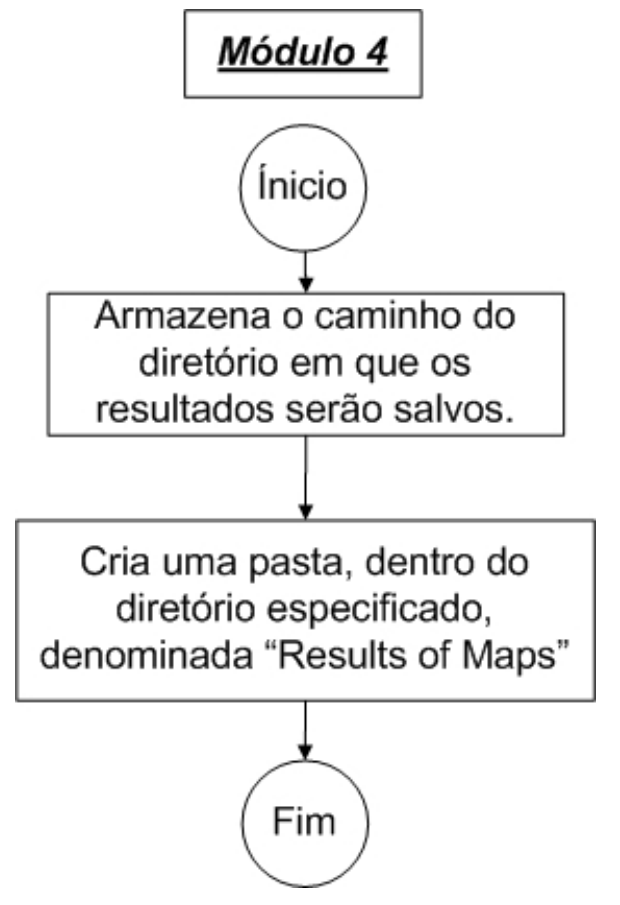

Figura 5.8: Fluxograma do Módulo 4.

O Módulo 5 possui três finalidades: (1) calcular os parâmetros dos tecidos (densidade, $\rho$ e fração peso de cada elemento químico constituinte do tecido, $\left.\omega_{i}\right)$; (2) gerar quatro arquivos, mediante uma análise das imagens de CT, e (3) salvar os resultados no diretório especificado.

Este Módulo apresenta os seguintes passos:

1. Verificar se algum caminho foi especificado;

2. Verificar se o Módulo 3 foi efetuado corretamente;

3. Armazenar o ROI efetuado na imagem, caso este tenha sido feito;

4. Gerar quatro arquivos em formato ASCII, nos quais três são formatados para o SCMS e o outro para o MCNP5.

O item quatro subdivide-se nas seguintes tarefas:

1. Efetuar o cálculo da densidade para os 24 grupos;

2. Efetuar o cálculo da composição de cada elemento do tecido $\left(\omega_{i}\right)$ para os 24 grupos; 
3. Armazenar todas as imagens contidas no diretório de entrada, proveniente do Módulo $1 ;$

4. Para todas as imagens gerar o mapa de tecidos e o mapa de densidade da imagem. Gravar o mapa de tecido num arquivo em formato ASCII denominado "Maps_Tissue" e gravar o mapa de densidade num arquivo em formato ASCII denominado "Maps_Density";

5. Após ler todas as imagens, a composição de todos os grupos presentes nas imagens são gravadas em um arquivo em formato ASCII denominado "Components";

6. Gravar uma tabela em formato ASCII denominada "Table_MDId", contendo as mnemónicas dos materiais com suas respectivas densidades e identificadores, para todos os grupos presentes nas imagens.

O mapa de tecido é uma matriz que contêm os identificadores dos tecidos $(I D)$, organizados de tal forma a representar a secção do corpo do paciente. O mapa de densidade é uma matriz que contêm as densidades relacionadas aos identificadores, organizadas da mesma forma que o mapa de tecidos. Todas as imagens analisadas, em relação ao mapa de tecido e densidade, gravarão seus resultados no mesmo arquivo, isto é, todos os mapas de tecidos estarão em "Maps_Tissue" e todos os mapas de densidade estarão em "Maps_Density".

Cada grupo possui um intervalo na escala de Hounsfield e um índice que identifica os tecidos compreendidos nesse intervalo. Dentro de cada grupo os parâmetros do tecido $\left(\rho, \omega_{i}\right)$ são os mesmos.

Os dois primeiros grupos são o $\operatorname{ar}(I D=24)$ e o pulmão $(I D=1)$. A composição do ar foi extraída da literatura, com sua densidade igual a 0,00121 g.cm ${ }^{-3}$ (Scheneider et al., 2000). A composição do pulmão foi estabelecida como sendo a composição do pulmão preenchido com sangue (ver TAB.4.1), juntamente com sua respectiva densidade igual a $0,296 \mathrm{~g} \cdot \mathrm{cm}^{-3}$.

A TAB.5.2 mostra os índices desses grupos com seus respectivos intervalos na escala de Hounsfield e com o parâmetro $\omega_{i}$ de cada elemento químico desse grupo que foram implementados no software ICCT. 
Tabela 5.2 - Grupo do ar e do pulmão com a fração em peso de cada elemento químico.

\begin{tabular}{ccccccccccccc}
\hline & & \multicolumn{10}{c}{$\omega_{i}(f p)$} \\
\cline { 3 - 12 } $\mathrm{ID}$ & $\mathrm{H}$ (Inferior) & $\mathrm{H}$ (Superior) & $\mathrm{H}$ & $\mathrm{C}$ & $\mathrm{N}$ & $\mathrm{O}$ & $\mathrm{Na}$ & $\mathrm{P}$ & $\mathrm{S}$ & $\mathrm{Cl}$ & $\mathrm{Ar}$ & $\mathrm{K}$ \\
\hline 24 & -1000 & -950 & - & - & 75,5 & 23,2 & - & - & - & - & 1,3 & - \\
1 & -950 & -120 & 10,3 & 10,5 & 3,1 & 74,9 & 0,2 & 0,2 & 0,3 & 0,3 & - & 0,2 \\
\hline
\end{tabular}

Nesses dois grupos, mesmo que sejam modificados os limites superiores, não ocorrerá mudanças nas frações em peso dos elementos químicos contidos nesses grupos.

Os próximos sete grupos estão relacionados aos tecidos moles. A TAB.5.3 apresenta os índices do grupos de tecidos moles com seus respectivos intervalos na escala de Hounsfield.

Tabela 5.3 - Grupos do tecido mole os intervalos de Hounsfield correspondentes.

\begin{tabular}{ccc}
\hline ID & $H$ (Inferior) & $H$ (Superior) \\
\hline 2 & -120 & -83 \\
3 & -83 & -53 \\
4 & -53 & -23 \\
5 & -23 & 7 \\
6 & 7 & 18 \\
7 & 18 & 80 \\
8 & 80 & 120 \\
\hline
\end{tabular}

O tecido mole possui duas equações de interpolação para transformar a unidade de Hounsfield em frações em peso de um elemento químico presente no tecido $\left(\omega_{i}\right)$. A primeira é a Eq.(4.25) compreendida entre o tecido adiposo 3 e a glândula adrenal. A segunda a Eq.(4.27) compreendida entre a parede do intestino grosso e o tecido conectivo.

O parâmetro do tecido $\left(\omega_{i}\right)$ dos grupos com $I D$ entre $I D=2 I D=6$, foram encontrados mediante o valor médio estipulado pelos limiares inferiores e superiores, em unidades de Hounsfield, para cada intervalo. Esses valores foram utilizados na equação de interpolação Eq.(4.25) para obter a fração em peso de cada elemento do tecido referente ao grupo a que pertence.

Para esses cincos grupos citados anteriormente, fica claro que, a medida que se modifica os limites superiores, ocorrerá variações nas medidas das frações em peso dos elementos 
químicos contidos nesses grupos.

O grupo sete está no intervalo da equação de interpolação, Eq.(4.27), porém, tal grupo não foi subdividido pois os tecidos nele contidos que possuem valores de Hounsfield entre 23 e 100, estão no conjunnto dos tecidos que possuem uma fraca correlação com a unidade de Hounsfield, isto é verificado na FIG.4.2 cujos valores dos tecidos na escala de Hounsfield entre 0 e 100 são ortogonais à hipérbole.

Assim, esse grupo calcula o parâmetro, $\omega_{i}$, de cada elemento químico do tecido, com base nas médias dos parâmetros referentes aos 35 tipos de tecidos contidos no intervalo entre a parede do intestino grosso e o tecido conectivo. O valor da densidade nesse grupo é de $1,06 \mathrm{~g} \cdot \mathrm{cm}^{-3}$.

O grupo 8 representa o tecido mole de elevada unidade de Hounsfield e recebe o parâmetro $\omega_{i}$, de cada elemento químico, do tecido conectivo, contidos na TAB.4.1. A densidade para esse grupo é de $1,07 \mathrm{~g} . \mathrm{cm}^{-3}$.

A TAB.5.4 apresenta os parâmetros do tecido referente aos $I D=7$ e $I D=8$.

Tabela 5.4 - Grupos de tecido mole, $I D=7$ e $I D=8$, com a fração em peso de cada elemento químico.

\begin{tabular}{cccccccccccc}
\hline & & \multicolumn{10}{c}{$\omega_{i}(f p)$} \\
\cline { 3 - 10 } ID & H (Inferior) & $\mathrm{H}$ (Superior) & $\mathrm{H}$ & $\mathrm{C}$ & $\mathrm{N}$ & $\mathrm{O}$ & $\mathrm{Na}$ & $\mathrm{P}$ & $\mathrm{S}$ & $\mathrm{Cl}$ & $\mathrm{K}$ \\
\hline 7 & 18 & 80 & 10,3 & 13,4 & 3,0 & 72,3 & 0,2 & 0,2 & 0,2 & 0,2 & 0,2 \\
8 & 80 & 120 & 9,4 & 20,7 & 6,2 & 62,2 & 0,6 & - & 0,6 & 0,3 & - \\
\hline
\end{tabular}

Nesses dois últimos grupos é evidente que mesmo ao modificar os limites superiores não ocorrerá variações nas frações em peso dos elementos químicos contidos nesses grupos.

O tecido esquelético é divido em 15 grupos do $I D=9$ a $I D=23$ e o cálculo do parâmetro do tecido $\left(\omega_{i}\right)$ é efetuado para todos os grupos, por intermédio da equação de interpolação Eq.(4.23) que possui como primeira componente a medula amarela/vermelha e como segunda o osso cortical.

O valor da unidade de Hounsfield utilizado para o cálculo do parâmetro $\omega_{i}$ sempre é considerado o valor médio entre os valores limiares de cada grupo. 
Em relação ao parâmetro da densidade $(\rho)$, o software ICCT efetua o cálculo para todos os grupos citados anteriormente. Primeiramente, para realizar os cálculos, foram utilizadas as Eq.(4.22), Eq.(4.24), Eq.(4.26) e outras funções para correlacionar a unidade de Hounsfield com os valores de densidade do tecido do corpo.

Dessa forma, no intervalo da escala de Hounsfield de -1000 até o valor do tecido adiposo 3 foi utilizada uma equação da reta entre estes dois extremos com a densidade no primeiro extremo igual a $0,00121 \mathrm{~g} \cdot \mathrm{cm}^{-3}$.

Entre o tecido adiposo 3 e o tecido conectivo são utilizadas duas equações de interpolação diferentes: Eq.(4.24) que possui como primeira componente o tecido adiposo 3 e como segunda a glândula adrenal; e Eq.(4.26) que possui a primeira componente a parede do intestino grosso e a segunda o tecido conectivo.

Entre a segunda componente, a glândula adrenal, da Eq.(4.24) e a primeira componente, parede do intestino grosso, da Eq.(4.26), há um gap, e nesse caso o ICCT considera a densidade constante, com valor de $1,03 \mathrm{~g} \cdot \mathrm{cm}^{-3}$.

Para valores da unidade de Hounsfield acima do tecido conectivo, a densidade foi calculada através da Eq.(4.22) em que possui a primeira componente é a medula amarela/vermelha (1:1) e a segunda é o osso cortical.

A FIG.5.9 mostra a correlação da unidade de Hounsfield com a densidades $(\rho)$.

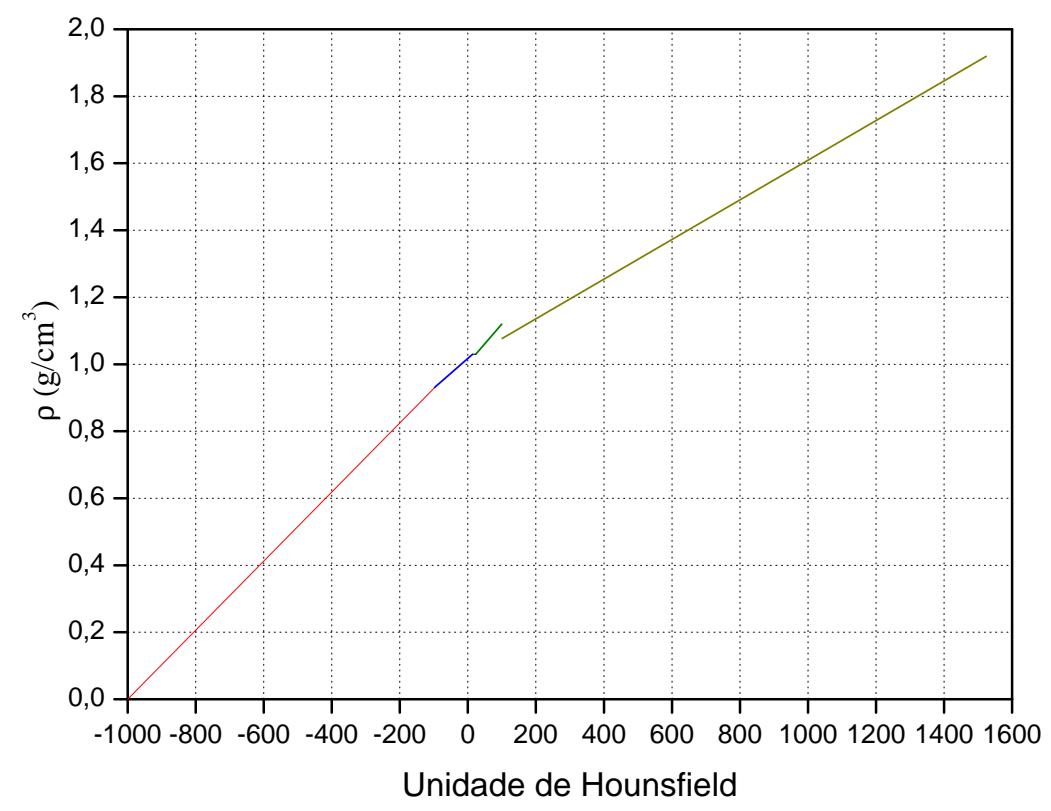

Figura 5.9: Correlação da unidade de Hounsfield com a densidade. 
Na FIG.5.10 observa-se de maneira mais clara o intervalo entre as unidades de Hounsfield de 0 à 120 .

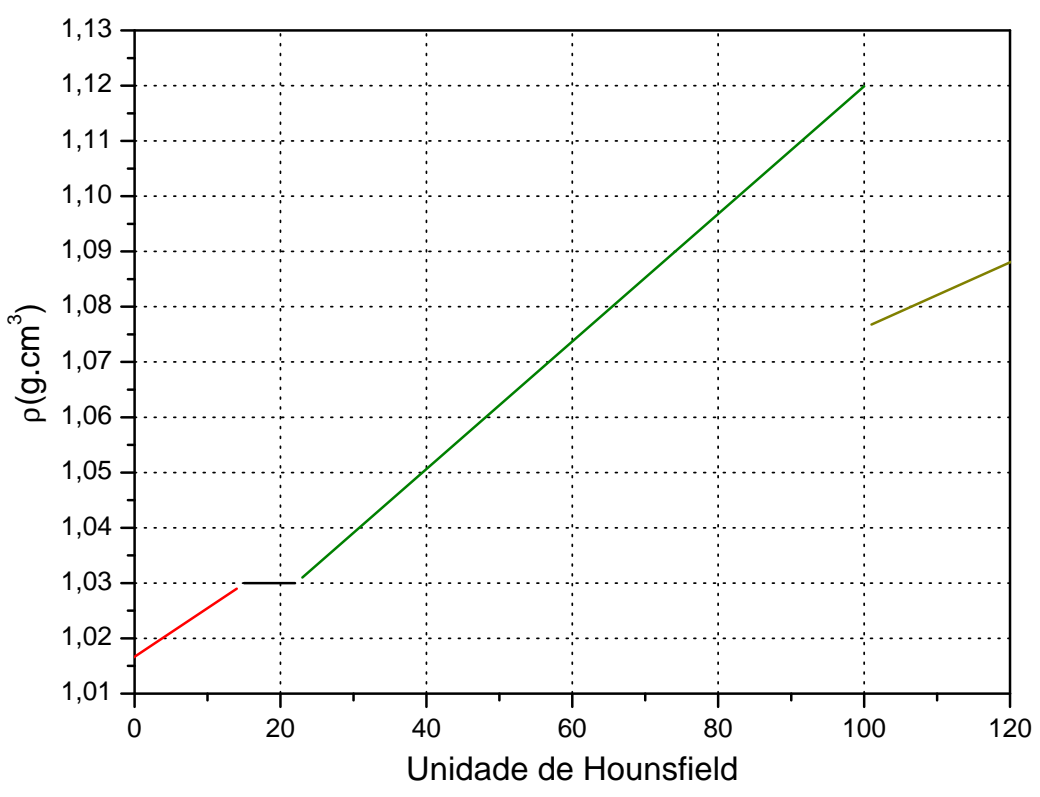

Figura 5.10: Correlação da unidade de Hounsfield com a densidade. Ampliação da região de $H$ de 0 á 120 da FIG.5.9.

Desta forma, o valor da densidade em cada grupo é calculado com base nas funções descritas anteriormente com a utilização dos valores médios da unidade de Hounsfield de cada grupo.

Com base no que foi dito sobre a maneira pelo qual foi efetuado o cálculo dos parâmetros do tecido, fica mais claro o entendimento das restrições. Em relação ao $I D=1$, ele identifica o tecido pulmonar, então é de se esperar que a unidade de Hounsfield do tecido pulmonar calculada baseando-se nos dados da literatura, esteja presente nesse intervalo. No $I D=7$, como os parâmetros do tecido foram encontrados por meio da média dos parâmetros dos 35 tipos de tecidos entre a parede do intestino grosso e o tecido conectivo, é esperado que o número de Hounsfield médio entre esses 35 tipos de tecidos esteja contido neste intervalo. Como o $I D=8$ é composto pelos parâmetros do tecido conectivo, é de se esperar que esse esteja contido neste intervalo. O fluxograma do Módulo 5, está representado na FIG.5.11 


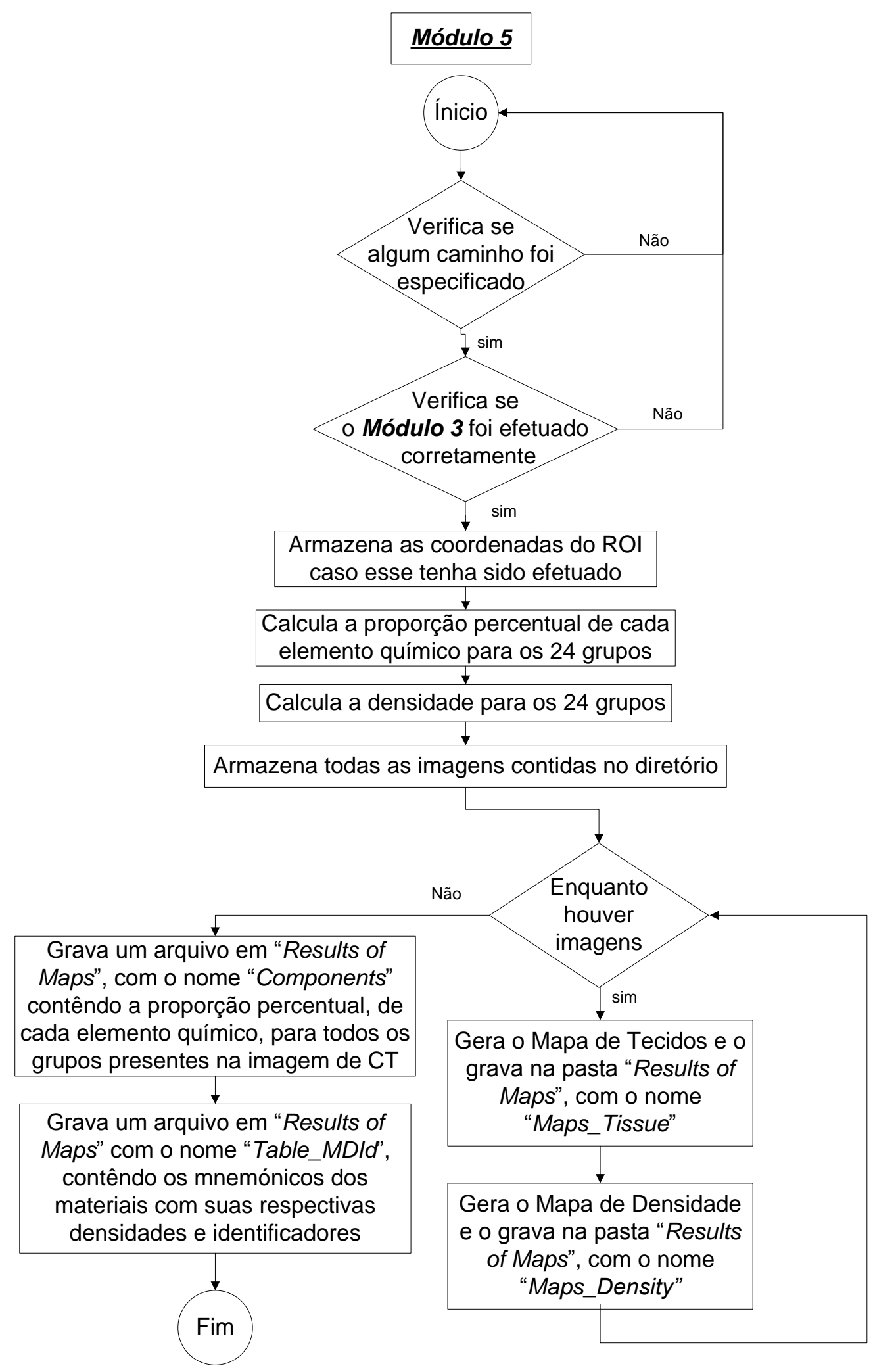

Figura 5.11: Fluxograma do Módulo 5.

De forma geral, o ICCT pode ser descrito como o esquema apresentado na FIG.5.12. 


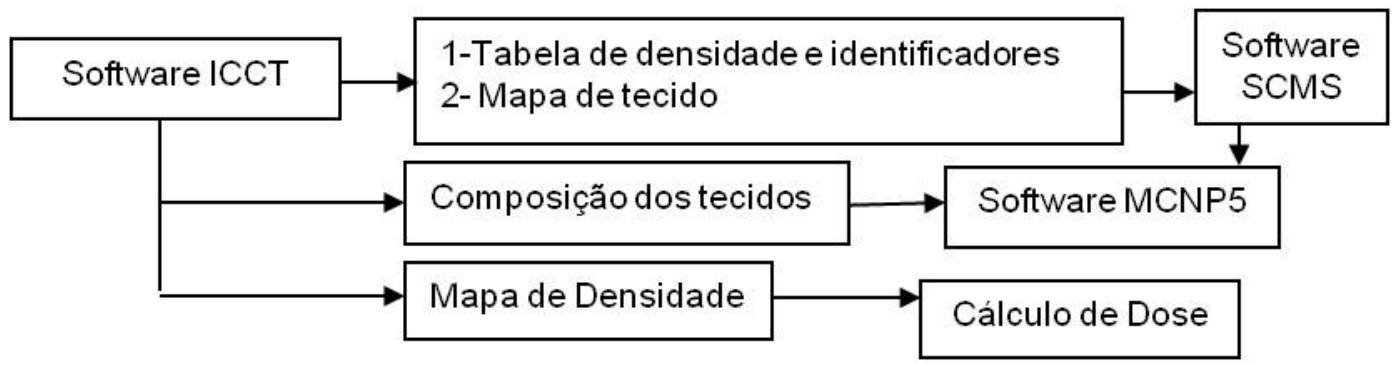

Figura 5.12: Esquema da utilização do ICCT para fornecer dados para o SCMS e para o MCNP5.

O software processa as imagens de CT fornecidas e gera quatro resultados: (1) mapa de densidade, (2) mapa de tecido, (3) tabela da densidade relacionada com os identificadores e (4) uma saída da composição dos tecidos, sendo que todas estas saídas estão em formato de texto.

O mapa de tecido e a tabela de materiais estão formatados para servirem de dados de entrada para o software SCMS. Os dados da composição estão formatados para servirem de dado de entrada para o código MCNP5. Por fim, o mapa da densidade é utilizado para estimar a dose em cada voxel após o código MCNP5 fornecer a tabela de energia depositada por voxel.

\subsubsection{Testes efetuados no Software ICCT}

Uma das formas de testar o Módulo 1 do ICCT seria por intermédio das medidas do número de Hounsfield dos 16 objetos simuladores. Porém, isto não foi possível, pois não havia disponível esses objetos simuladores.

Foi proposto então comparar os dados gerados pelo ICCT, com os dados adquiridos por Schneider et al. (2000). Primeiramente foram obtidos os valores de $k_{1}$ e $k_{2}$ mediante as unidade de Hounsfield dos objetos simuladores medidos por Schneider et al. (2000). Em seguida esses valores foram comparados com os adquiridos por Schneider et al. (2000).

Os valores de $k_{1}$ e $k_{2}$ obtidos pelo ICCT, foram: $k_{1}=1,23 \times 10^{-3}$ e $k_{2}=3,06 \times 10^{-5}$, já Schneider et al. (2000) obtiveram valores $k_{1}=1,24 \times 10^{-3}$ e $k_{2}=3,06 \times 10^{-5}$. Foi observado uma pequena diferença no valor de $k_{1}(0,8 \%)$. Isso mostra uma alta precisão do software ICCT em resolver o sitema de equação não linear e encontrar $k_{1}$ e $k_{2}$. As diferenças ocorridas foram devido à pequenas variações nas especificações das massas e 
números atômicos dos elementos químicos e a erros de truncamentos.

Outra maneira encontrada para avaliar o Módulo 1 foi obter um gráfico no qual o eixo da abscissa contêm as unidades de Hounsfield dos 71 tecidos adquiridos por Schneider et al. (2000) e o eixo das ordenadas os valores, dos mesmos tecidos, obtidos pelo software ICCT. Esse gráfico é apresentado na FIG.5.13. Com base nesta figura, observa-se uma alta correlação do ICCT com os valores obtidos por Schneider et al. (2000), o que indica que o software efetua de forma correta o cálculo da unidade de Hounsfield dos tecidos.

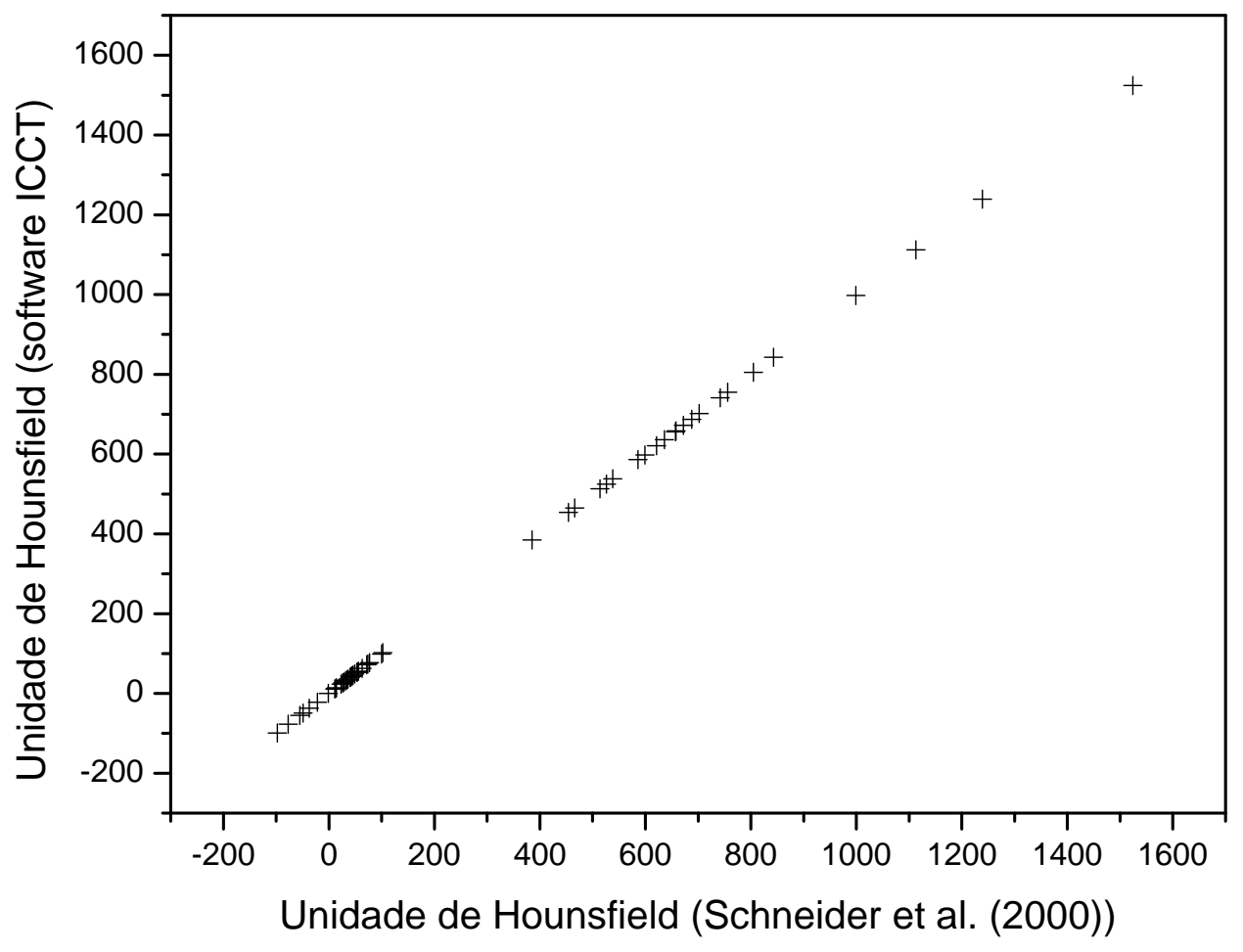

Figura 5.13: Comparação do cálculo do número de Hounsfield entre ICCT e Schneider et al. (2000).

Na TAB.5.5 apresenta-se os valores da unidade de Hounsfield calculados pelo ICCT para os tecidos moles contidos na TAB.4.1. E na TAB.5.6, apresentam-se os valores da unidade de Hounsfield dos tecidos esqueléticos contidos na literatura (Woodard et al., 1986).

Tabela 5.5 - Unidade de Hounsfield dos tecidos esqueléticos calculada pelo software ICCT.

\begin{tabular}{lclc}
\hline Tecido Mole & Hounsfield & Tecido Mole & Hounsfield \\
\hline Pulmão preenchido de sangue & -741 & Aorta & 43 \\
Continua na próxima página... & & & 4
\end{tabular}


Tabela 5.5 - Continuação

\begin{tabular}{|c|c|c|c|}
\hline Tecido Mole & Hounsfield & Tecido Mole & Hounsfield \\
\hline Tecido adiposo 3 & -99 & Coração 2 & 43 \\
\hline Tecido adiposo 2 & -77 & Rins 2 & 43 \\
\hline Tecido adiposo 1 & -55 & Fígado 1 & 43 \\
\hline Glândula mamária 1 & -37 & Músculo estriado 2 & 43 \\
\hline Glândula mamária 2 & 0 & Músculo estriado 3 & 44 \\
\hline Cérebro (fluído cérebro espinhal) & 13 & Coração 3 & 45 \\
\hline Glândula adrenal & 14 & Glândula mamária 3 & 45 \\
\hline Intestino grosso (parede) & 23 & Rins 3 & 46 \\
\hline Urina & 26 & Ovários & 46 \\
\hline Vesícula biliar & 27 & Lente ocular & 49 \\
\hline Sistema linfático & 29 & Fígado 2 & 53 \\
\hline Pâncreas & 32 & Traquéia & 54 \\
\hline Próstata & 34 & Baço & 54 \\
\hline Cérebro (massa branca) & 34 & Coração preenchido de sangue & 56 \\
\hline Testículos & 36 & Sangue & 56 \\
\hline Cérebro (massa cinza) & 40 & Fígado 3 & 63 \\
\hline Músculo estriado 1 & 40 & Pele 1 & 72 \\
\hline Estômago & 41 & Pele 2 & 74 \\
\hline Coração 1 & 41 & Pele 3 & 77 \\
\hline Rins 1 & 41 & Tecidos conectivos & 99 \\
\hline Tireóide & 42 & & \\
\hline
\end{tabular}

Tabela 5.6 - Unidade de Hounsfield dos tecidos esqueléticos calculada pelo software ICCT.

\begin{tabular}{|c|c|c|c|}
\hline Tecido esquelético & Hounsfield & Tecido esquelético & Hounsfield \\
\hline Medula amarela & -49 & $2^{\mathrm{a}}, 6^{\mathrm{a}}$ Costela (homem) & 656 \\
\hline Medula amarela / vermelha & -23 & Osso inominado (homem) & 658 \\
\hline Medula vermelha & 11 & C4 excluindo cartilagem (homem) & 672 \\
\hline Cartilagem & 102 & Fêmur (osso total) & 687 \\
\hline Esterno & 385 & Fêmur & 702 \\
\hline Sacro (homem) & 454 & Osso inominado (mulher) & 741 \\
\hline D6, L3 incluindo cartilagem (homem) & 465 & Clavícula, escápula & 755 \\
\hline D6, L3 excluindo cartilagem (homem) & 525 & Úmero (eixo cilíndrico) & 805 \\
\hline Úmero (cabeça) & 538 & $10^{\mathrm{a}}$ Costela (homem) & 843 \\
\hline
\end{tabular}


Tabela 5.6 - Continuação

\begin{tabular}{lclc}
\hline Tecido esquelético & Hounsfield & Tecido esquelético & Hounsfield \\
\hline Fêmur (cabeça) & 538 & Crânio & 998 \\
Fêmur (trocanter conical) & 586 & Mandíbula & 1112 \\
C4 incluindo cartilagem (homem) & 598 & Fêmur (eixo cilíndrico) & 1239 \\
Sacro (mulher) & 621 & Osso cortical & 1524 \\
Úmero & 636 & & \\
\hline
\end{tabular}

A fim de verificar a precisão de cada um dos 24 grupos construídos pelo ICCT, foi realizada uma simulação destes 24 grupos mediante os dados de Schneider et al. (2000). Vale lembrar que os valores de $k_{1}$ e $k_{2}$ estão fortemente ligados ao equipamento de CT e por isso esses 24 grupos que serão apresentados não podem ser utilizados para estimar os parâmetros do tecido de outro equipamento de CT.

Dessa forma, na TAB.5.7 apresentam-se os 24 grupos construídos pelo ICCT.

Tabela 5.7 - Parâmetros do tecido $\left(\rho, \omega_{i}\right)$, construídos pelo ICCT, dos 24 grupos.

\begin{tabular}{|c|c|c|c|c|c|c|c|c|c|c|c|c|c|c|c|}
\hline \multirow[b]{2}{*}{$I D$} & \multirow[b]{2}{*}{$H$ (Inferior) } & \multirow[b]{2}{*}{$H$ (Superior) } & \multirow[b]{2}{*}{$\rho\left(\mathrm{g} / \mathrm{cm}^{3}\right)$} & \multicolumn{12}{|c|}{$\omega_{i}(p p)$} \\
\hline & & & & $\mathrm{H}$ & $\mathrm{C}$ & $\mathrm{N}$ & $\mathrm{O}$ & $\mathrm{Na}$ & $\mathrm{Mg}$ & $\mathrm{P}$ & $\mathrm{S}$ & $\mathrm{Cl}$ & $\mathrm{Ar}$ & $\mathrm{K}$ & $\mathrm{Ca}$ \\
\hline 24 & -1000 & -950 & 0,00121 & - & - & 75,5 & 23,2 & - & - & - & - & - & 1,3 & - & - \\
\hline 1 & -950 & -120 & 0,296 & 10,3 & 10,5 & 3,1 & 74,9 & 0,2 & - & 0,2 & 0,3 & 0,3 & - & 0,2 & - \\
\hline 2 & -120 & -83 & 0,88 & 11,6 & 69,1 & 0,1 & 18,9 & 0,1 & - & - & 0,1 & 0,1 & - & - & - \\
\hline 3 & -82 & -53 & 0,96 & 11,3 & 56,2 & 0,9 & 31,2 & 0,1 & - & - & 0,1 & 0,1 & - & - & - \\
\hline 4 & -52 & -23 & 0,98 & 11,0 & 45,5 & 1,6 & 41,4 & - & - & 0,1 & 0,2 & 0,2 & - & 0,1 & - \\
\hline 5 & -22 & 7 & 1,01 & 10,8 & 35,3 & 2,2 & 51,1 & - & - & 0,1 & 0,2 & 0,2 & - & 0,1 & - \\
\hline 6 & 8 & 18 & 1,03 & 10,6 & 28,7 & 2,6 & 57,5 & - & - & 0,1 & 0,2 & 0,2 & - & 0,1 & - \\
\hline 7 & 19 & 80 & 1,06 & 10,3 & 13,4 & 3,0 & 72,3 & 0,2 & - & 0,2 & 0,2 & 0,2 & - & 0,2 & - \\
\hline 8 & 80 & 120 & 1,07 & 9,4 & 20,7 & 6,2 & 62,2 & 0,6 & - & - & 0,6 & 0,3 & - & - & - \\
\hline 9 & 120 & 200 & 1,11 & 9,4 & 45,2 & 2,5 & 35,5 & 0,1 & - & 2,2 & 0,2 & 0,1 & - & 0,1 & 4,6 \\
\hline 10 & 200 & 300 & 1,16 & 8,8 & 42,0 & 2,7 & 36,4 & 0,1 & 0,1 & 3,1 & 0,2 & 0,1 & - & 0,1 & 6,6 \\
\hline 11 & 300 & 400 & 1,22 & 8,1 & 38,7 & 2,9 & 37,3 & 0,1 & 0,1 & 4,0 & 0,2 & 0,1 & - & 0,1 & 8,5 \\
\hline 12 & 400 & 500 & 1,28 & 7,5 & 35,8 & 3,1 & 38,1 & 0,1 & 0,1 & 4,8 & 0,2 & 0,1 & - & 0,1 & 10,3 \\
\hline 13 & 500 & 600 & 1,34 & 7,0 & 33,1 & 3,2 & 38,8 & 0,1 & 0,1 & 5,5 & 0,2 & 0,1 & - & - & 11,9 \\
\hline 14 & 600 & 700 & 1,40 & 6,5 & 30,6 & 3,4 & 39,5 & 0,1 & 0,1 & 6,2 & 0,2 & 0,1 & - & - & 13,4 \\
\hline 15 & 700 & 800 & 1,46 & 6,0 & 28,3 & 3,5 & 40,1 & 0,1 & 0,1 & 6,8 & 0,2 & 0,1 & - & - & 14,8 \\
\hline 16 & 800 & 900 & 1,52 & 5,6 & 26,2 & 3,6 & 40,6 & 0,1 & 0,1 & 7,4 & 0,3 & - & - & - & 16,0 \\
\hline 17 & 900 & 1000 & 1,58 & 5,2 & 24,3 & 3,7 & 41,1 & 0,1 & 0,2 & 7,9 & 0,3 & - & - & - & 17,2 \\
\hline 18 & 1000 & 1100 & 1,64 & 4,8 & 22,5 & 3,8 & 41,6 & 0,1 & 0,2 & 8,4 & 0,3 & - & - & - & 18,3 \\
\hline 19 & 1100 & 1200 & 1,70 & 4,5 & 20,8 & 3,9 & 42,1 & 0,1 & 0,2 & 8,8 & 0,3 & - & - & - & 19,3 \\
\hline
\end{tabular}

Continua na próxima página... 
Tabela 5.7 - Continuação

\begin{tabular}{|c|c|c|c|c|c|c|c|c|c|c|c|c|c|c|c|}
\hline \multirow[b]{2}{*}{$I D$} & \multirow[b]{2}{*}{$H$ (Inferior) } & \multirow[b]{2}{*}{$H$ (Superior) } & \multirow[b]{2}{*}{$\rho\left(\mathrm{g} / \mathrm{cm}^{3}\right)$} & \multicolumn{12}{|c|}{$\omega_{i}(p p)$} \\
\hline & & & & $\mathrm{H}$ & $\mathrm{C}$ & $\mathrm{N}$ & $\mathrm{O}$ & $\mathrm{Na}$ & $\mathrm{Mg}$ & $\mathrm{P}$ & $\mathrm{S}$ & $\mathrm{Cl}$ & $\mathrm{Ar}$ & $\mathrm{K}$ & $\mathrm{Ca}$ \\
\hline 20 & 1200 & 1300 & 1,76 & 4,2 & 19,3 & 4,0 & 42,5 & 0,1 & 0,2 & 9,3 & 0,3 & - & - & - & 20,2 \\
\hline 21 & 1300 & 1400 & 1,82 & 3,9 & 17,8 & 4,1 & 42,9 & 0,1 & 0,2 & 9,7 & 0,3 & - & - & - & 21,1 \\
\hline 22 & 1400 & 1500 & 1,88 & 3,6 & 16,5 & 4,1 & 43,2 & 0,1 & 0,2 & 10,0 & 0,3 & - & - & - & 21,9 \\
\hline 23 & 1500 & 1600 & 1,94 & 3,3 & 15,2 & 4,2 & 43,6 & 0,1 & 0,2 & 10,4 & 0,3 & - & - & - & 22,7 \\
\hline
\end{tabular}

A seguir, os parâmetros dos tecidos de alguns dos 24 grupos foram comparados com os valores das TAB.4.1 e TAB.4.2, e com os valores retirados da ICRP - 110 .

A comparação foi efetuada da seguinte maneira:

- Calculou-se $k_{1}$ e $k_{2}$ mediante os dados fornecidos por Schneider et al. (2000);

- Por intermédio das Eq.(4.5) e Eq.(3.46), adquiriu-se as unidades de Hounsfield dos tecidos contidos nas TAB.4.1 e TAB.4.2 e dos tecidos contidos na ICRP - 110;

- Encontrou-se para cada tecido os seus respectivos grupos mediante a TAB.5.7;

- Para cada tecido, calculou-se a diferença entre os parâmetros $\left(\rho, \omega_{i}\right)$ e verificou-se qual o desvio máximo em cada parâmetro.

Para os grupos com $I D=2$ ao $I D=6$ e pela TAB.4.1, foram obtidos os seguintes desvios máximos em relação a $\omega_{i}$, em frações em peso $(f p)$, contidos na TAB.5.8.

Tabela 5.8 - Desvios máximos, em frações em peso $(f p)$, obtidos para os grupos de $I D=2$ ao $I D=6$.

\begin{tabular}{ccccccccc}
\hline $\mathrm{H}$ & $\mathrm{C}$ & $\mathrm{N}$ & $\mathrm{O}$ & $\mathrm{Na}$ & $\mathrm{P}$ & $\mathrm{S}$ & $\mathrm{Cl}$ & $\mathrm{K}$ \\
\hline 0,2 & 5,1 & 0,8 & 5,6 & 0,1 & 0,1 & 0,1 & 0,1 & 0,1 \\
\hline
\end{tabular}

Na elaboração da TAB.5.8 os desvios em relação ao tecido do fluído cerebro espinhal, foram desconsiderados devido a valores de desvios altos, principalmente para carbono e oxigênio, que foram de 28, 6 e 30, 5 frações em peso ( $f p$ ) respectivamente.

Em relação aos demais tecidos, também observou-se que os desvios máximos de carbono e oxigênio foram relativamente elevados em comparação aos demais, em torno de 5 frações 
em peso (TAB.5.8). O desvio máximo encontrado para densidade foi de apenas 0,05 g.cm $\mathrm{cm}^{-3}$.

Os desvios máximos em relação ao parâmetro $\omega_{i}$ do grupo com $I D=7$ estão contidos na TAB.5.9.

Tabela 5.9 - Desvios máximos, em frações em peso $(f p)$, para o grupo de $I D=7$.

\begin{tabular}{ccccccccc}
\hline $\mathrm{H}$ & $\mathrm{C}$ & $\mathrm{N}$ & $\mathrm{O}$ & $\mathrm{Na}$ & $\mathrm{P}$ & $\mathrm{S}$ & $\mathrm{Cl}$ & $\mathrm{K}$ \\
\hline 0,7 & 12,9 & 2,9 & 13,9 & 0,2 & 0,2 & 0,2 & 0,4 & 0,2 \\
\hline
\end{tabular}

Para esse grupo também observa-se altos desvios em relação a carbono e oxigênio, 12,9 e 13,9 fp respectivamente (TAB. 5.9). O desvio máximo encontrado para a densidade foi de apenas $0,04 \mathrm{~g} \cdot \mathrm{cm}^{-3}$.

Os desvios máximos em relação a $\omega_{i}$, em frações em peso $(f p)$, obtidos para os grupo de $I D=2$ ao $I D=8$ comparado com o ICRP-110 estão contidos na TAB.5.10.

Tabela 5.10 - Desvios máximos em relação a $\omega_{i}$, em frações em peso $(f p)$, obtidos para os grupos do tecido mole

\begin{tabular}{ccccccccc}
\hline $\mathrm{H}$ & $\mathrm{C}$ & $\mathrm{N}$ & $\mathrm{O}$ & $\mathrm{Na}$ & $\mathrm{P}$ & $\mathrm{S}$ & $\mathrm{Cl}$ & $\mathrm{K}$ \\
\hline 0,6 & 16,3 & 2,4 & 25,6 & 0,2 & 0,2 & 2,0 & 0,2 & 0,2 \\
\hline
\end{tabular}

Nessa comparação também observou-se altos desvios em relação ao carbono e oxigênio, 16,3 e 25,6 fp respectivamente (TAB.5.10). O desvio máximo encontrado para densidade foi de apenas $0,05 \mathrm{~g} . \mathrm{cm}^{-3}$.

Dessa forma fica claro que, em relação aos tecidos moles, os maiores desvios ocorrem para o carbono e o oxigêneo. É também importante mencionar que nesse intervalo há uma alta precisão na determinação da densidade $\left(0,05 \mathrm{~g} \cdot \mathrm{cm}^{-3}\right)$.

A influência dos altos desvios, encontrados para carbono e oxigênio, em relação a distribuição de dose serão analisados posteriormente.

Os desvios máximos em relação a $\omega_{i}$, em frações em peso $(f p)$, obtidos para os grupos de $I D=9$ ao $I D=23$ mediante a comparação com a TAB.4.2 estão contidos na TAB.5.11. 
Tabela 5.11 - Desvios máximos em relação a $\omega_{i}$, em frações em peso $(f p)$, obtidos para os grupos do tecido esquelético

\begin{tabular}{ccccccccccc}
\hline $\mathrm{H}$ & $\mathrm{C}$ & $\mathrm{N}$ & $\mathrm{O}$ & $\mathrm{Na}$ & $\mathrm{Mg}$ & $\mathrm{P}$ & $\mathrm{S}$ & $\mathrm{Cl}$ & $\mathrm{K}$ & $\mathrm{Ca}$ \\
\hline 0,4 & 9,3 & 0,8 & 9,2 & 0,1 & 0,1 & 0,4 & 0,3 & 0,1 & 0,1 & 1,4 \\
\hline
\end{tabular}

Nos elementos químicos carbono e oxigênio foram observados altos desvios, 9,3 e 9,2 $f p$ respectivamente (TAB.5.11). Para o tecido esquelético é importante mencionar a boa precisão encontrada para hidrogênio, fósforo e cálcio, 0,4, 0,4 e 1,4 fp respectivamente . O primeiro é um elemento importante na distribuição de dose com emissores de fótons e os outros dois são elementos que influenciam grandemente na distribuição de dose para emissores beta. Posteriormente será abordado a influência de cada um desses elementos na distribuição de dose. O desvio máximo encontrado para densidade foi de $0,05 \mathrm{~g} . \mathrm{cm}^{-3}$.

Os desvios máximos em relação a $\omega_{i}$, em frações em peso $(f p)$, para os grupos de $I D=9$ ao $I D=23$ em comparação ao ICRP-110 estão contidos na TAB.5.12.

Tabela 5.12 - Desvios máximos em relação a $\omega_{i}$, em frações em peso $(f p)$, obtidos para os grupos do tecido esquelético

\begin{tabular}{ccccccccccc}
\hline $\mathrm{H}$ & $\mathrm{C}$ & $\mathrm{N}$ & $\mathrm{O}$ & $\mathrm{Na}$ & $\mathrm{Mg}$ & $\mathrm{P}$ & $\mathrm{S}$ & $\mathrm{Cl}$ & $\mathrm{K}$ & $\mathrm{Ca}$ \\
\hline 0,5 & 36,2 & 4,0 & 37,4 & 0,5 & 2,2 & 0,1 & 0,4 & 2,8 & 0,1 & 2,8 \\
\hline
\end{tabular}

Foram observados altos desvios de carbono e oxigênio, 36,2 e 37,4 fp respectivamente, e uma boa precisão para hidrogênio, fósforo e cálcio, 0,5, 0,1 e 2,8 $f p$ respectivamente (TAB.5.12). O desvio máximo encontrado para densidade foi de $0,08 \mathrm{~g} . \mathrm{cm}^{-3}$.

A seguir foi efetuada uma simulação, do ICCT, para apresentar os dados de saída. Para isso, foram processadas duas imagens de CT da região do tórax apresentadas na FIG.5.14. Não foi delimitada nenhuma região de interesse (ROI).

O arquivo "Table_MDId" é apresentado na FIG.5.15. 


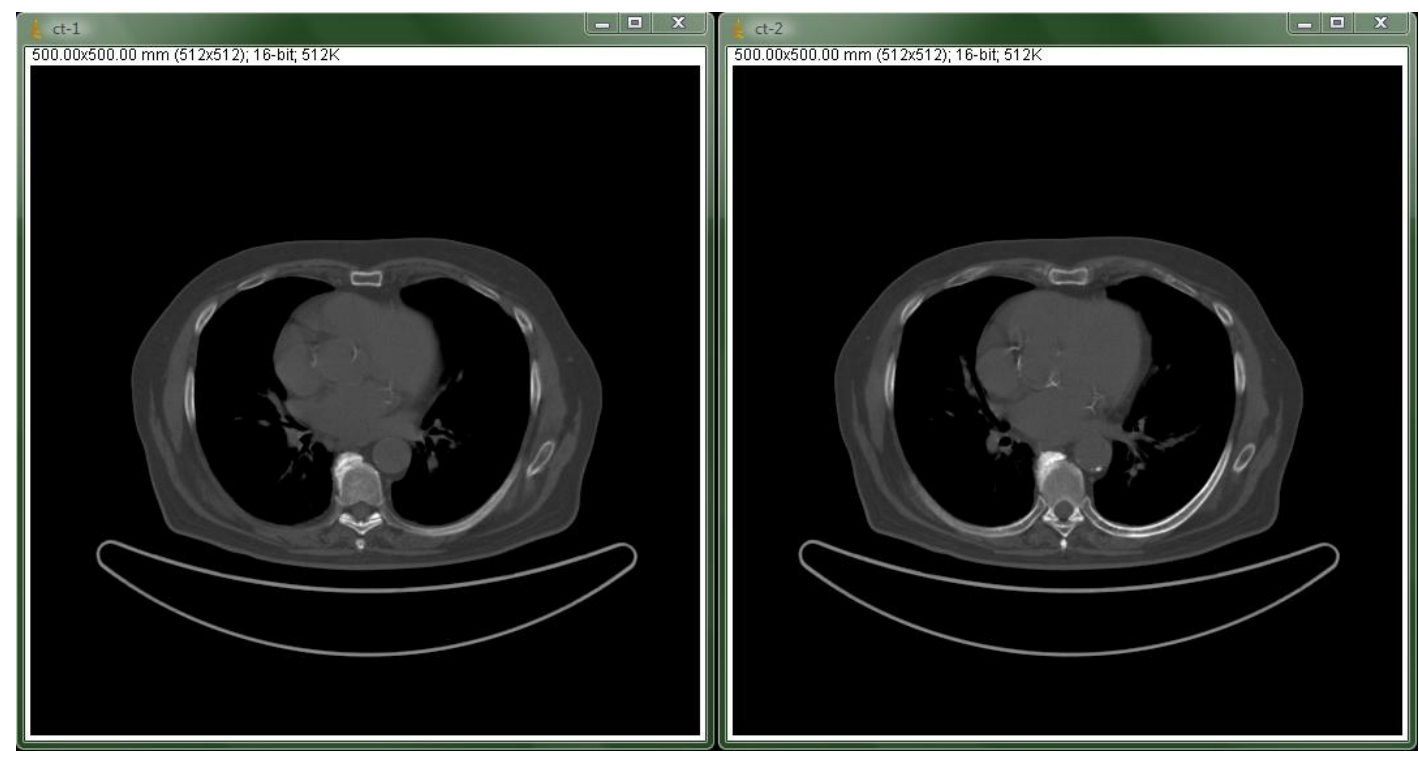

Figura 5.14: Imagens de CT utilizadas para adquirir os resultados do ICCT.

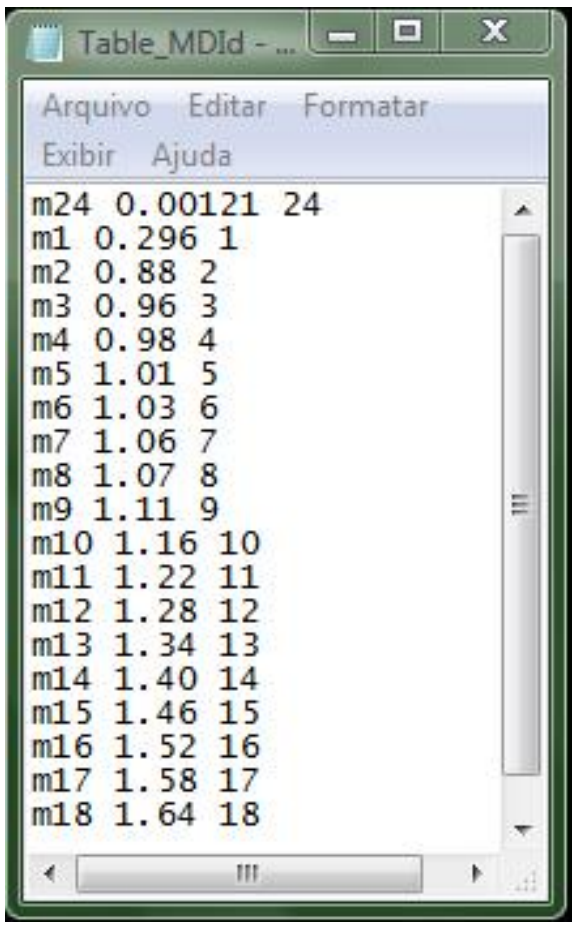

Figura 5.15: Apresentação do arquivo Table_MDId. 
O mapa de tecido e o mapa de densidade são apresentados na FIG.5.16.

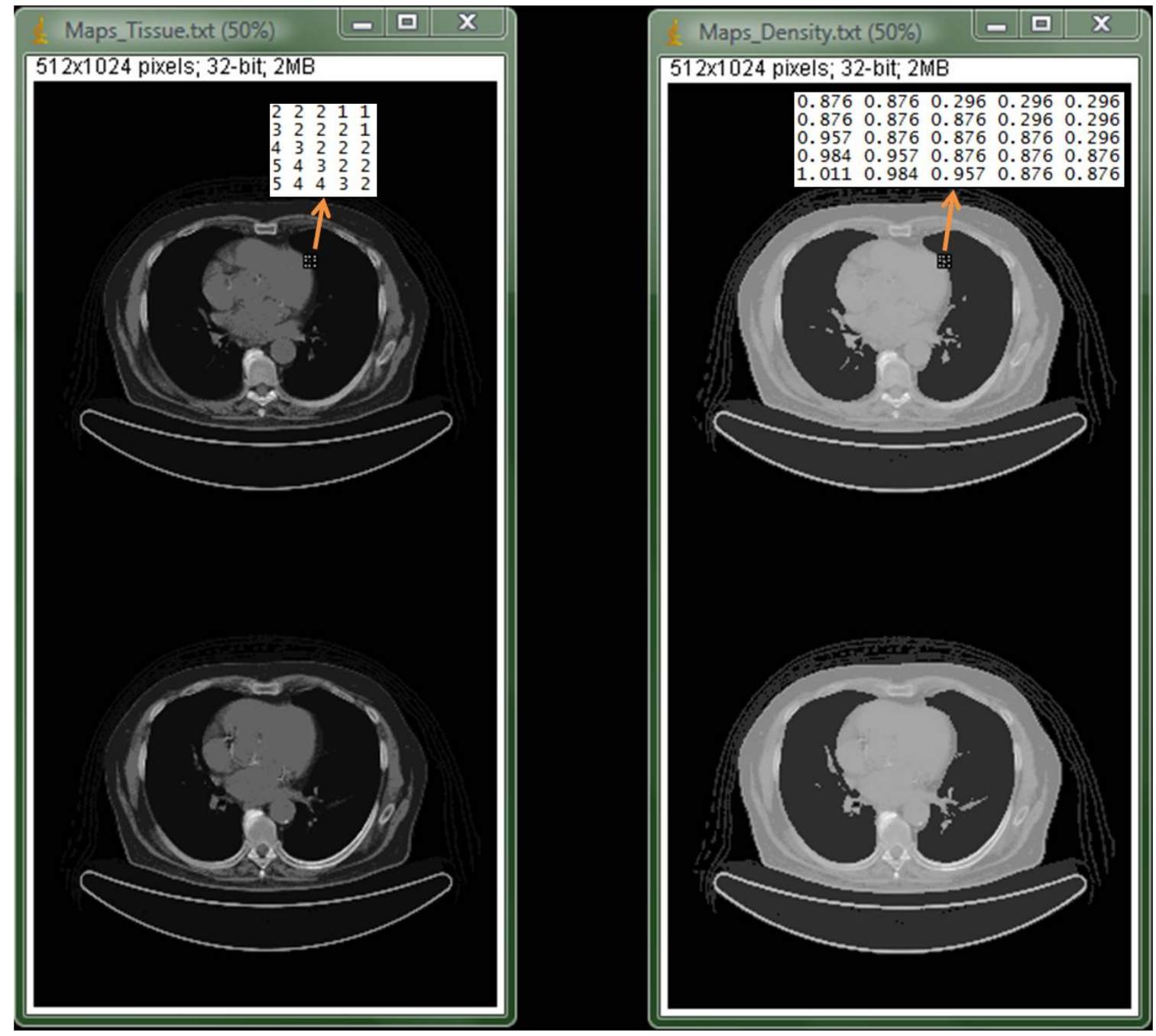

Figura 5.16: Mapa de tecido (à esquerda) e mapa de densidade (direita). 
O arquivo "Components" é apresentado na FIG.5.17.

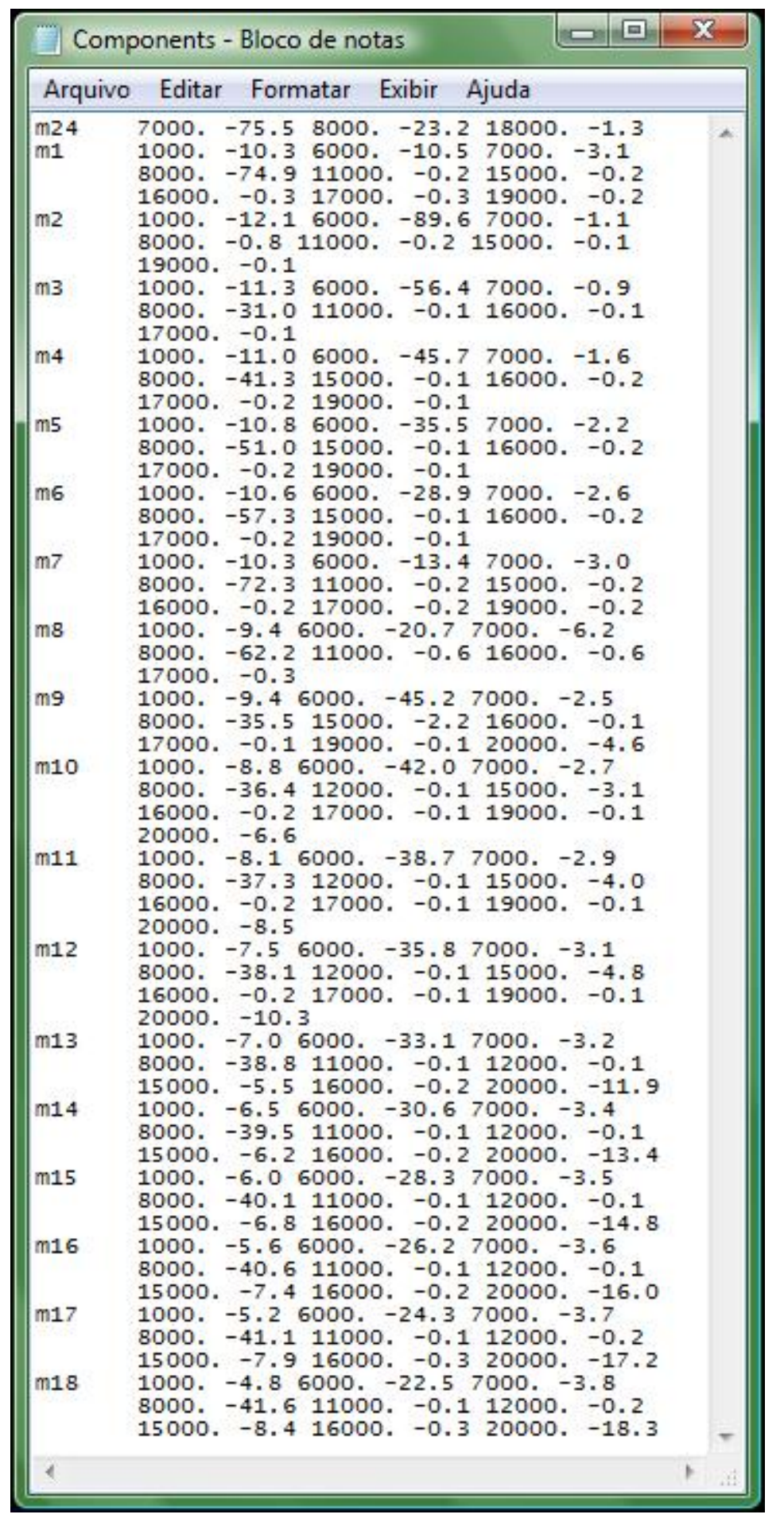

Figura 5.17: Apresentação do arquivo Components. 


\subsection{Software para Correção de Atenuação para imagens PET e SPECT -ACPS}

O software ACPS é composto basicamente por três módulos. Cada módulo possui uma função específica, porém, a combinação dos três possui a única finalidade de armazenar, num arquivo em formato ASCII, a atividade relativa proveniente de uma imagem de SPECT ou PET.

O arquivo gerado servirá como dado de entrada para o software SCMS que por sua vez irá gerar a fonte de radiação interna ao paciente para o MCNP5.

Na FIG.5.18 está apresentado a especificação geral de cada módulo com suas respectivas funções.

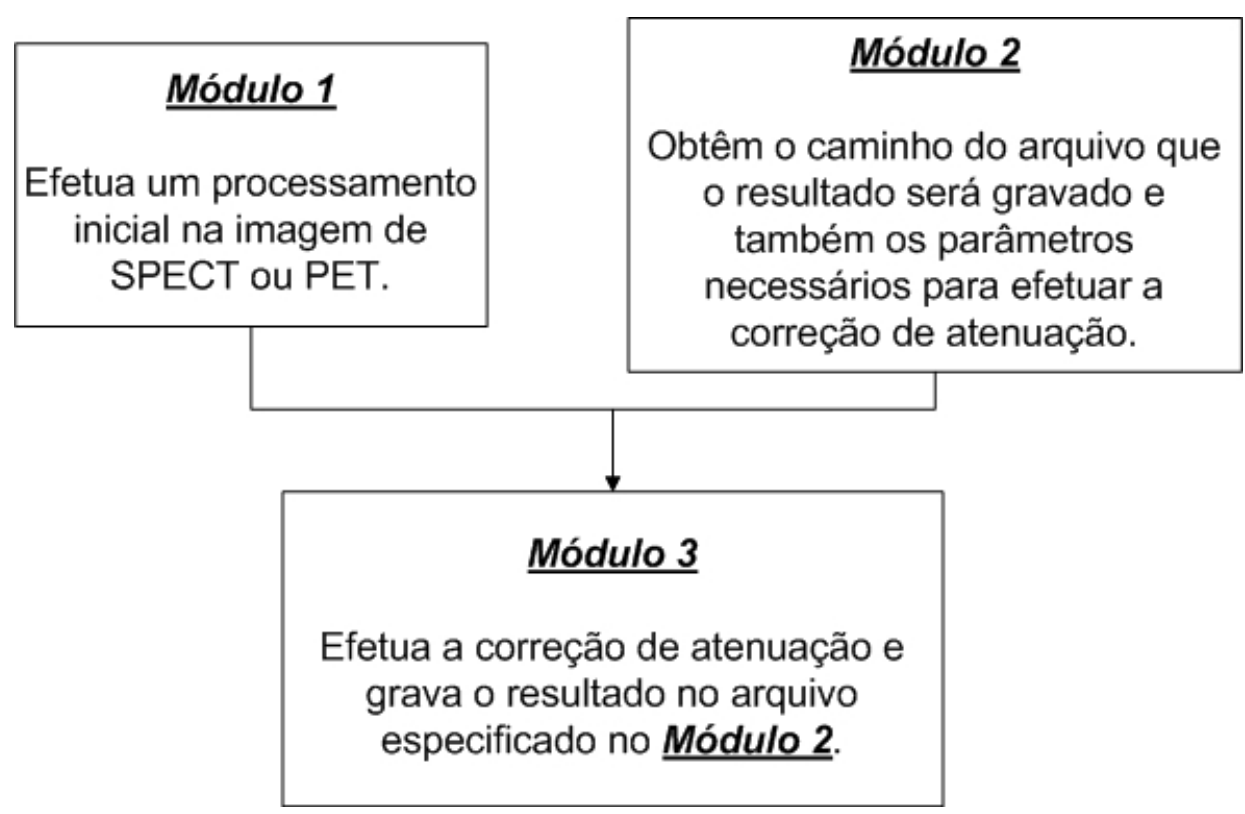

Figura 5.18: Especificação geral de cada módulo e suas respectivas funções.

A seguir cada módulo é descrito de forma detalhada:

\section{MÓDULO 1}

A principal função deste módulo é processar a imagem de tal forma que o método de correção de atenuação possa ser aplicado. Para este módulo ser ativado há a necessecidade de uma imagem (SPECT ou PET) e uma região de interesse (ROI) delimitada nessa imagem. Essa região é referente ao local em que a correção deverá ser efetuada. 
Após esse processo o algoritmo segue os seguintes passos:

1. Gerar uma cópia da imagem original juntamente com a região de interesse;

2. Preencher os pixels da nova imagem que estão fora do ROI com o valor 0;

3. Preencher os pixels no interior do ROI com o valor 1 ;

4. Inicializar a tela inicial do próximo módulo.

O fluxograma desse módulo está apresentado na FIG.5.19.

\section{MÓDULO 2}

Esse módulo possui dois principais objetivos: (1) obter o caminho do arquivo no qual o resultado deverá ser gravado e (2) obter os parâmetros para que a correção de atenuação, mediante o método de Chang de $1^{a}$ ordem homegêneo ou heterogêneo, possa ser realizado.

Na FIG.5.20 é apresentada a tela deste módulo, denominada Parameter for Attenuation Corretion.

Este módulo é dividido em quatro partes:

1. Armazenar o arquivo no qual o resultado será gravado. Essa parte esta situada em Out file text;

2. Armazenar o tipo de correção que será feito (homogênea ou heterogênea) e conforme a situação, habilitar os campos correspondentes;

3. Armazenar as informações caso a correção escolhida seja a heterogênea, caso contrário fica desabilitada. Essa parte esta situada em Map of attenuation Coefficient;

4. Armazenar informações adicionais necessárias para efetuar a correção. Caso a correção seja homogênea os três campos estarão habilitados, caso contrário somente o campo do Attenuation Coefficient será desabilitado. Essa parte esta situada em Additional Information.

Dentre as quatro partes a terceira é subdividida em três sub-passos:

1. Armazenar a imagem do mapa do coeficiente de atenuação linear; 


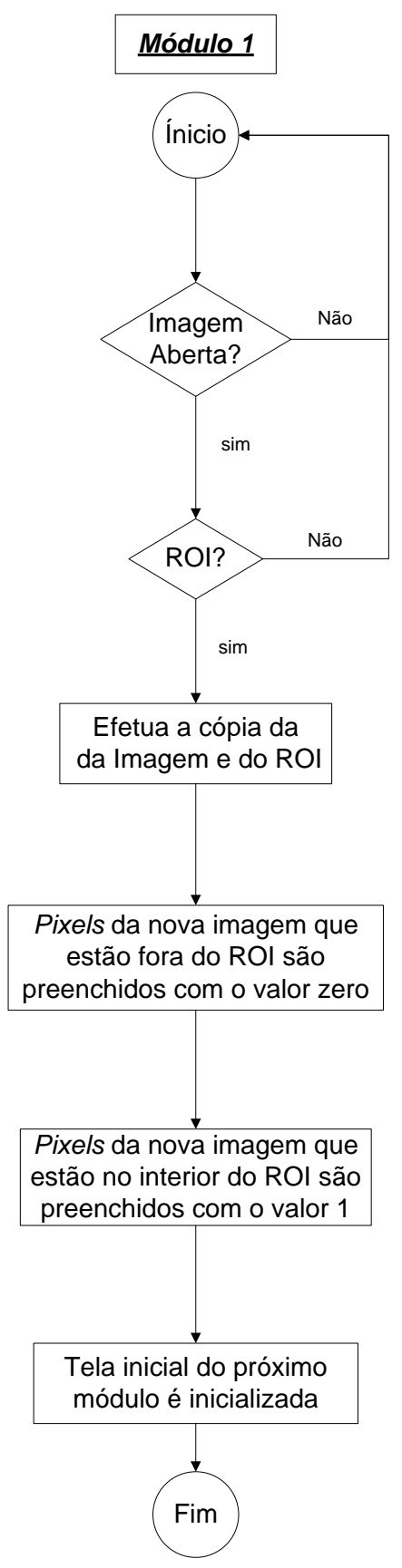

Figura 5.19: Fluxograma do Módulo 1. 


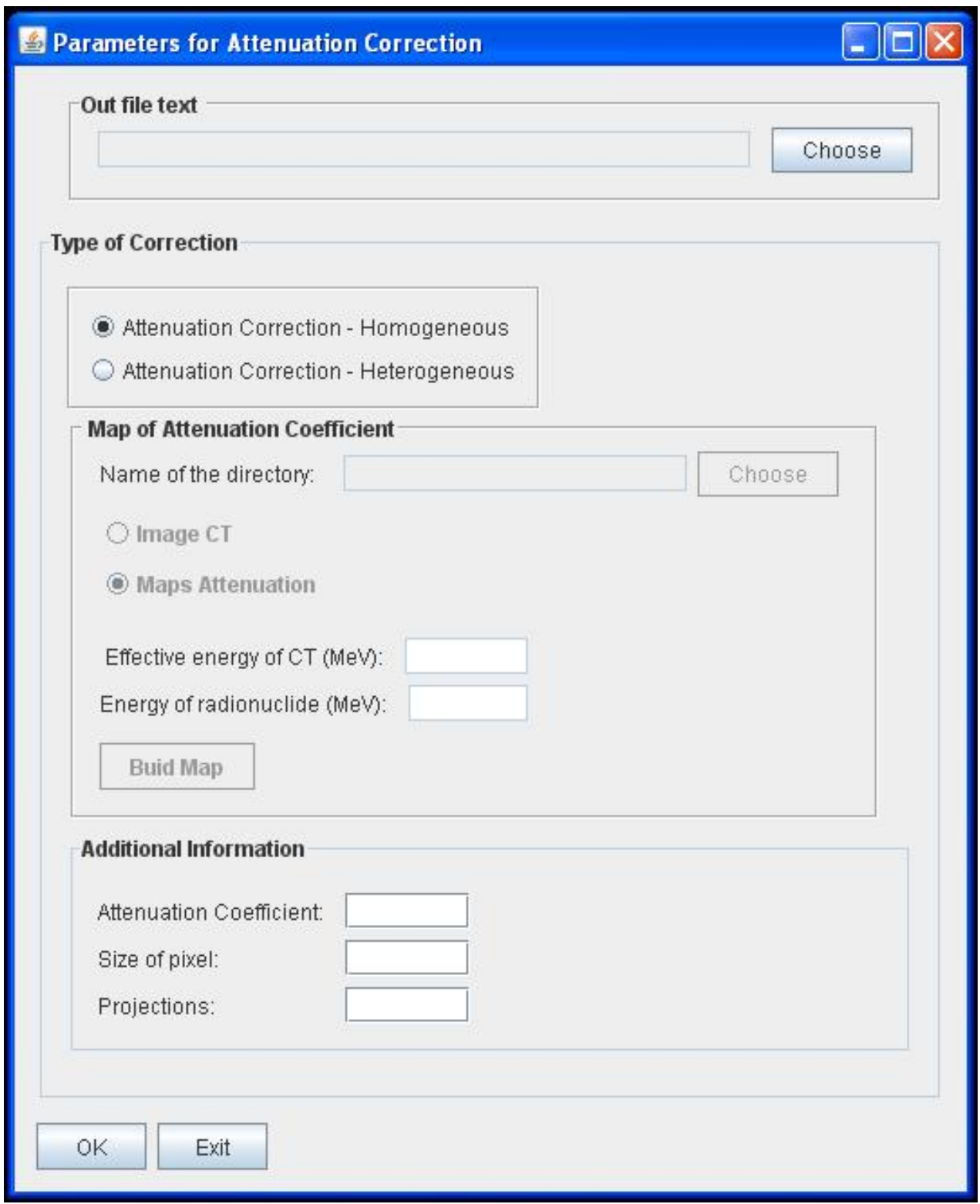

Figura 5.20: Tela inicial do Módulo 2, denominada "Parameters for Attenuation Correction". 
2. Armazenar a imagem se esta for fornecida pelo CT ou se for um mapa dos coefientes de atenuação linear, gerados com a mesma energia do radionuclídio emissor. Se for uma imagem de CT os campos Effective energy of $\mathrm{CT}(\mathrm{MeV})$ e Energy of radionuclide $(M e V)$ são habilitados, caso contrário não;

3. Gerar o mapa dos coeficientes de atenuação linear referente a imagem de SPECT ou PET.

Em relação ao segundo item, caso a imagem fornecida seja de CT o algoritmo realizará os seguintes passos:

- Armazenará a energia efetiva do CT;

- Armazenará a energia do radionuclídeo utilizado para fazer a imagem de SPECT ou PET;

- Obterá o coeficiente de atenuação de massa $(\mu / \rho)$ da água em relação a essas duas energias por intermédio de uma equação de interpolação;

- Calculará um fator de correção correspondente a razão do coeficiente de atenuação de massa da água, para a energia do radionuclídeo, com o coeficiente de atenuação de massa da água, para a energia efetiva do CT. Esse fator de correção será utilizado para escalonar a imagem dos coeficientes de atenuação linear provenientes do CT para a energia do radionuclídeo em que foi realizada a imagem;

- O mapa dos coeficientes de atenuação linear será gerado.

Geralmente as imagens de CT possuem uma resolução maior em relação as de SPECT ou PET. Assim, o último item mencionado segue os seguintes procedimentos para construir o mapa de atenuação:

- Gerar, por intermédio da imagem de CT, uma matriz de mesma dimensão da imagem de SPECT ou PET. Para realizar esse processo, cada conjunto de pixels da imagem de CT, os quais representam um pixel na imagem de SPECT ou PET, são agrupados em um só pixel que é a média dos pixels do conjunto; 
- Transformar as unidades de Hounsfield contidas na matriz anterior nos coeficientes de atenuação linear por meio da Eq.(4.30) e por fim o fator de correção é aplicado a cada valor encontrado.

O fluxograma do Módulo 2 está apresentado na FIG.5.21.

\section{MÓDULO 3}

Embora o Módulo 3 seja acessado por um botão, "OK", contido no Parameters Attenuation Correction, ele é considerado um outro módulo e não uma parte do Módulo 2 .

Esse módulo apresenta duas funções: (1) efetuar a correção de atenução pelo método de Chang de $1^{a}$ ordem com o tipo de correção especificado (homogêneo ou heterogêneo) e (2) gravar o resultado da atividade relativa no arquivo especificado.

Ele é subdividido em duas funções principais:

1. Escolher da correção Homogêneo ou Heterogênea;

2. Gravar a atividade relativa no aquivo especificado.

Com base nas informações fornecidas pelos Módulos 1 e 2 e mediante o método de Chang de $1^{a}$ ordem, mencionado no capítulo de Materiais e Métodos na subseção 4.2.5, o primeiro item realiza a correção de atenuação linear homogênea ou heterogênea, dependendo do requisitado no Módulo 2. Esse item gerará um matriz contendo os valores da atividade corrigida, da imagem de SPECT ou PET.

Após esse procedimento, ocorre o processo em que essa matriz é gravada no arquivo especificado. Esse item segue os seguinte passos:

- Encontrar o valor de atividade máxima na matriz;

- Dividir os valores da matriz pelo valor máximo obtendo o valor relativo da atividade;

- Gravar a matriz no arquivo especificado.

O fluxograma do Módulo 3 está apresentado na FIG.5.22. 


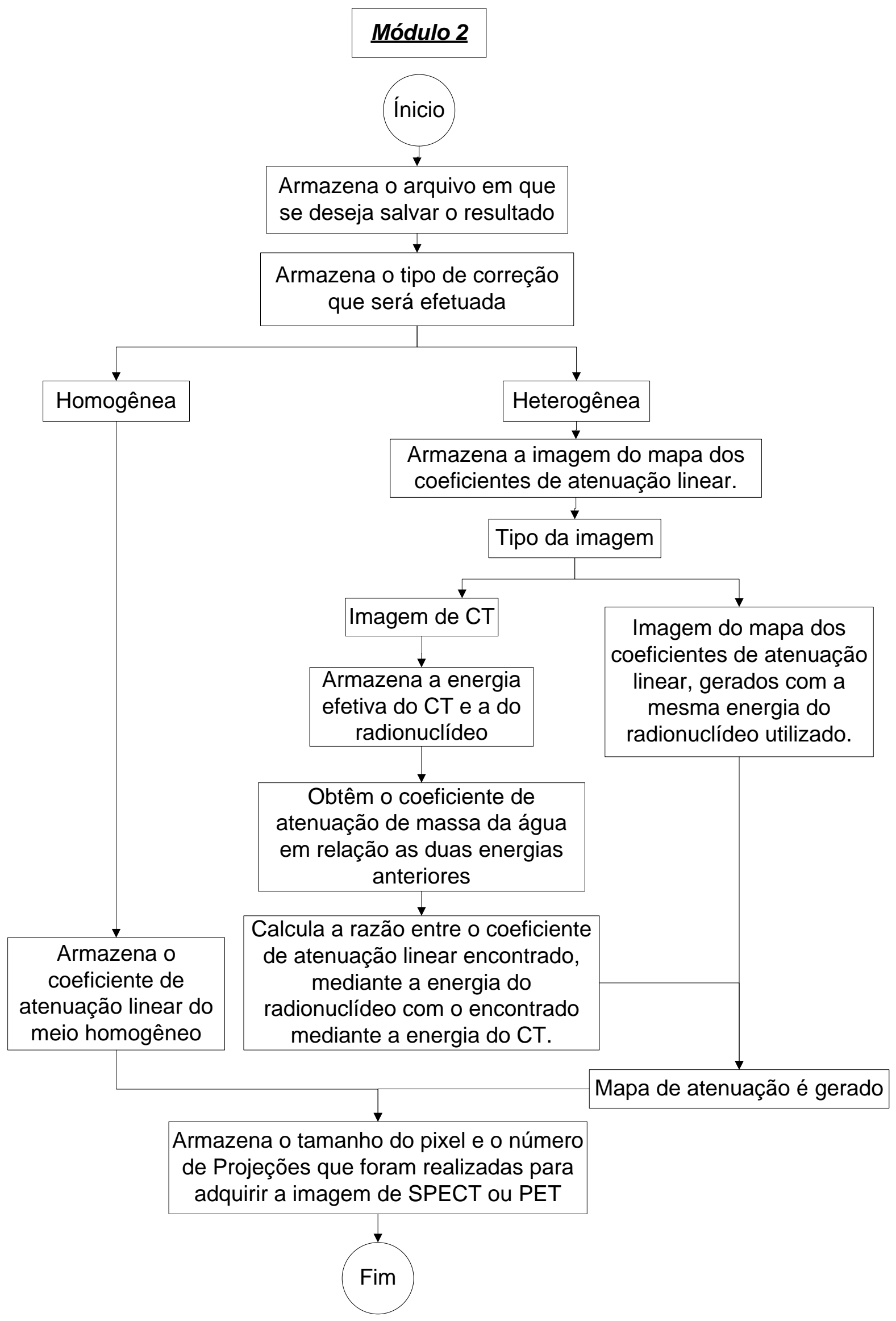

Figura 5.21: Fluxograma do Módulo 2. 


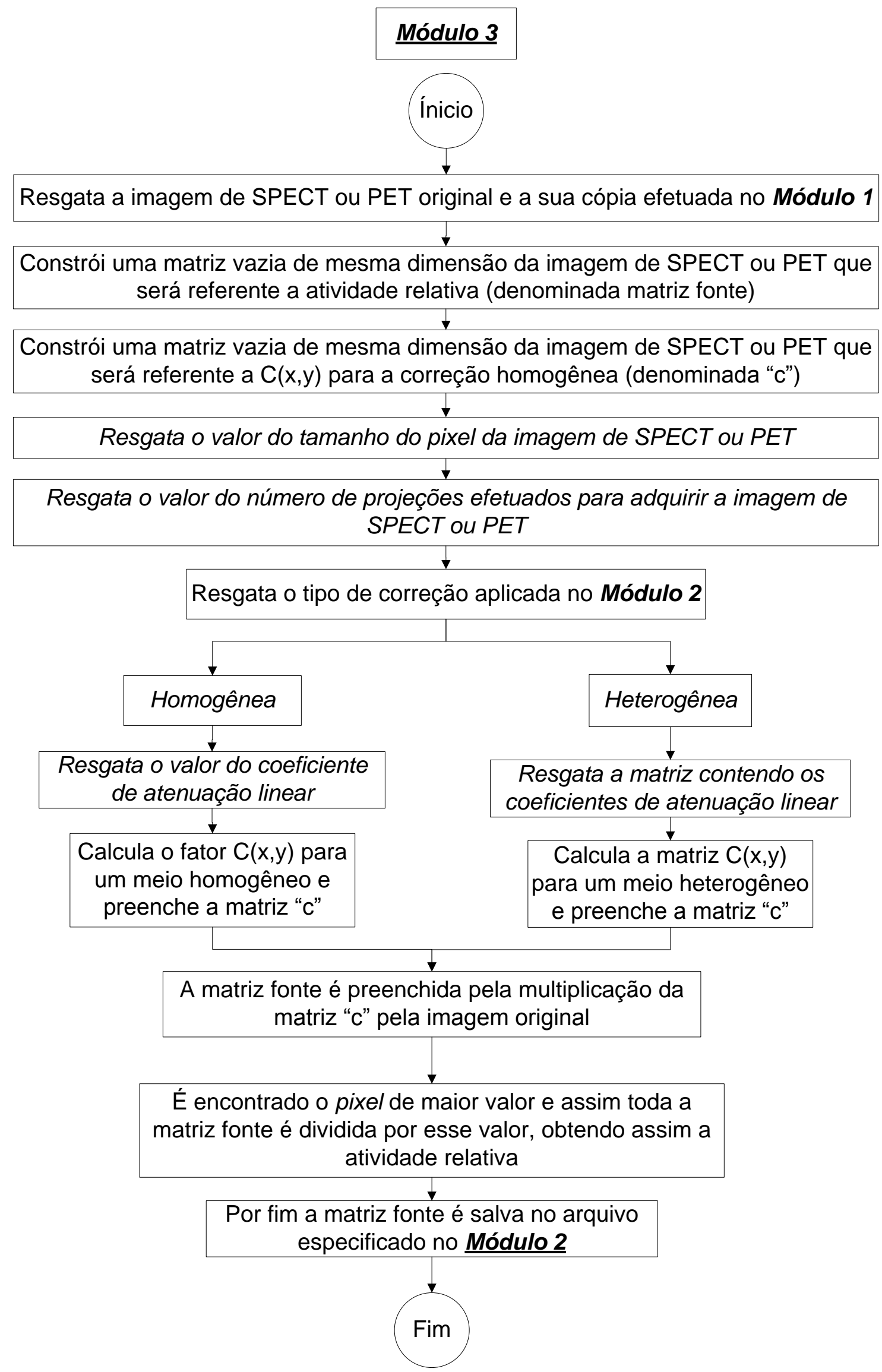

Figura 5.22: Fluxograma do Módulo 3. 


\subsubsection{Testes efetuados no Software ACPS}

Para verificar o correto funcionamento do ACPS em relação a correção de atenuação homogênea, foi utilizada uma imagem com dimensão 5 X 5 contendo os valores 0 e 1 . $\mathrm{O}$ primeiro passo, foi ler a imagem mediante o software ImageJ e realizar o ROI ao redor dos números 1.

Na FIG.5.23 é apresentado o esquema da imagem utilizada juntamente com os valores e os índices em cada pixel e por fim a localização do ROI nessa imagem.

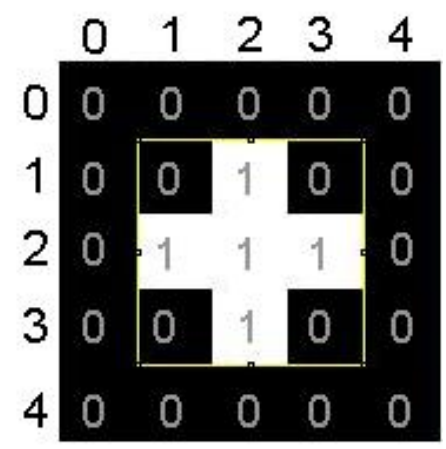

Figura 5.23: Esquema da imagem utilizada para verificar o funcionamento do ACPS.

Após este procedimento, o plugin ACPS foi acionado. Os valores do coeficiente de atenuação, do tamanho do pixel e do número de projeções foram de $0,14 \mathrm{~cm}^{-1}, 1 \mathrm{~cm}$ e 4 respectivamente. O nome do arquivo de saída foi estipulado como "Resultado.txt". Na FIG.5.24 é apresentado o arquivo de saída.

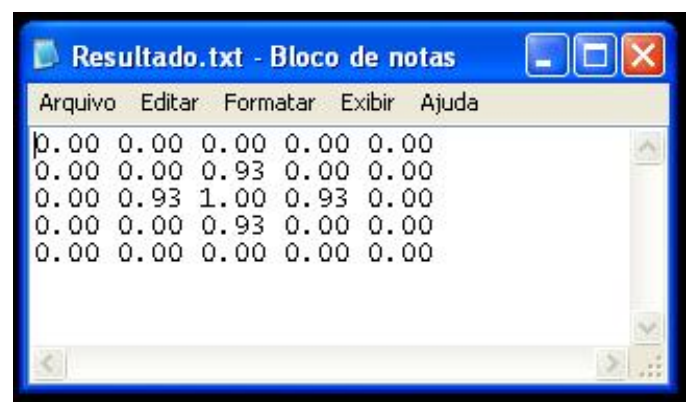

Figura 5.24: Arquivo de saída gerado pelo ACPS.

Para se certificar do resultado gerado pelo ACPS, em relação a correção homogênea, foi apenas necessário calcular $C(x, y)$, expresso na Eq.(4.28), para a componente central 
da imagem e para uma das componentes ao seu redor, pois nesse caso em específico, todas as componentes ao redor da central darão o mesmo resultado para $C(x, y)$.

A seguir, é efetuado o cálculo da componente central:

$$
C(2,2)=\frac{1}{\frac{1}{4} \cdot(4) \cdot e^{-0,14 \cdot 1}}=1,15
$$

Uma das componentes ao redor da central é dada por:

$$
C(1,2)=\frac{1}{\frac{1}{4} \cdot\left[(3) \cdot e^{-0,14 \cdot 0}+e^{-0,14 \cdot 2}\right]}=1,07
$$

Com base nos valores de $C(x, y)$ é então possível obter a matriz contida em "Resultado.txt". Isto é realizado, primeiramente pela multiplição da matriz $C(x, y)$ pela imagem original e depois cada elemento dessa matriz originada será dividido pelo maior elemento nela contido.

Se considerar a imagem original como uma matriz " $m$ ", tem-se que o valor no elemento central, $m(2,2)$ é:

$$
m(2,2)=\frac{1,15}{1,15}=1
$$

Em relação ao $m(1,2)$ tem-se:

$$
m(1,2)=\frac{1,07}{1,15}=0,93
$$

Assim, observou-se que a matriz contida em "Resultado.txt" está de acordo com os cálculos efetuados anteriormente, portanto o ACPS está efetuando o cálculo da correção homogênea corretamente.

Para analisar o ACPS em relação a correção heterogênea foi necessário construir uma imagem para representar a imagem de CT que será utilizada para construir o mapa dos coeficientes de atenuação. Essa imagem possui dimensão 10 X 10.

Na FIG.5.25 observa-se a imagem que representa a imagem de CT. 


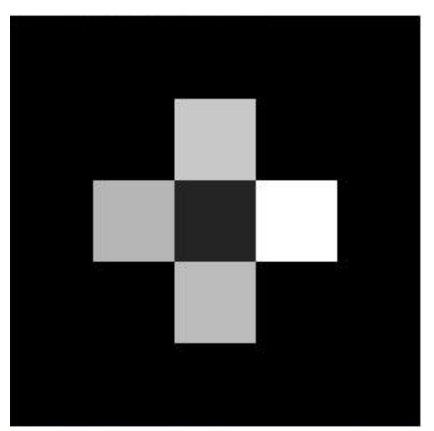

Figura 5.25: Representação de uma imagem de CT.

A matriz desta imagem é mostrada na FIG.5.26.

\begin{tabular}{|llllllllll|}
\hline-1000 & -1000 & -1000 & -1000 & -1000 & -1000 & -1000 & -1000 & -1000 & -1000 \\
-1000 & -1000 & -1000 & -1000 & -1000 & -1000 & -1000 & -1000 & -1000 & -1000 \\
-1000 & -1000 & -1000 & -1000 & 100 & 100 & -1000 & -1000 & -1000 & -1000 \\
-1000 & -1000 & -1000 & -1000 & 100 & 100 & -1000 & -1000 & -1000 & -1000 \\
-1000 & -1000 & 0 & 0 & -800 & -800 & 400 & 400 & -1000 & -1000 \\
-1000 & -1000 & 0 & 0 & -800 & -800 & 400 & 400 & -1000 & -1000 \\
-1000 & -1000 & -1000 & -1000 & 30 & 30 & -1000 & -1000 & -1000 & -1000 \\
-1000 & -1000 & -1000 & -1000 & 30 & 30 & -1000 & -1000 & -1000 & -1000 \\
-1000 & -1000 & -1000 & -1000 & -1000 & -1000 & -1000 & -1000 & -1000 & -1000 \\
-1000 & -1000 & -1000 & -1000 & -1000 & -1000 & -1000 & -1000 & -1000 & -1000 \\
\hline
\end{tabular}

Figura 5.26: Matriz da imagem de CT.

A imagem utilizada para efetuar a correção heterogênea foi a apresentada na FIG.5.23. Os valores do tamanho do pixel e do número de projeções foram igual a $1 \mathrm{~cm}$ e $4 \mathrm{~cm}$, respectivamente. O nome do arquivo de saída foi estipulado como "Resultado.txt".A representação do arquivo de saída está apresentada na FIG.5.27.

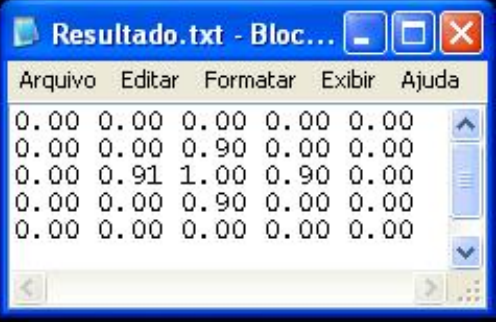

Figura 5.27: Resultado gerado pelo ACPS.

Para verificar o resultado gerado pelo ACPS foi efetuado o cálculo de $C(x, y)$, expresso na Eq.(4.28), para a componente central e para todas as componentes ao seu redor.

Antes de realizar esse cálculo foi preciso obter a matriz dos coeficientes de atenuação. Na FIG.5.28 pode-se observar esta matriz. 


\begin{tabular}{c|c|c|c|c|c|}
\multicolumn{1}{c}{0} & 1 & 2 & 3 & 4 \\
\cline { 2 - 6 } 0 & 0 & 0 & 0 & 0 & 0 \\
\hline 1 & 0 & 0 & 0,14 & 0 & 0 \\
\hline 2 & 0 & 0,13 & 0,03 & 0,18 & 0 \\
\hline 3 & 0 & 0 & 0,13 & 0 & 0 \\
\hline 4 & 0 & 0 & 0 & 0 & 0 \\
\hline
\end{tabular}

Figura 5.28: Matriz dos coeficientes de atenuação.

Essa matriz é obtida por intermédio da seguinte expressão:

$$
M(x, y)=\left[\left(\frac{H}{1000}+1\right) \cdot \mu_{H_{2} O}^{E}\right] \cdot \frac{\mu_{H_{2} O}^{E}}{\mu_{H_{2} O}^{C T}}
$$

onde,

- $\mu_{H_{2} O}^{E}$ é o coeficiente de atenuação da água para a energia do radionuclídeo;

- $\mu_{\mathrm{H}_{2} \mathrm{O}}^{C T}$ é o coeficiente de atenuação da água para a energia efetiva do CT;

Os valores de $\mu_{H_{2} O}^{E}$ e $\mu_{H_{2} O}^{C T}$ foram encontrados aplicando-se uma função de interpolação com os dados de $\mu_{\mathrm{H}_{2} \mathrm{O}}$ em relação à energia $(\mathrm{MeV})$, obtidos pela biblioteca do NIST (NIST, 2010).

Com base nesses dados foi possível efetuar os cálculos de todas as componentes de $C(x, y)$ :

$$
\begin{gathered}
C(2,2)=\frac{1}{\frac{1}{4} \cdot\left[e^{-0,14}+e^{-0,13}+e^{-0,13}+e^{-0,18}\right]}=1,15 \\
C(2,1)=\frac{1}{\frac{1}{4} \cdot\left[e^{-0,0}+e^{-0,0}+e^{-0,0}+e^{-(0,03+0,18)}\right]}=1,05 \\
C(3,2)=\frac{1}{\frac{1}{4} \cdot\left[e^{-0,0}+e^{-0,0}+e^{-0,0}+e^{-(0,14+0,03)}\right]}=1,04 \\
C(2,3)=\frac{1}{\frac{1}{4} \cdot\left[e^{-0,0}+e^{-0,0}+e^{-0,0}+e^{-(0,13+0,03)}\right]}=1,04 \\
C(1,2)=\frac{1}{\frac{1}{4} \cdot\left[e^{-0,0}+e^{-0,0}+e^{-0,0}+e^{-(0,13+0,03)}\right]}=1,04
\end{gathered}
$$


Para encontrar os valor contidos na FIG.5.27, a imagem original foi multiplicada pela matriz $C(x, y)$ e por fim cada pixel foi dividido pelo pixel de maior valor, assim como efetuado para o método homogêneo.

Se considerar a matriz resultado como " $m$ " tem-se que, ao efetuar o cálculo mencionado acima: $m(2,2)=1,00, m(2,1)=0,91, m(3,2)=0,90, m(2,3)=0,90, m(1,2)=0,90 \mathrm{e}$ os demais pixels recebem o valor 0 .

Dessa forma, o resultado gerado pelo ACPS esta em conformidade com o método de Chang de $1^{a}$ ordem modificado para correção heterôgenea que foi mencionado na seção 4.2 .5 . 


\subsection{Influência da composição química dos tecidos no cálculo da dose absorvida}

É sabido que o ICCT divide os tecidos do corpo humano em até 24 grupos mediante os valores de Hounsfield adquiridos do CT.

Foi observado que determinados grupos possuem variações na composição química dos tecidos quando comparados com a literatura. Tais grupos representam o tecido mole com intervalo entre, $I D=2$ ao $I D=8$, e o esquelético com intervalo entre, $I D=9$ ao $I D=23$.

Este experimento foi proposto a fim de observar a influência dessas variações no cálculo da dose absorvida.

Mediante o código MCNP5, foram efetuadas simulações com três fontes de radiação em que calculou-se a dose absorvida para um determinado grupo (tecido mole, por exemplo) e a dose absorvida para um tecido da literatura, em que a sua unidade de Hounsfield estivesse contida dentro do intervalo do grupo avaliado, conforme mencionado na secão 4.2.3. Com base nesses resultados, verificou-se a diferença na dose absorvida em relação ao tecido da literatura.

Como mencionado na seção 4.2 .3 a fontes de radiação utilizadas foram: duas de fótons, uma com energia de $0,14 \mathrm{MeV}$ e a outra de $1 \mathrm{MeV}$, e uma fonte de elétrons de $1 \mathrm{MeV}$.

Em relação ao tecido mole foi escolhido o grupo de $I D=7$ em que se obteve as maiores variações na composição, em especial para os elementos químicos carbono e oxigênio. O material escolhido, referente à literatura, foi a urina. Na TAB.5.13 são apresentadas as variações entre a composição do tecido da urina e a do grupo de $I D=7$.

Tabela 5.13 - Variações, em frações em pesos $(f p)$, da composição química, obtidas entre a urina e o grupo de $I D=7$.

\begin{tabular}{ccccccccc}
\hline $\mathrm{H}$ & $\mathrm{C}$ & $\mathrm{N}$ & $\mathrm{O}$ & $\mathrm{Na}$ & $\mathrm{P}$ & $\mathrm{S}$ & $\mathrm{Cl}$ & $\mathrm{K}$ \\
\hline 0,7 & $-12,9$ & $-2,0$ & 13,9 & 0,2 & $-0,1$ & $-0,2$ & 0,4 & 0,0 \\
\hline
\end{tabular}

Na TAB.5.14 contêm as diferenças na dose absorvida, em percentagem, entre a urina e o grupo de $I D=7$. 
Tabela 5.14 - Diferença percentual na dose absorvida obtidas entre a urina e o grupo de $I D=7$.

\begin{tabular}{lc}
\hline Fonte & Diferença na dose absorvida (\%) \\
\hline $0,14 \mathrm{Mev}$ - fótons & 1,08 \\
$1 \mathrm{Mev}$ - fótons & 1,18 \\
$1 \mathrm{Mev}$ - elétron & 0,78 \\
\hline
\end{tabular}

Observa-se, mediante a TAB.5.14, que embora o ICCT não determine de forma precisa a fração em peso de carbono e oxigênio, isto não influênciou de forma significativa no cálculo da dose absorvida.

Para o tecido esquelético foi escolhido o grupo de $I D=12$ em que se obteve as maiores variações na composição, em especial para os elementos químicos carbono e oxigênio. O tecido escolhido, referente à literatura, foi o tecido D6, L3 incluindo Cartilagem (homem). Na TAB.5.15 são apresentadas as variações entre a composição do tecido D6, L3 incluindo Cartilagem (homem) e a do grupo de $I D=12$.

Tabela 5.15 - Variações, em frações em pesos $(f p)$, da composição química, obtidas entre o tecido D6, L3 incluindo Cartilagem (homem) e o grupo de $I D=12$.

\begin{tabular}{cccccccccc}
\hline $\mathrm{H}$ & $\mathrm{C}$ & $\mathrm{N}$ & $\mathrm{O}$ & $\mathrm{Na}$ & $\mathrm{P}$ & $\mathrm{S}$ & $\mathrm{Cl}$ & $\mathrm{K}$ & $\mathrm{Ca}$ \\
\hline$-0,2$ & $-9,3$ & 0,5 & 9,2 & 0,0 & 0,0 & 0,1 & 0,0 & 0,0 & $-0,5$ \\
\hline
\end{tabular}

Na TAB.5.16 contêm as diferenças na dose absorvida, em frações em pesos, entre o tecido D6, L3 incluindo Cartilagem (homem) e o grupo de $I D=12$.

Tabela 5.16 - Diferença percentual na dose absorvida obtidas entre o tecido D6, L3 incluindo Cartilagem (homem) e o grupo de $I D=12$.

\begin{tabular}{lc}
\hline Fonte & Diferença na dose absorvida (\%) \\
\hline $0,14 \mathrm{Mev}$ - fótons & 0,32 \\
$1 \mathrm{Mev}$ - fótons & 0,47 \\
$1 \mathrm{Mev}$ - elétron & 0,18 \\
\hline
\end{tabular}


Por intermédio da TAB.5.16, observa-se que apesar do ICCT não determinar de forma precisa a fração em peso de carbono e oxigênio, isto não influênciou de forma significativa no cálculo da dose absorvida.

É também observado que embora o grupo de $I D=12$ seja o que apresentou as maiores variações na dose absorvida, a variação de fósforo, cálcio e hidrogênio tiveram uma alta precisão. Tais elementos químicos se não determinados com um alto grau de precisão podem levar a diferenças consideráveis na dose absorvida (Yoriyaz et al., 2009).

\subsection{Análise da influência da quantidade de tecidos no cálculo da dose absorvida}

Como dito anteriormente, na secão 4.2.4, este experimento foi realizado para avaliar a influência que a quantidade de tecidos tem sobre o cálculo da dose absorvida.

Desta forma, foi selecionada uma região de interesse, ilustrada na FIG.4.5; esta região foi processada de duas formas:

METODOLOGIA 1: subdividiu-se a imagem, com auxílio da unidade de Hounsfield $(H)$, em 4 tipos de tecido: ar ( $H$ entre -1000 à -950), pulmão ( $H$ entre -950 à -200), tecido mole ( $H$ entre -200 à 120) e tecido esquelético ( $H$ entre 120 à 3000) (FIG.5.29 (B));

METODOLOGIA 2: o ICCT, através de sua metodologia desenvolvida, subdividiu a imagem em 19 tecidos: 1 grupo do tecido pulmonar, 7 grupos de tecido mole e 11 grupos de tecido esquelético (TAB.5.7) (FIG.5.29 (A)).

Essas subdivisões em tecidos formou um mapa de tecido, como observado na FIG.5.29. Nestas mesmas figuras é possível observar a diferença considerável do número de tecidos. Estes mapas de tecidos serviram como dado de entrada para o software SCMS que por sua vez gerou um arquivo de entrada para o códico MCNP5.

O código MCNP5 transformou estes mapas de tecidos num objeto simulador baseado em voxels. O cálculo da dose absorvida foi realizado em cada voxel do objeto simulador, para ambas as metodologias, conforme mencionado na seção 4.2.4.

Comparando os valores obtidos nas duas metodologias, observou-se uma diferença no cálculo da dose de até $47 \%$ quando utilizou-se uma fonte de eletróns de $1 \mathrm{MeV}$ e uma 

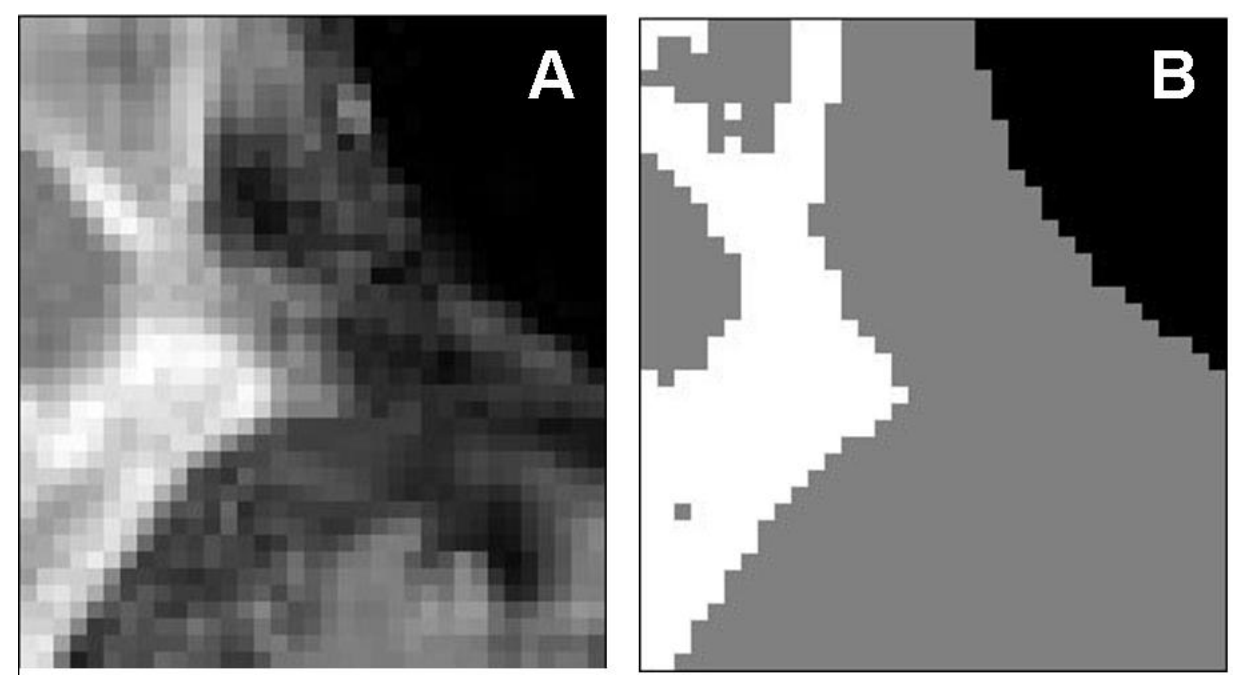

Figura 5.29: Imagem do mapa de tecidos com 19 tecidos (A), imagem do mapa de tecido com 4 tecidos (B).

diferença de até $44 \%$ quando utilizou-se uma fonte de photons de $1 \mathrm{MeV}$.

Observa-se que a metodologia padrão, negligencia a dose real depositada nestes tecidos. Isso ocorre, pois a subdivisão em apenas 4 grupos de tecidos, ignora as diversas composições e densidades dos mesmos. Como já observado, a composição química dos tecidos não altera o cálculo de dose tanto quanto a densidade. Neste ponto apresenta-se uma grande vantagem do software ICCT, que por subdividir os tecidos em mais grupos, calcula com maior precisão a dose depositada, tendo por base a densidade dos tecidos. 


\section{Capítulo 6}

\section{CONCLUSÃO}

O primeiro objetivo foi concluído ao se desenvolver o software denominado ICCT, desenvolvido usando a linguagem JAVA e o método de Schneider et al. (2000). Ele foi capaz de converter as imagens fornecidas por equipamentos de Tomografia Computadorizada em parâmetros do tecido $\left(\rho, \omega_{i}\right)$. No método utilizado, os parâmetros do tecido são encontrados por meio de um cálculo estequiométrico entre a unidade de Hounsfield dos tecidos da literatura e dos tecidos do paciente, obtidos através de imagens tomográficas. Os dados gerados mostraram uma alta precisão para determinar a densidade; já em relação à composição dos tecidos, os elementos que obtiveram maior variação foram o carbono e oxigênio.

Foram realizados experimentos para verificar a influência dessas variações no cálculo da dose absorvida. Essas variações em relação a composição dos tecidos, gerada pelo ICCT, não afetaram de forma significativa a dose absorvida. Para o tecido mole foi encontrada uma diferença máxima na dose de 1,18\%, considerando fótons de $1 \mathrm{MeV}$ e 0,14 $\mathrm{MeV}$; e uma variação máxima na dose de $0,78 \%$, considerando elétrons de $1 \mathrm{MeV}$. Os resultados obtidos neste trabalho indicaram que variações na quantidade de tecidos e principalmente na densidade dos mesmos, ocasionam diferenças consideráveis na dose, (> $40 \%$ para fontes de fótons e elétrons de $1 \mathrm{MeV})$.

A grande vantagem do ICCT é a sua capacidade de determinar a composição química e a densidade dos tecidos específicos de cada paciente, com uma boa resolução, o que resulta numa melhor determinação da dose absorvida.

Embora o software ICCT tenha sido concluído, ele não pôde ser validado, pois para isto, é necessário a presença de um objeto simulador com os materiais especificados na TAB.5.1 e isso será objeto de um estudo futuro. 
Outro objetivo foi desenvolver um software que convertesse imagens tomográficas provindas de aparelhos PET e SPECT, os quais fornecem a distribuição da atividade no paciente, em um arquivo contendo a distribuição da atividade relativa. Este arquivo deveria ser lido pelo software SCMS.

O software desenvolvido para atender a este objetivo, foi denominado ACPS. Antes de gerar os arquivos para o SCMS foi necessário implementar um cálculo para correção de atenuação. O método utilizado foi o de Chang de $1^{a}$ ordem tanto, para regiões homogêneas (coeficiente de atenuação linear é constante em todos os pixels), como para heterogêneas (coeficiente de atenuação linear varia em cada pixel). O ACPS atendeu ao objetivo fornecendo resultados satisfatórios.

Por fim, os dois softwares foram implementados como plugins do ImageJ, concluindo o terceiro objetivo. 
Capítulo 7

\section{APÊNDICE}

Cálculo para obtenção da Eq.(4.19)

Dada a Eq.(7.1):

$$
\bar{\mu}=\frac{\rho_{1} \rho_{2}}{W_{1}\left(\rho_{2}-\rho_{1}\right)+\rho_{1}}\left[W_{1}\left(\frac{\bar{\mu}_{1}}{\rho_{1}}-\frac{\bar{\mu}_{2}}{\rho_{2}}\right)+\frac{\bar{\mu}_{2}}{\rho_{2}}\right]
$$

Substituindo em:

$$
H=\left(\frac{\bar{\mu}}{\bar{\mu}_{H_{2} O}}-1\right) * 1000
$$

encontra-se a sequinte equação:

$$
H=\left[\frac{\rho_{1} \rho_{2}}{W_{1}\left(\rho_{2}-\rho_{1}\right)+\rho_{1}} \cdot\left[\frac{1}{\bar{\mu}_{H_{2} O}}\right]\left[W_{1}\left(\frac{\bar{\mu}_{1}}{\rho_{1}}-\frac{\bar{\mu}_{2}}{\rho_{2}}\right)+\frac{\bar{\mu}_{2}}{\rho_{2}}\right]-1\right] * 1000
$$

A Eq.(7.3) pode ser reescrita na forma:

$$
H=\left[\frac{\rho_{1} \rho_{2}}{W_{1}\left(\rho_{2}-\rho_{1}\right)+\rho_{1}} \cdot\left[W_{1}\left[\frac{\bar{\mu}_{1}}{\bar{\mu}_{H_{2} O}} \cdot \frac{1}{\rho_{1}}-\frac{\bar{\mu}_{2}}{\bar{\mu}_{H_{2} O}} \cdot \frac{1}{\rho_{2}}\right]+\frac{\bar{\mu}_{2}}{\bar{\mu}_{H_{2} O}} \cdot \frac{1}{\rho_{2}}\right]-1\right] * 1000
$$

Sabendo-se que:

$$
\frac{\bar{\mu}}{\overline{\bar{\mu}}_{\mathrm{H}_{2} \mathrm{O}}}=\frac{H}{1000}+1
$$

Tem-se:

$$
\begin{gathered}
H=\left[\frac{\rho_{1} \rho_{2}}{W_{1}\left(\rho_{2}-\rho_{1}\right)+\rho_{1}}\left[W_{1}\left[\left(\frac{H_{1}}{1000}+1\right) \frac{1}{\rho_{1}}-\left(\frac{H_{2}}{1000}+1\right) \frac{1}{\rho_{2}}\right]+\left(\frac{H_{2}}{1000}+1\right) \frac{1}{\rho_{2}}\right]-1\right] * 1000 \\
H=\left[\frac{\rho_{1} \rho_{2}}{W_{1}\left(\rho_{2}-\rho_{1}\right)+\rho_{1}}\left[W_{1}\left(\frac{H_{1}+1000}{1000 \rho_{1}}-\frac{H_{2}+1000}{1000 \rho_{2}}\right)+\frac{H_{2}+1000}{1000 \cdot \rho_{2}}\right]-1\right] * 1000
\end{gathered}
$$$$
H=\left[\frac{\rho_{1} \rho_{2}}{W_{1}\left(\rho_{2}-\rho_{1}\right)+\rho_{1}}\left[W_{1}\left(\frac{\left(H_{1}+1000\right) \rho_{2}-\left(H_{2}+1000\right) \rho_{1}}{1000 \rho_{1} \rho_{2}}\right)+\frac{H_{2}+1000}{1000 \rho_{2}}\right]-1\right] * 1000
$$ 


$$
\begin{gathered}
H=\left[\frac{\rho_{1} \rho_{2}}{W_{1}\left(\rho_{2}-\rho_{1}\right)+\rho_{1}}\left[W_{1}\left(\frac{\left(\rho_{2} H_{1}+1000 \rho_{2}-\rho_{1} H_{2}-1000 \rho_{1}\right)+H_{2} \rho_{1}+1000 \rho_{1}}{1000 \rho_{1} \rho_{2}}\right)\right]-1\right] * 1000 \\
H=\left[\left[W_{1}\left(\frac{\left(\rho_{2} H_{1}+1000 \rho_{2}-\rho_{1} H_{2}-1000 \rho_{1}\right)+H_{2} \rho_{1}+1000 \rho_{1}}{\left(W_{1}\left(\rho_{2}-\rho_{1}\right)+\rho_{1}\right) 1000}\right)\right]-1\right] * 1000 \\
H=\left(\frac{W_{1}\left(\rho_{2} H_{1}+1000 \rho_{2}-\rho_{1} H_{2}-1000 \rho_{1}\right)+W_{1} H_{2} \rho_{1}+1000 W_{1} \rho_{1}}{\left(W_{1}\left(\rho_{2}-\rho_{1}\right)+\rho_{1}\right)}\right)-1 \\
H=\frac{W_{1}\left(\rho_{2} H_{1}-\rho_{1} H_{2}\right)-\left(W_{1}\left(\rho_{2}-\rho_{1}\right)+\rho_{1}\right)}{\left(W_{1}\left(\rho_{2}-\rho_{1}\right)+\rho_{1}\right)}
\end{gathered}
$$

Assim, obtên-se a equação:

$$
H=\frac{W_{1}\left(\rho_{2} H_{1}-\rho_{1} H_{2}\right)+H_{2} \rho_{1}}{W_{1}\left(\rho_{2}-\rho_{1}\right)+\rho_{1}}
$$

A seguir $W_{1}$ é isolado da Eq.(7.5) resultando em:

$$
W_{1}=\frac{\rho_{1}\left(H_{2}-H\right)}{H\left(\rho_{2}-\rho_{1}\right)+\left(H_{2} \rho_{1}-H_{1} \rho 2\right)}
$$


Capítulo 8

\section{REFERÊNCIAS BIBLIOGRÁFICAS}

1. AN LIU, L.E.; WILLIAMS, G.L.; DAVE, M.Y.; JEFRREY, Y.C.; WONG \& ANDREW, A.R. A radionuclide therapy treatment planning and dose estimation system. J. Nucl. Med., v. 40, n. 7, p. 1151-1153, 1999.

2. ATTIX, F.H. Introduction to radiological physics and radiation dosimetry. Alemanha: Wiley-VCH, 2004a. cap.7, Gama and x-ray interation in matter. p. 154155.

3. ATTIX, F.H. Introduction to radiological physics and radiation dosimetry. Alemanha: Wiley-VCH, 2004b. cap.8, Charged-Particle Interactions in Matter. p. 160-202.

4. BARDIÈS, M.; MYERS, M.J. Computational methods in radionuclide dosimetry. Phys. Med. Biol., v. 41, p. 1941-1955, 1996.

5. BOOTH T.E.; GOORLEY J.T.; SOOD A.; BROWN F.B.; HUGHES H.G.; SWEEZY J.E.; BULL J.S.; MOSTELLER R.D.; BARRETT R.F.; COX L.J.; PRAEL R.E.; POST S.E.; FORSTER R.A.; SELCOW E.C.; ROBERTS T.L. $\boldsymbol{M C N P}$ - $\boldsymbol{A}$ General Monte Carlo N-Particle Transport Code, Version 5. v. 2. Novo México: Los Alamos National Laboratory, 2003. (LA-CP-03-0245).

6. CHANG, L.T. A method for attenuation correction in radionuclide computed tomography. IEEE Trans. Nucl. Sci., NS-25, p. 638-643, 1978. 
7. CHERRY, S.R.; SORENSON, J.A.; PHELPS, M.E. Physics in nuclear medicine. 3.ed. Estados Unidos: Elsevier Science, 2003a. cap.1, What is nuclear medicine? p. $1-6$.

8. CHERRY, S.R.; SORENSON, J.A.; PHELPS, M.E. Physics in nuclear medicine. 3.ed. Estados Unidos: Elsevier Science, 2003b. cap.5, Radionuclide and radiopharmaceutical production. p. 58-60.

9. CHIAVASSA, S.; BARDiÈS, M.; GUIRAUD-VITAUX, F.; BRUEL, D.; JOURDAIN, J.; FRANCK, D.; AUBINEAU-LANIÈCE, I. OEDIPE: A personalized dosimetric tool associating voxel-based models with MCNPX. Cancer Biother. Radiopharm., v. 20, n. 3, p. 325-332, 2005.

10. CLAIRAND, I.; RICARD, M.; GOURIOU, J.; DI PAOLA, M.; AUBERT, B. DOSE3D: EGS4 Monte Carlo code-based software for internal radionuclide dosimetry. $\boldsymbol{J}$. Nucl. Med. , v. 40, n. 9, p. 1517-1523, 1999.

11. DeITEL, H.M.; DEITEL, P.J. Java Como Programar. 6.ed. Brasil: Pearson Education, 2005.

12. DENARDO, G.L.; SYSKO, V.V.; DENARDO, S.J. Cure of incurable lymphoma. Int. J. Radiat. Oncol. Biol. Phys., v. 66, n. 2, p. S46-S56, 2006.

13. DIVOLI, A.; CHIAVASSA, S.; FERRER, L.; BARBET, J.; FLUX, G.D.; BARDIÈS, M. Effect of patient morphology on dosimetric calculations for internal irradiation as assessed by comparisons of Monte Carlo versus conventional methodologies. $\boldsymbol{J} \mathbf{N u c l}$ Med. , v. 50, n. 2, p. 316-323, 2009.

14. GARDIN, I.; BOUCHET, L.G.; ASSIÉ, K.; CARON, J.; LISBONA, A.; FERRER, L.; BOLCH, W.E.; VERA, P. Voxeldose: a computer program for 3-D dose calculation in therapeutic nuclear medicine. Cancer Biother. Radiopharm., v. 18, n .1, p. 109-115, 2003.

15. GOLDSMITH, S.J. Radioimmunotherapy of lymphoma: Bexxar and Zevalin. Semin. Nucl. Med., v. 40, n. 2, p.122-135, 2010. 
16. GRUDZINSKI, J.J.; YORIYAZ, H.; DELUCA JUNIOR, P.M.; WEICHERT, J.P. Patient specific treatment planning for systemically administered radiopharmaceuticals radiopharmaceuticals using $\mathrm{PET} / \mathrm{CT}$ and Monte Carlo simulation. $\boldsymbol{A p p l}$. Radiat. Isot., v. 68, n. 1, p. 59-65, 2010.

17. GUY, M.J.; FLUX, G.D.; PAPAVASILEIOU, P.; FLOWER, M.A.; OTT, R.J. RMDP: A dedicated package for ${ }^{131}$ I SPECT quantification, registration and patient-specific dosimetry. Cancer Biother Radiopharm., v. 18, n. 1, p. 61-69, 2003.

18. HOBBS, R.F.; WAHL, R.L.; LOFGE, M.A.; JAVADI, M.S.; CHO, S.Y.; CHIEN, D.T.; EWERTZ, M.E.; ESAIAS, C.E.; LADENSON, P.W.; SGOUROS, G. ${ }^{124}$ I PETbaded 3D-RD dosimetry for a pediatric thyroid cancer patient: real-time treatment planning and methodologic comparison. J. Nucl. Med., v. 50, n. 11, p. 18441847, 2009.

19. ICRP, 110. Adult reference computational phantoms. ICRP Puplication 110, 2010 .

20. IMAGEJ. Disponível em: < http://rsbweb.nih.gov/ij/ $>$. Acesso em: 26 abr. 2010.

21. INSTITUTO NACIONAL DO CÂNCER. Estimativa da incidência de câncer no Brasil 2010. Disponível em: < http://www.inca.gov.br/estimativa/2010 >. Acesso em: 26 abr. 2010.

22. KAK, A,C.; SLANEY, M. Principles of computerized tomographic imaging. Nova York, NY: IEEE Press, 1988. cap.4, Measurement of projection data - the nondiffracting case. p. 113 - 120.

23. KAPLAN, I. Nuclear Physics. 2.ed. Estados Unidos: Addison-Wesley, 1977. cap.15, Gamma-rays and Gamma-decay. p. 395-446.

24. LOEVInGER, R.; BERMAN, M. MIRD Pamphlets. Nova York, NY: Society of Nuclear Medicine, 1976. panfleto 1: A Schema for absorbed-dose calculations for biologically-distributed radionuclides. p. 9-14. 
25. McCUlLOUGH, E.C. Photon attenuation in computed tomography. Med Phys., v. 2, n. 6, p. 307-320, 1975.

26. NIST (National Institute of Standards an Technology). X-Ray Mass Attenuation Coefficients. Water liquid. Disponível em: < http://physics.nist.gov/PhysRefData/ XrayMassCoef/ComTab/water.html. > Acesso em: 10 out. 2010.

27. NETBEANS. Disponível em: < http ://netbeans.org/features/index.html $>$. Acesso em: 15 abr. 2010.

28. POWSNER R.A.; POWSNER E. R. Essential nuclear medicine physics 2.ed. Massachussets, Estados Unidos: Blackwell, 2006. cap.8. p. 114 - 127.

29. RADAR. Available Phantoms. Disponível em: < http : //www.doseinfo-radar.com/

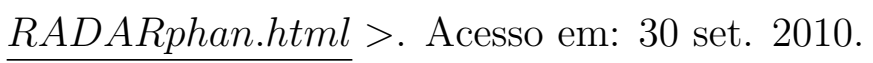

30. RASANEH, S.; RAJABI, H.; BABAEI, M.H.; DAHA, F.J.; SALOUTI, M. Radiolabeling of Transtuzumab with ${ }^{177} \mathrm{Lu}$ via DOTA, a new radiopharmaceutical for radioimmunotherapy of breast cancer. Nucl. Med. Biol., v. 36, p. 363-369, 2009.

31. ROCHA, A.F.G. Medicina nuclear. Rio de Janeiro, RJ: Guanabara Koogan, 1976.

32. RUGGIERO M.A.G.; LOPES V.L.R. Cálculo numérico: aspectos teóricos e computacionais. 2.ed. São Paulo, SP: Makron, 1996. cap.2, Zeros reais de funções reais. p. $66-67$.

33. RUTHERFORD, R.A.; PULLAN, B.R.; ISHERWOOD, I. Measurement of effective atomic number and electron density using an EMI scanner. J. Neuroradiol., v. 11, p. 15-21, 1976.

34. SAHA, G.B. Fundamentals of Nuclear Pharmacy. 4.ed. Cleveland, OH: Springer-Verlag, 1998. cap.6, Radiopharmaceuticals and methods of radiolabeling. p. $80-81$.

35. SCHNEIDER, W.; BORTFELD, T.; SCHLEGEL, W. Correlation between CT numbers and tissue parameters needed for Monte Carlo simulations of clinical dose distributions. Phys. Med. Biol., v. 45, p. 459-478, 2000. 
36. SGOUROS, G. Dosimetry of internal emitters. J. Nucl. Med., v. 46, n. 1, p. $18-27,2005$.

37. SOlBERG T.D.; DEMARCO J.J.; CHETTY I.J.; MESA A.V.; CAGNON C.H.; LI A.N.; MATHER K.K.; MEDIN P.M.; ARELLANO A.R.; SMATHERS J.B. A review of radiation dosimetry applications using the MCNP Monte Carlo Code. $\boldsymbol{R} \boldsymbol{a}$ diochim. Acta, 89, p. 337-355, 2001.

38. SPRAWLS JUNIOR, P. Physical principles of medical imaging. 2.ed. Madison, WI: Medical Physics Publishing, 1995.

39. STABIN, M.; ZAIDI, H. Monte Carlo codes for use in therapeutic nuclear medicine. In:

ZAIDI, H.; SGOUROS, G.Therapeutic applications of Monte Carlo calculations in nuclear medicine. Londres: Institute of Physics Publishing, 2003. p. $133-153$.

40. StaBin, M.G. Nuclear medicine dosimetry. Phys. Med. Biol., v. 51, p. R187R202, 2006.

41. STABIN, M.G. The case for patient-specific dosimetry in radionuclide therapy. Cancer Biother. Radiopharm., v. 23, n. 3, p. 273-285, 2008a.

42. STABIN, M.G. The importance of patient-specific dose calculations in nuclear medicine. Nucl. Eng. Techon., v. 40, n. 7, p. 527-532, 2008b.

43. STABIN, M.G; FLUX, G.D. Internal dosimetry as a tool for radiation protection of the patient in nuclear medicine. Biomed. Imaging Interv. J., v. 6, n. 2, p. $1-11,2007$.

44. TSUI, B.M.W.; GULBERG, G.T.; EDGERTON, E.R.; BALLARD, J.G.; PERRY, J.R.; McCARTNEY, W.H.; BERG, J. Correction of nonuniform attenuation in cardiac SPECT imaging. J. Nucl. Med., v. 30, n. 4, p. 497-507, 1989.

45. WHITE, D.R.; WOODARD, H.Q.; HAMMOND, S.M. Average soft-tissue and bone models for use in radiation dosimetry. Br. J. Radiol., v. 60, p. 907-913, 1987. 
46. WILDERMAN, S.J.; DEWARAJA, Y.K. Method for fast CT/SPECT-Baded 3D Monte Carlo absorbed dose computations in internal emitter therapy. IEEE Trans. Nucl. Sci., v. 54, n. 1, p. 146-151, 2007.

47. WOODARD, H.Q.; WHITE, D.R. Bone models for use in radiotherapy dosimetry. Br. J. Radiol., v. 55, n. 652, p. 277-282, 1982.

48. WOODARD, H.Q.; WHITE, D.R. The composition of body tissues. $\boldsymbol{B} \boldsymbol{r} . \boldsymbol{J} \cdot \boldsymbol{R} \boldsymbol{a}-$ diol., v. 59, p. 1209-1219, 1986.

49. YORIYAZ, H.; STABIN, M.G.; DOS SANTOS, A. Monte Carlo MCNP-4B-based absorbed dose distribution estimates for patient-specific dosimetry. J. Nucl. Med., v. 42, n. 4 , p. 662-669, 2001.

50. YORIYAZ, H.; MORALLES, M.; SIQUEIRA, P.T.D.; GUIMARÃES, C.C.; CINTRA, F.B.; DOS SANTOS, A. Physical models, cross sections, and numerical approximations used in MCNP and GEANT4 Monte Carlo codes for photon an electron absorbed fraction calculation. Med. Phys., v. 36, n. 11, p. 5198-5213, 2009.

51. ZAIDI, H. The Monte method: theory and computational issues. In:

ZAIDI, H.; SGOUROS, G.Therapeutic applications of Monte Carlo calculations in nuclear medicine. Londres: Institute of Physics Publishing, 2003. p. 133-153.

52. ZANZONICO, P.B. Internal radionuclide radiation dosimetry: a review of basic concepts and recent developments. J Nucl Med., v. 41, n. 2, p. 297-308, 2000.

53. ZANZONICO, P.B.; POSTON, J.W. Computation methods in internal radiation dosimetry. In:

ZAIDI, H.; SGOUROS, G. Therapeutic applications of Monte Carlo calculations in nuclear medicine. Londres: Institute of Physics Publishing, 2003. p. $89-95$. 